\title{
The Characterization of Vicker's
}

\section{Microhardness Indentations and}

\section{Pile-Up Profiles as a Strain-Hardening} Microprobe

Manuscript Completed: March 1998

Date Published: April 1998

C. Santos, Jr./NRC

G. R. Odette, G. E. Lucas, B. Schroeter, D. Klinginsmith/UC

T. Yamamoto/TU

Department of Mechanical Engineering

University of California at Santa Barbara

Santa Barbara, CA 93106

Institute for Materials Research

Tohoku University

2-1-1 Katahira, Aoba-ku

Sendai

Japan 980-77

C. Santos, Jr., NRC Project Manager

Division of Engineering Technology

Office of Nuclear Regulatory Research

U.S. Nuclear Regulatory Commission

Washington, DC 20555-0001 


\section{DISCLAMMER}

This report was prepared as an account of work sponsored by an agency of the United States Government. Neither the United States Government nor any agency thereof, nor any of their employees, makes any warranty, express or implied, or assumes any legal liability or responsibility for the accuracy, completeness, or usefulness of any information, apparatus, product, or process disclosed, or represents that its use would not infringe privately owned rights. Reference herein to any specific commercial product, process, or service by trade name, trademark, manufacturer, or otherwise does not necessarily constitute or imply its endorsement, recom. mendation, or favoring by the United States Government or any agency thereof. The views and opinions of authors expressed herein do not necessarily state or reflect those of the United States Government or any agency thereof. 


\section{DISCLAIMER}

Portions of this document may be illegible electronic image products. Images are produced from the best available original document. 


\begin{abstract}
Microhardness measurements have long been used to examine strength properties and changes in strength properties in metals, for example, as induced by irradiation. Microhardness affords a relatively simple test that can be applied to very small volumes of material. Microhardness is nominally related to the flow stress of the material at a fixed level of plastic strain. Further, the geometry of the pile-up of material around the indentation is related to the strain-hardening behavior of a material; steeper pile-ups correspond to smaller strain-hardening rates. In this study the relationship between pile-up profiles and strain hardening is examined using both experimental and analytical methods. Vickers microhardness tests have been performed on a variety of metal alloys including low alloy, high $\mathrm{Cr}$ and austenitic stainless steels. The pile-up topology around the indentations has been quantified using confocal microscopy techniques. In addition, the indentation and pile-up geometry has been simulated using finite element method techniques. These results have been used to develop an improved quantification of the relationship between the pile-up geometry and the strain-hardening constitutive behavior of the test material.
\end{abstract}





\section{Table of Contents}

Chapter 1: Introduction 1

$\begin{array}{ll}\text { Chapter 2: Background } & 3\end{array}$

$\begin{array}{ll}\text { Chapter 3: Materials, Experiments and Results } & 17\end{array}$

$\begin{array}{ll}\text { Chapter 4: Finite Element Analysis } & 57\end{array}$

$\begin{array}{ll}\text { Chapter 5: Conclusions and Future Work } & 71\end{array}$

$\begin{array}{ll}\text { References } & 73\end{array}$

$\begin{array}{ll}\text { Appendix A: Experimental Tensile Data } & 78\end{array}$

Appendix B: Topographical Maps from Experimental Indentation Tests 89 


\section{List of Figures}

Figure 2.1a

Typical stress strain curve for a metal at low strains

Figure 2.1b

Figure 2.2a

Typical true stress-strain and engineering stress-strain curves for a metal

True stress plastic strain curves for materials exhibiting a variety of power law strain hardening behavior $(\mathrm{n}=0.05$, 0.15 , and 0.30 )

Figure $2.2 \mathrm{~b}$

$\log$ (True stress) vs $\log ($ Plastic Strain) for materials exhibiting a variety of power law strain hardening behavior $(\mathrm{n}=0.05,0.15$, and 0.30$)$

Figure 2.3

Geometry of a Vicker's-type indenter. Figure taken from Metals Handbook [28]

Figure 2.4

Surface topology associated with a)high work hardening materials and b)low work hardening materials. Figure taken from Jayakumar [24]

Figure 3.1

$\log \sigma_{t}$ vs $\log \epsilon_{p}$ for a)A302B b)A533B c)Model A533B Control d)Model A533B LTI and e)Model A533B ITI f) NbTi g)AISI $302 \mathrm{SS} \mathrm{h}$ )F-82H and i)HT-9

Figure 3.2

Contour plots of a)NbTi and b)annealed AISI 302 SS

Figure 3.3

Contour plots of a)NbTi and b)HT-9

Figure 3.4

Illustration of a)idealized topographical map of an indent and b)corresponding profile

Figure 3.5

Illustration of a)typical topographical map of an indent and $b$ ) a corresponding average height profile 
Figure 3.6

Figure 3.7

Figure 3.8

Figure 3.9

Figure 3.10a

Figure 3.10b

Figure 3.10c

Figure $3.10 \mathrm{~d}$

Figure 3.11

Figure 3.12
Full length average height profiles for $\mathrm{F}-82 \mathrm{H}$ indent 5 along a)side 1 showing the entire range of heights $b$ ) side 2 showing the entire range of heights $c$ ) side 1 showing only the heights above 0 and d)side 2 showing only the heights above 0

Full length average height profiles for $\mathrm{F}-82 \mathrm{H}$ indent 1 along a) side 1 showing the entire range of heights $b$ ) side 2 showing the entire range of heights $\mathrm{c}$ )side 1 showing only the heights above 0 and d) side 2 showing only the heights above 0

a)Contour plot of $\mathrm{A} 302 \mathrm{~B}$ indentation with the corresponding average height profiles along b) side 1 and c) side 2 of the indent

a)Contour plot of A533B indentation with the corresponding average height profiles along $b$ ) side 1 and c) side 2 of the indent

Characteristic full length average height profiles

Characteristic full length average height profiles for heights between 0 and $1 \mu \mathrm{m}$

Characteristic half length average height profiles

heights between 0 and $1 \mu \mathrm{m}$

Parameters used to characterize average height profiles

Correlation between $n$ and $h_{p} / L_{m p}$ from conical and 53 pyramidal indenters. Pyramid indenter results were taken from average height profiles taken over a)the full width and b)half width. The cone results were taken from work done by Maliyakal Jayakumar [24] 

average height profile for all the materials considered in this study. The solid line shows a least squares fit to all the data points. The dashed line represents the best fit to the materials except $\mathrm{NbTi}$ and annealed stainless steel.

Figure 4.1

Top view of finite element model

Figure 4.2

Finite element model in the undeformed condition

Figure 4.3

Finite element model in the deformed condition

61

Figure 4.4

Average height profile for FEM $n=0.1$ and A302B

64

Figure 4.5

Average height profiles for $\mathrm{FEM} \mathrm{n}=0.05$, A533B Model alloy control and A533B Model alloy LTI

Figure 4.6

Average height profiles for FEM models with $\mathrm{n}=0.00$, 67 $0.05,0.11,0.20$ and 0.30

Figure 4.7

Correlation between $\mathrm{n}$ and $h_{\mathrm{p}} / \mathrm{L}_{00}$ for both experimental 68 and FEM results 
List of Tables

Table $3.1 \quad$ Compositions, heat treatments, and irradiation conditions of materials examined in this study

Table 3.2

Tensile properties of materials examined in this study

Table 3.3a

Hardness values (VHN) and diagonal lengths at $200 \mathrm{~g}$ for 28 $\mathrm{A} 302 \mathrm{~B}, \mathrm{~A} 533 \mathrm{~B}, \mathrm{HT}-9, \mathrm{~F}-82 \mathrm{H}, \mathrm{Nb}-\mathrm{Ti}$ and annealed AISI $302 \mathrm{SS}$

Table $3.3 \mathrm{~b}$

Hardness values (VHN) and diagonal lengths at $200 \mathrm{~g}$ for A533B model alloy in the unirradiated (Control), LTI $\left(60^{\circ} \mathrm{C}\right)$, and $\operatorname{ITI}\left(290^{\circ} \mathrm{C}\right)$ conditions

Table 3.4

Half profile parameters for the full width and half width average height profiles and average work hardening exponents for each material 


\section{Chapter 1}

Introduction

Microhardness tests have long been used as a microprobe of the relative strength of materials. While a variety of techniques are available, the Vickers microhardness test is probably the most widely used. The tests are relatively simple to perform, and they deform only a minute amount of material, so that they can be used in a semi-non-destructive fashion either to provide quality assurance in manufacturing or to assess the mechanical state of parts in service. In addition, microhardness tests are of interest where small volumes of material are available for testing: for example, in irradiation experiments or in situations where biopsies can be removed from large structures in service.

To first order, the Vickers microhardness (and indeed hardness numbers in general) is proportional to the flow stress of a material; and both theoretical and empirical relationships have been developed to relate hardness numbers to various measures of strength[1-8]. However, a number of studies have demonstrated that additional information is available about the constitutive behavior (stress-strain) of the material from the indentation process if the distribution of plastic flow, including the pile-up of material around the indentation, can be characterized. Indeed, a number of correlations have been derived between pile-up geometry and various characteristics of post-yield plastic deformation, including work-hardening, uniform elongation, Luders strain, and the nature of slip (coarse vs. fine)[9-24]. A variety of methods have been used to characterize the pile-up geometry, including profilometry [22,23] and interferometry $[22,24]$; but their application can be tedious and difficult, and the indentation profile can sometimes be damaged in the process. Hence, application of these methods have been limited. 
The advent of the confocal microscope and recent improvements in its application [25] provide a promising alternative approach to characterizing the indentation geometry and the distribution of the pile-up around the indentation. Confocal microscopy can provide a quantitative threedimensional topography of a surface in a complete non-destructive way. Hence, the purpose of this study was to investigate the applicability of confocal microscopy to the characterization of Vickers indentation geometry and to examine possible relations between the indentation geometry and characteristics of the material constitutive behavior. 


\section{Chapter 2}

Background

\subsection{The Yield Stress and Strain Hardening in Materials}

During a standard tensile test the initial deformation is elastic. Hooke's law states that the stress versus strain relationship is initially linear with a slope equal to the elastic modulus (E). Deformation in this region is completely recovered upon load removal. However, as the strain increases, a point is reached at which the deformation is no longer completely recoverable. The stress at the onset of plastic deformation is known as the yield stress. In the frequent case where the yield point is not distinctly observable on a load displacement curve, the stress associated with $0.2 \%$ plastic strain is used to define the yield stress as illustrated in Figure 2.1a. Plastic strains are defined by lines drawn parallel to the elastic line (e.g., with a slope of E); thus point $\mathrm{A}$ in Figure $2.1 \mathrm{a}$ represents a $0.2 \%$ plastic strain and point $\mathrm{B}$ defines the $0.2 \%$ yield stress $\left(\sigma_{y}\right)$. Note tensile data is often based on the displacement of load train components, like the crosshead of a test frame, that adds extra displacements which increase with load (machine compliance). In this case using a line drawn parallel to the linear portion of the load-net displacement line can still be used to obtain a good estimate of $\sigma_{y^{*}}$ 


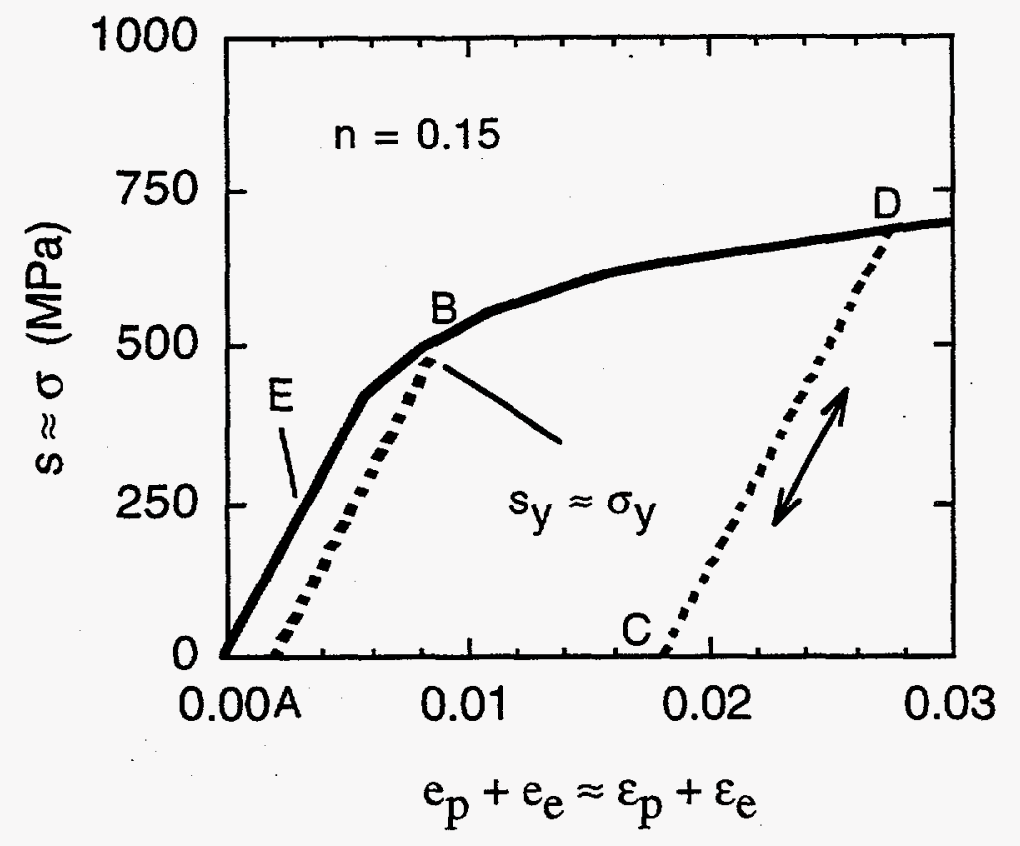

Figure 2.1a. Typical stress strain curve for a metal at low strains.

As illustrated in Figure 2.1b the stress required to cause additionl plastic deformation beyond yield usually increases with increasing plastic strain, a phenomenon known as strain hardening. Strain hardening is the result of long-range stress field interactions between dislocations. Dislocationdislocation interactions provide greater resistance to subsequent dislocation motion through processes such as: dislocation multiplication; dislocation intersection; dislocation-obstacle interactions including the production of dislocation debris, tangles, braids, and cell structures[26]. Strain may also 
induce phase changes (as e.g., with martensite formation in unstabilized stainless steels) [27].

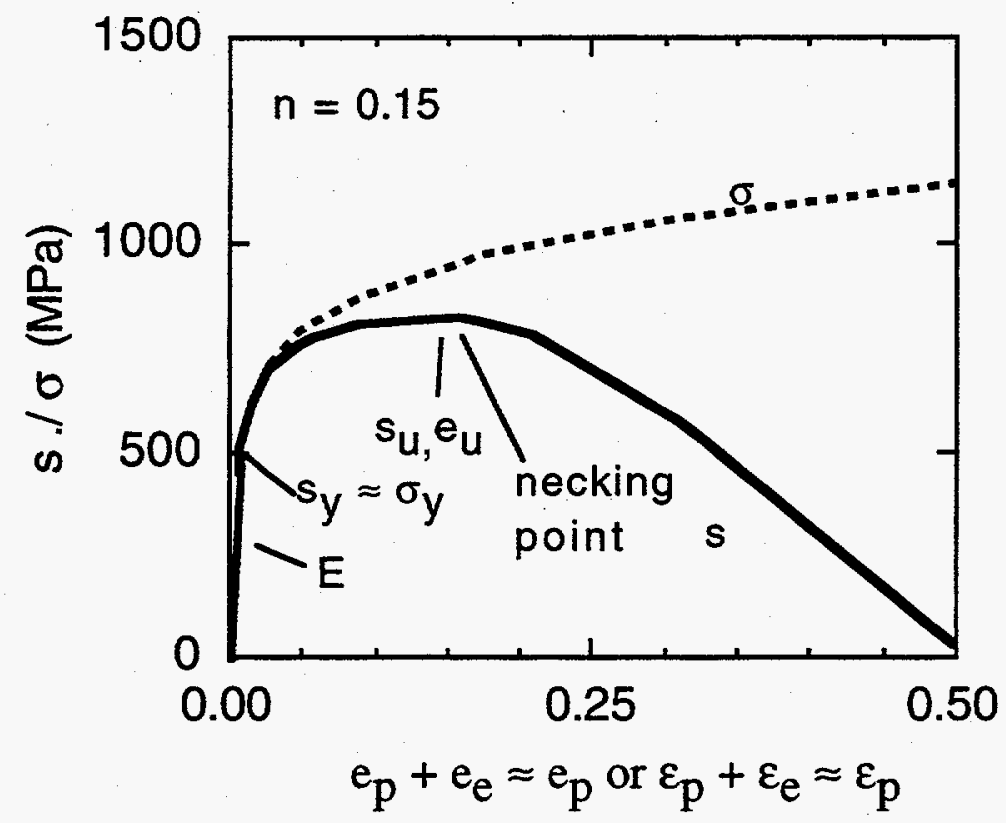

Figure 2.1b. Typical true stress/strain (dashed line) and engineering stress/strain (solid line) curves for a metal.

Thus the flow stress $(\sigma)$ is a function of the plastic strain $\left(\varepsilon_{\mathrm{p}}\right)$ again defined by drawing a line parallel to the initial region with a linear slope, indicated by points $C$ and $D$ in Figure 2.1a. Figure $2.1 \mathrm{~b}$ shows two curves 
representing engineering (solid line) and true (dashed line) stress and strain respectively.

Engineering stress (S) and strain (e) are calculated from the applied load (P) and changes in length of the specimen $(\Delta \mathrm{L})$ as $S=P / A_{0}$ and $e=\Delta \mathrm{L} / \mathrm{L}$ where $L$ and $A_{o}$ are the initial length and cross sectional area of the gauge. However, during a tensile test the actual dimensions of the specimen continually change. True stress $(\sigma)$ and true strain $(\varepsilon)$ are based on the instantaneous specimen dimensions. True stress/strains and engineering stresses/strains are related by:

$$
\begin{aligned}
& \sigma=s(e+1) \\
& \varepsilon=\ln (e+1)
\end{aligned}
$$

Note at small strains $S \approx \sigma$ and $e \approx \varepsilon$.

For a finite rate of strain hardening the loads required to continue deformation increase up to a maximum associated with the formation of a necked region in a tensile specimen. Necking occurs when the reduction in load needed to cause continued deformation decreases more rapidly than the increase in load caused by strain hardening. Thus deformation localizes in the neck, beginning at the maximum stress in $S(e)$, known as the ultimate tensile strength $\left(S_{u}\right)$. The corresponding plastic strain is known as the uniform elongation $\left(e_{u}\right)$. Thereafter engineering stress, $S$, decreases and 
the specimen finally fractures at a strain known as the total elongation $\left(e_{t}\right)$, which is a sensitive function of the tensile specimen dimensions.

However the true stress, $\sigma$, continues to increase with plastic strain, $\varepsilon$, but due to the inhomogeneous deformation it is difficult to define true stressstrain relations from tensile tests beyond the point of necking. Note this is an attribute of the tensile test and is not the same for other deformation geometries. For example engineering stresses continue to increase at strains beyond the $e_{u}$ found in tensile tests when the material is deformed under compression. However, even compression tests have limited strain ranges due to large geometry changes producing barreling shapes as well as friction effects.

In general, the $\sigma(\varepsilon)$ behavior of materials is complex. Typical patterns include low strain deformation with low hardening rates followed by regions of high hardening followed by a tendency for $\sigma$ to saturate at higher strains. Note that due to the limited range of tensile tests, high strain $\sigma(\varepsilon)$ behavior is often not well characterized. In spite of these complexities, however, the $\sigma(\varepsilon)$ for many metals can be described by a simple power law strain hardening model. These models take different forms, but can be represented as

$$
\sigma(\varepsilon) / \sigma_{\mathrm{y}}=\left(\varepsilon / \varepsilon_{\mathrm{y}}\right)^{\mathrm{n}}
$$


where $\varepsilon_{\mathrm{y}}$ is the yield strain (e.g., $\varepsilon_{\mathrm{y}}=0.002$ ), and $\mathrm{n}$ is the strain hardening exponent. Equation (3) can be rewritten as

$$
\begin{aligned}
\log \sigma(\varepsilon) & =\log \sigma_{y}+n \log \left(\varepsilon / \varepsilon_{y}\right) \\
& =\log \sigma_{y}-n \log \varepsilon_{y}+n \log \varepsilon \\
& =\text { constant }+n \log \varepsilon
\end{aligned}
$$

Thus in this case a plot of $\log \sigma$ versus $\log \varepsilon$ will be linear with a slope of $n$ and $\log \sigma=\log \sigma_{\mathrm{y}}$ at $\varepsilon=\varepsilon_{\mathrm{y}}$. For $\mathrm{n}=0$ there is no strain hardening and the material is said to be perfectly elastic-plastic. For metals values of $n$ are almost always $<0.5$ and a value of 0.3 represents a very high rate of strain hardening. Typically structural alloys have values of $\mathrm{n}$ ranging from about 0.05 to 0.3 .

Figure 2.2 illustrates such power law strain hardening behavior for $n=0.05$, 0.15 , and 0.3 in terms of both normal $\sigma(\varepsilon)$ (Figure 2.2a) and $\log \sigma-\log \varepsilon$ (Figure 2.2b) plots.

Note that the idealized constitutive behavior $[\sigma(\varepsilon)]$ represented by the power law hardening is only an approximate representation for any real material. Further the stress strain behavior is generaly influenced by temperature, strain rate and the multiaxial stress state iimposed on the region under deformation. 


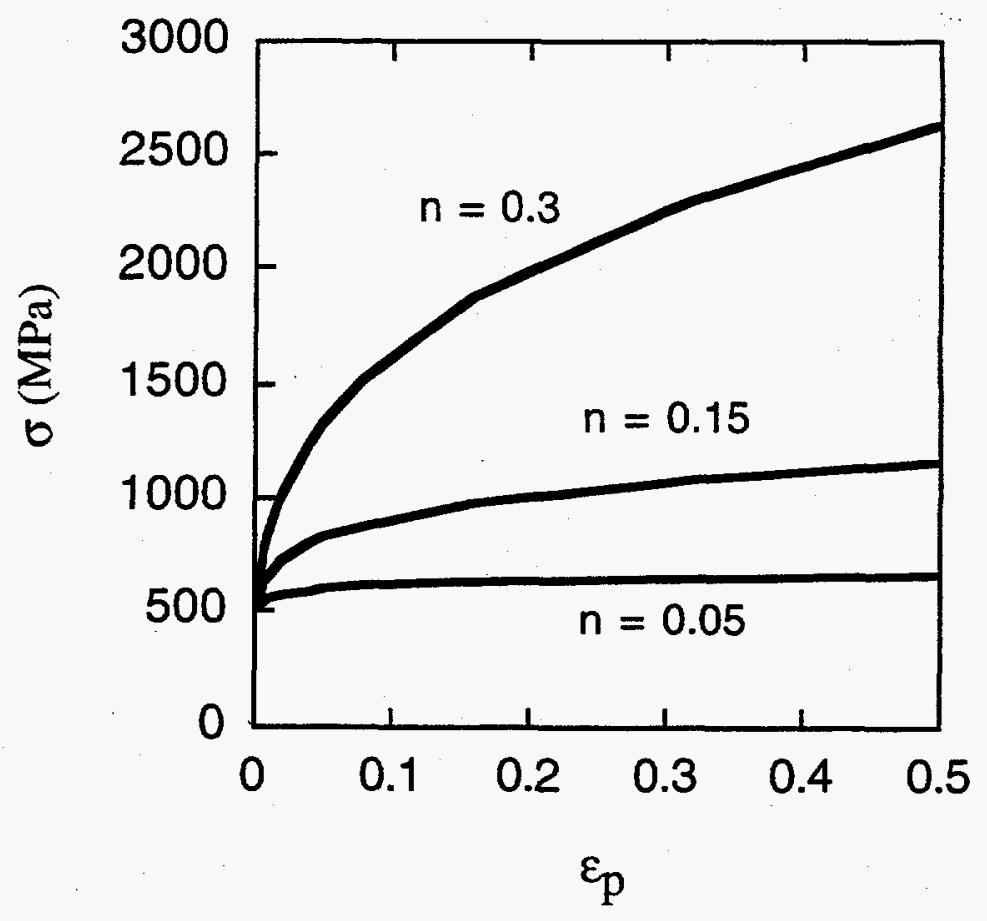

Figure 2.2a. True stress plastic strain curves for materials exhibiting a variety of power law strain hardening behavior $(n=0.05$, 0.15 , and 0.30 ) 


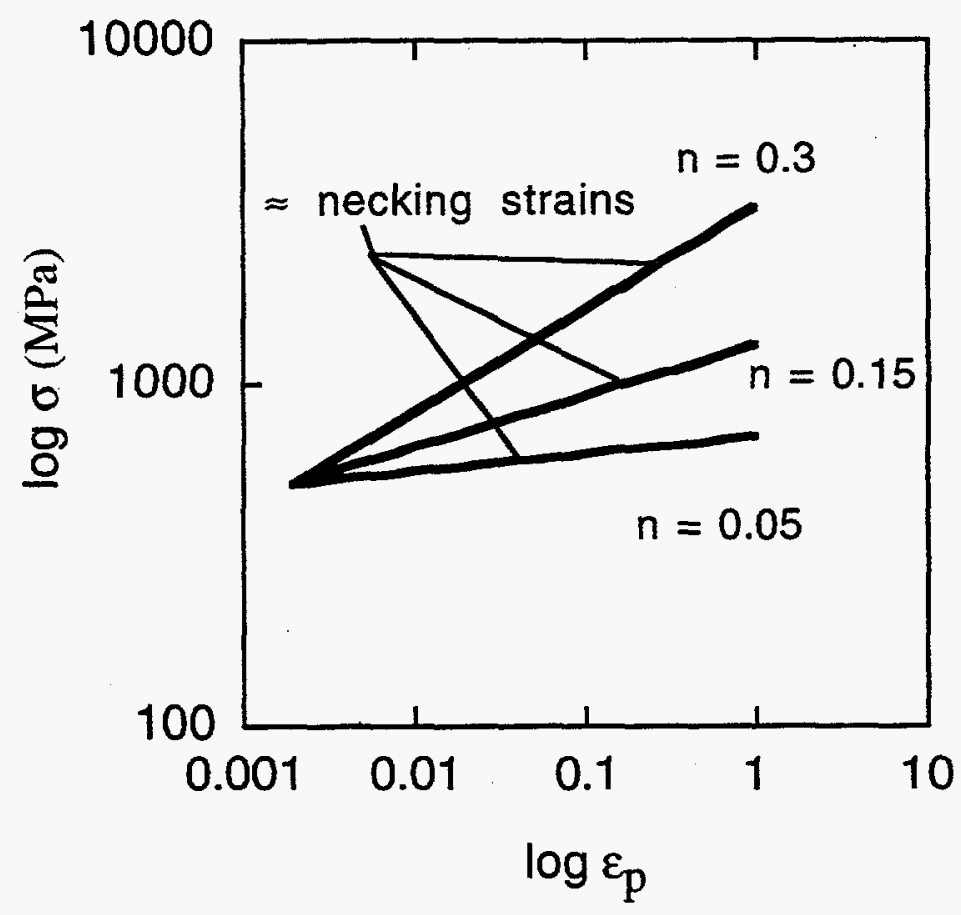

Figure 2.2b. $\log$ (True Stress) vs. $\log$ (Plastic Strain) for materials exhibiting a variety of power law strain hardening behavior $(\mathrm{n}=0.05,0.15$, and 0.30$)$ 


\subsection{Hardness Testing}

Static indentation tests are simple and widely used for measuring material strength properties. In these tests an indenter of a given geometry is applied to the surface of a specimen at a known load and leaves a permanent impression in the material. Based on the load and the area of the indentation an applied pressure can be calculated. This pressure is used as a measure of the hardness of the material. Typically indenter shapes are spherical, conical or pyramidal. The area used in hardness calculations can be either the projected area of the indentation or the actual contact area between the indenter and material depending on the hardness test being used [1].

Vickers hardness testing uses the inverted diamond pyramid indenter with a square base shown in Figure 2.3.

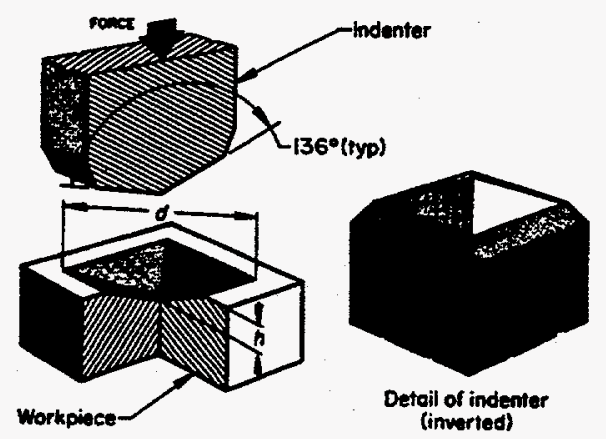

Figure 2.3. Geometry of a Vickers-type indenter. Figure taken from Metals Handbook [28]. 
The angles between opposite faces and edges of the pyramid are 136 and 148 degrees respectively. A Vickers Hardness Number (VHN) is calculated from the following equation:

$$
\mathrm{VHN}=\mathrm{P} / \mathrm{A}_{\mathrm{p}}=2 * \mathrm{P} * \sin (68) / \mathrm{d}^{2}
$$

where $\mathrm{P}$ is the applied load in $\mathrm{kg}, \mathrm{A}_{\mathrm{p}}$ is the projected area on the surface in $\mathrm{mm}^{2}$, and $\mathrm{d}$ is the average of the two diagonals in $\mathrm{mm}[28]$. The sharp point and edges of a Vickers indenter cause plastic deformation to occur in the material immediately upon contact. The deformation along the diagonals of the indent is not elastically recovered upon removal of the load. Thus, the measured diagonals are that of the impression at full load [1].

Microhardness tests are generally hardness tests which are conducted at loads less than $1 \mathrm{~kg}$, (typically between 100 and $500 \mathrm{~g}$ ). Microhardness tests typically use conical or pyramid shaped indenters, since the pressures applied by spherical indenters at these low loads are generally not enough to cause plastic deformation in most materials.

The ratio between the indentation depth and diagonal is constant for any given load for a Vickers indent. The stress/strain fields around Vickers indents are geometrically self-similar and it is generally assumed that the VHN represents an average flow stress at a strain of about 8\% [2]. During the indentation process, the material below and around the indenter is being plastically deformed, under constraint by the surrounding material which is 
only deforming elastically. This constraint produces multiaxial stresses that elevate the flow stress by a factor of about 3 above the corresponding stress under uniaxial loads, based on slip line theory. Thus, the Vickers Hardness Number, which has units of stress, is proportional to 3 times the flow stress, in the same units, of the material at nominal $8 \%$ plastic strain [2].

The plastic deformation redistributes material flowing from below the initial planar surface to a pile-up surrounding the indent. The geometry of the pile-up depends on the strain hardening of the material. In one limit, for a material that strain hardens at a high rate, the volume of material directly beneath and surrounding the indenter will quickly become much more difficult to deform than the material at larger distances. The hardened regions transfers stresses to the softer surrounding material which is then preferentially deformed. Eventually this softer material will strain harden and the entire process evolves until the static load equilibrium is reached. The resulting indentation shown in Figure 2.4a is characterized by material along the edges of the indent having "sunk-in" below the height of the specimen surface surrounded by shallow and extended pileups of equal volume to the material which was displaced by the indenter [24].

At the other limit, for a non-strain hardening material, the regions under and surrounding are equally difficult to deform. This causes the material displaced by the indenter to be preferentially extruded near the edges of the 
indenter resulting in high and narrow pileups. Figure $2.4 \mathrm{~b}$ illustrates indent topography for a low strain hardening material [24].

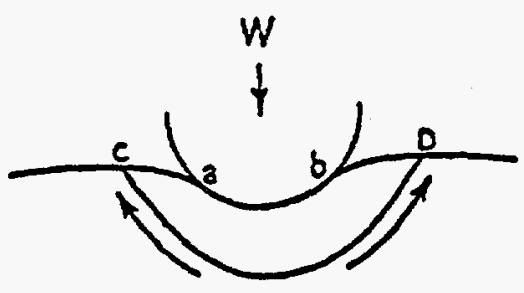

(a)

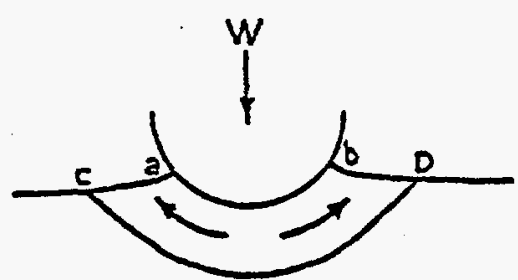

(b)

Figure 2.4 Surface topology associated with a) high work hardening materials and b) low work hardening materials. Figure taken from Jayakumar [24].

As a rule of thumb, the diameter of the pile-up area is approximately 3 times the indent diagonal. The depth at which material is plastically deformed is about 10 times the indent depth [2].

Thus in addition to using microhardness to measure an effective flow stress of a material, the pile-up topology can be used to estimate the post-yield strain rate. Developing a simple, quantitative relationship between the 
pileup geometry and the average power law strain hardening exponent (n) was the primary objective of this study. 

Chapter 3

Materials, Experiments and Results

\subsection{Materials, Tensile Properties and Microhardness Testing}

Materials used in this study where chosen to represent a wide range of post yield constitutive properties, ranging from very high to very low strain hardening capacity. They included: 2 quenched and tempered martensitic 8 to $12 \mathrm{Cr}$ stainless steels; 3 quenched and tempered, low alloy, $\mathrm{Mn}-\mathrm{Mo}-\mathrm{Ni}$ bainitic pressure vessel steels, including a model alloy that was also characterized following low and intermediate temperature neutron irradiations; a solid solution $\mathrm{Nb}-\mathrm{Ti}$ alloy with very low strain hardening capacity; and a fully annealed, unstabilized AISI 302 austenitic stainless steel (SS) with very high strain hardening capacity. Compositions, heat treatments and, where pertinent, irradiation conditions are summarized in Table 3.1 . 
Table 3.1. Compositions, heat treatments, and irradiation conditions of materials examined in this study.

\begin{tabular}{|c|c|c|c|c|c|c|c|c|c|c|c|c|c|c|c|c|}
\hline Material & $\bar{C}$ & $\overline{\mathrm{Cu}}$ & $\overline{\mathrm{Ni}}$ & $\overline{\mathrm{Mn}}$ & $\overline{\mathrm{Si}}$ & $\overline{\mathrm{P}}$ & $\bar{S}$ & $\overline{\mathrm{Cr}}$ & $\overline{M o}$ & $\bar{W}$ & $\bar{V}$ & Ta & $\mathrm{Nb}$ & $\overline{\mathrm{Ti}}$ & $\begin{array}{c}\text { Heat } \\
\text { Treat } ¥\end{array}$ & $\begin{array}{l}\text { Irrad. } \\
\text { Cond } \ddagger\end{array}$ \\
\hline A302B & 0.23 & 0.20 & \begin{tabular}{|l|}
0.17 \\
\end{tabular} & 1.47 & 0.26 & 0.013 & 0.024 & 0.05 & 0.52 & $\ldots$ & 0.004 & $\ldots$ & -- & $\ldots$ & $T$ & 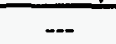 \\
\hline A533B & 0.23 & \begin{tabular}{|l|}
0.16 \\
\end{tabular} & 0.67 & 1.55 & 0.20 & 0.009 & 0.014 & 0.04 & 0.53 & $-\cdots$ & 0.003 & - & $\ldots$ & 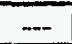 & 2 & - \\
\hline HT-9 & 0.23 & - & 0.51 & $0 . \overline{39}$ & 0.17 & 0.016 & 0.003 & 12.1 & $\overline{1.04}$ & 0.45 & 0.28 & - & $-\ldots$ & $\ldots$ & $\overline{3}$ & $\ldots$ \\
\hline F-82H & 0.10 & $=$ & - & 0.50 & 0.10 & 0.003 & 0.003 & 8.0 & - & 2.0 & 0.2 & 0.04 & $\cdots$ & -- & 4 & - \\
\hline $\begin{array}{c}\text { AISI } \\
302 \mathrm{SS}\end{array}$ & 0.15 & - & $8-10$ & 2.00 & 1.00 & 0.045 & 0.030 & $17-19$ & $\ldots$ & - & - & $\cdots$ & $\cdots$ & $\cdots$ & 5 & - \\
\hline $\mathrm{Nb}-\mathrm{Ti}$ & -- & $\ldots$ & - & - & - & $\ldots$ & - & $\ldots$ & - & $-\cdots$ & - & - & 52.5 & 47.5 & - & - \\
\hline $\begin{array}{r}\text { Model } \\
\text { A533B } \\
\end{array}$ & 0.14 & 0.42 & 0.81 & 1.34 & 0.13 & $<0.005$ & $\begin{array}{c}< \\
0.005\end{array}$ & 0.085 & \begin{tabular}{|c|}
0.53 \\
5 \\
\end{tabular} & -- & - & - & - & --- & 6 & - \\
\hline $\begin{array}{l}\text { Model } \\
\text { A533B }\end{array}$ & 0.14 & 0.42 & 0.81 & 1.34 & 0.13 & $<0.005$ & $\begin{array}{c}< \\
0.005\end{array}$ & 0.085 & $\begin{array}{c}0.53 \\
5\end{array}$ & - & - & $\cdots$ & -- & -- & 6 & $\overline{\mathrm{A}}$ \\
\hline $\begin{array}{c}\text { Model } \\
\text { A533B }\end{array}$ & $\overline{0.14}$ & 0.42 & 0.81 & 1.34 & 0.13 & $<0.005$ & $\begin{array}{c}< \\
0.005\end{array}$ & 0.085 & $\begin{array}{c}0.53 \\
5\end{array}$ & $\cdots$ & - & - & -- & $\cdots$ & 6 & $\bar{B}$ \\
\hline
\end{tabular}

* Heat Treatment

1. Austenitized $899^{\circ} \mathrm{C}, 6 \mathrm{hr}$; water quenched; tempered $649^{\circ} \mathrm{C}$, $6 \mathrm{hr}$; air cooled

2. Austenitized $871^{\circ} \mathrm{C}$, $4 \mathrm{hr}$; water quenched; tempered $663^{\circ} \mathrm{C}$, $4 \mathrm{hr}$; furnace cooled; stress relieved $607{ }^{\circ} \mathrm{C}, 40 \mathrm{hr}$

3. Austenitized $1050^{\circ} \mathrm{C}, 0.5 \mathrm{hr}$; lempered $760^{\circ} \mathrm{C}, 0.5 \mathrm{hr}$

4. Normalized $1040^{\circ} \mathrm{C}, 0.5 \mathrm{hr}$; tempered $740^{\circ} \mathrm{C}, 1 \mathrm{hr}$

5. Annealed $1050-1100^{\circ} \mathrm{C}, 0.5 \mathrm{hr}$; furnace cooled

6. Austenitized $900{ }^{\circ} \mathrm{C}$, $1 \mathrm{hr}$; tempered $664^{\circ} \mathrm{C}, 4 \mathrm{hr}$; air cooled

${ }^{t}$ Irradiation Condition

A. Low Temperature Irradiation (LTI) at $60^{\circ} \mathrm{C}$ to fast fluence of $0.3 \times 10^{19} \mathrm{n} / \mathrm{cm}^{2}$

B. Intermediate Temperature Irradiation (ITI) at $290^{\circ} \mathrm{C}$ to fast fluence of $1.0 \times 10^{19} \mathrm{n} / \mathrm{cm}^{2}$ 
The microstructures and tensile properties of all but the $\mathrm{Nb}$ - $\mathrm{Ti}$ and austenitic alloys had been characterized in previous studies $[25,29,30]$. The martensitic stainless steels had average prior austenite grain sizes ranging from $55 \mu \mathrm{m}$ (HT-9) to about $80 \mu \mathrm{m}$ (F-82H), subdivided into lath packets with average diameters of about $8 \mu \mathrm{m}$ (HT-9) to $12 \mu \mathrm{m}$ (F-82H) [30]. Both these alloys, provided in the form of rolled plate, have been widely studied in the fusion materials program; the F-82H was supplied by the Japanese Atomic Energy Research Institute. The martensitic steels had relatively high room temperature yield stress values of about 550 to $580 \mathrm{MPa}$. Two of the bainitic pressure vessel steels were taken from heavy section plates that were procured as reference materials for irradiation effects studies and reactor pressure vessel surveillance programs. They have primarily bainitic microstructures with average PAG sizes of about $50 \mu \mathrm{m}$, with room temperature yield stress values of about $470 \mathrm{MPa}$. The third pressure vessel steel was a small heat of a model bainitic A533-type steel rolled to a $25 \mathrm{~mm}$ plate with an unirradiated yield stress was about $530 \mathrm{MPa}$. This alloy was irradiated at both $60^{\circ}$ (LTI) and $290^{\circ} \mathrm{C}$ (ITI) to fast fluences of about 0.3 and $1 \times 10^{19} \mathrm{n} / \mathrm{cm}^{2}$ respectively. The irradiations resulted in yield similar stress elevations of 142 to $162 \mathrm{MPa}$ respectively.

The $\mathrm{Ti}-48.5 \mathrm{Nb}$ alloy was originally supplied, in the form of $2 \mathrm{~mm}$ rolled plate, by Pratt and Whitney Corporation for possible use in studies of ductile phase reinforced intermetallic TiAl composites. Previous studies 
had shown that this alloy class deforms by planar slip of superdislocations with very little strain hardening and very low uniform strains, prior to necking. However, details of processing history of the specific plate are not available. Miniature tensile specimens with gauge lengths of $9.0 \mathrm{~mm}$ were milled out of the plate; note these specimens are essentially the same as used in the previous studies of the other materials cited above. The AISI 302 SS was procured in the form of $0.51 \mathrm{~mm}$ highly cold rolled sheet. Miniature tensile specimens were punched from the sheet prior to annealing. Thirty minute annealing treatments in a helium environment from 800 to $1100^{\circ} \mathrm{C}$ were evaluated to determine the condition of full recovery. The reference annealing treatment was $1050^{\circ} \mathrm{C}$ to $1100^{\circ} \mathrm{C}$ followed by a slow cool. The tensile specimens of both the $\mathrm{Ti}-\mathrm{Nb}$ and austenitic alloys were tested at room temperature at rates of $0.508 \mathrm{~mm} /$ minute, similar to test conditions for the other materials.

All of the tensile data were analyzed and characterized up to the uniform strain $\left(e_{\mathrm{u}}\right)$ in a self-consistent fashion. Raw load displacement records were digitized and converted to true-stress $\left(\sigma_{t}\right) /$ true-strain $\left(\varepsilon_{t}\right)$ data files using conventional definitions and the load-displacement slope to correct for compliance. Second order effects of load train compliance that have been shown to be small are ignored. Representative plots of these files for each material are shown in Figure 3.1 as a set of discrete points of $\log \left(\sigma_{t}\right)$ $\log \left(\varepsilon_{i}\right)$. Three characteristic types of behavior were observed. In most 
cases (HT-9, A302, A533, and the model A533B alloy in all conditions) the log-log plots have 2 distinct regimes: a low strain/low strain hardening regime followed by higher strain hardening at higher strains. The strain level separating these regions depended on the material and was increased by irradiation, particularly at the lower temperature. The A302B and A533B alloys show a slight decline in the strain hardening at the highest strains. However this may be due to necking rather than the constitutive behavior of the materials. A second type of behavior ( $\mathrm{F}-82 \mathrm{H}$ and $\mathrm{Nb}-\mathrm{Ti})$ appeared to show a slightly decreasing strain hardening slope at higher strains. The effect was most pronounced in a $\mathrm{Nb}-\mathrm{Ti}$ alloy occurring in the very limited strain range $(<0.8 \%)$ prior to necking. Finally, the AISI 302 SS showed three regimes of strain hardening: low hardening rates up to about strains of approximately $2 \%$, followed by a second regime with much higher hardening rates. However in the case of the unstablized austenitic alloy, a third regime was observed beyond strains of about $25 \%$, with high strength levels and associated with deformation induced martensitic transformations. This expected behavior was confirmed by direct magnetic measurements in the highly deformed regions of the tensile specimens. 

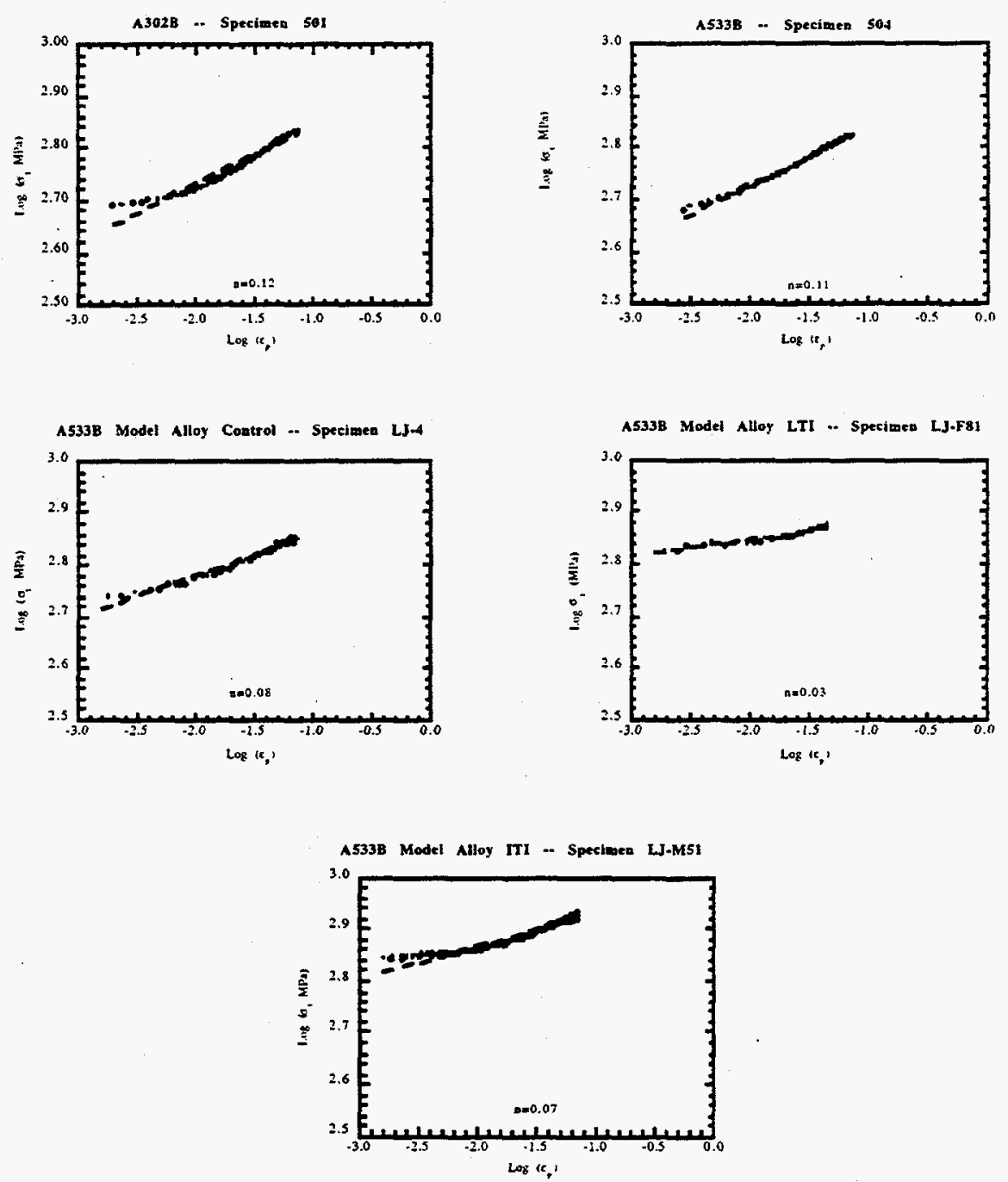

Figure $3.1 \log \sigma_{t}$ vs $\log \varepsilon_{\mathrm{p}}$ for a)A302B b)A533B c)Model A533B Control d)Model A533B LTI and e)Model A533B ITI. 

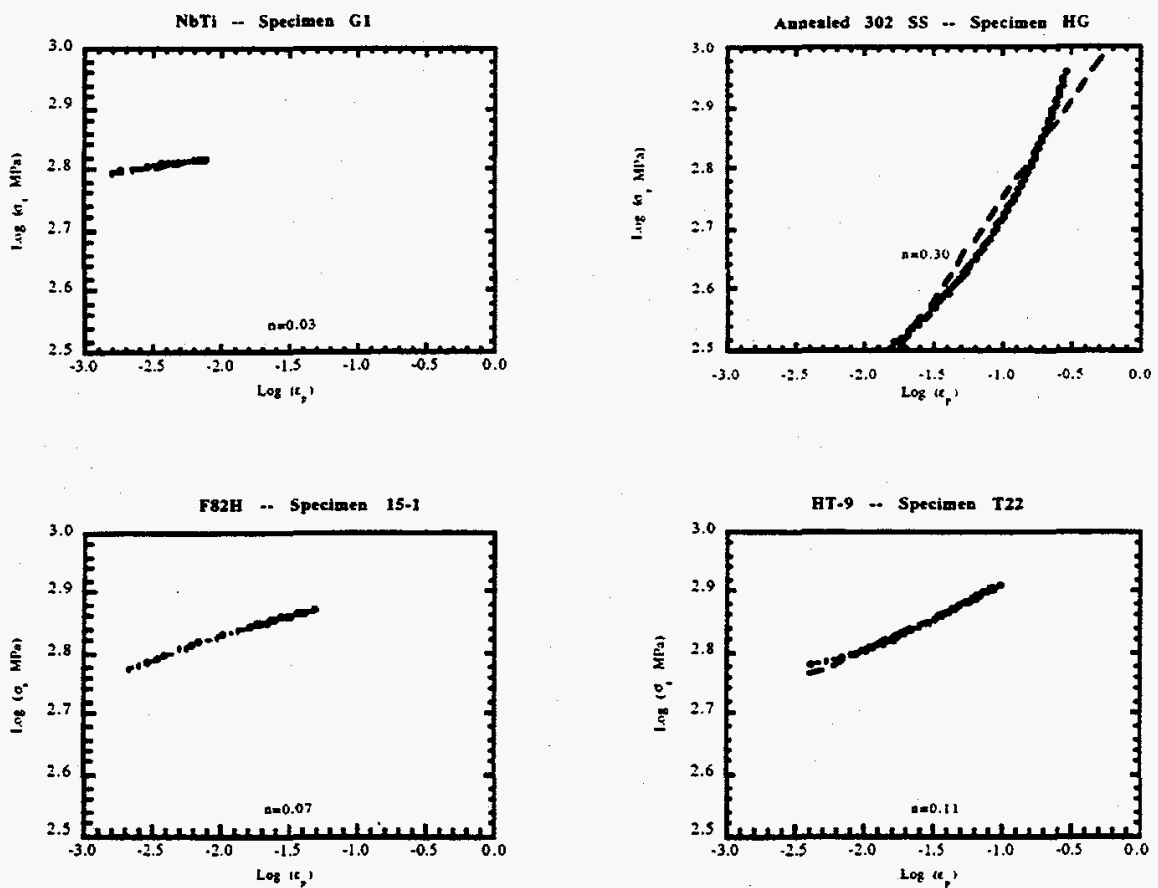

Figure 3.1 $\log \sigma_{\mathrm{t}}$ vs $\log \varepsilon_{\mathrm{p}}$ for f)NbTi g)AISI $302 \mathrm{SS}$ h)F-82H and i)HT-9. 
Given this rather complex behavior it is clearly not possible to define a single parameter to rigorously define post yield strain hardening behavior. However, since hardness tests implicitly probe a wide range of strains from yield to well beyond the uniform necking strain limiting the regime of tensile tests, the data were analyzed simply by fitting an average strain hardening exponent curve, shown as the dashed lines in Figure 3.1. In general the fits were reasonable with correlation coefficients values ranging from 0.94 to 0.99. The most significant exception was the austenitic stainless steel; in this case the third regime associated with formation of martensite was not included in the analysis. Even with this simplification the simple power law fit to the stainless steel was less accurate than in the other cases. The justification (or not) for these approximations, including that for the case of the AISI 302 SS, is being examined by comparison of simulation results from ongoing finite element method (FEM) studies using different types of constitutive laws. However, complete resolution of the implications of the simple power law approximation are beyond the scope of the present study. The tensile properties and fitted strain hardening exponents for the materials in this study are summarized in Table 3.2 . 
Table 3.2. Tensile properties of materials examined in this study.

\begin{tabular}{|c|c|c|c|c|c|}
\hline Material & Specimen & $\sigma_{\mathrm{v}}(\mathrm{Mpa})$ & $\sigma_{\mathrm{u}}(\mathrm{MPa})$ & $\mathrm{e}_{\mathrm{u}}(\%)$ & $\mathrm{n}$ \\
\hline \multirow[t]{3}{*}{$\mathrm{NbTi}$} & $\overline{G 1}$ & 600 & 628 & 3.4 & 0.03 \\
\hline & $\mathrm{G} 2$ & 600 & 629 & 3.1 & 0.03 \\
\hline & G3 & 590 & 620 & 3.0 & 0.03 \\
\hline \multirow[t]{2}{*}{$\begin{array}{c}\text { Model } \\
\text { A533B LT }\end{array}$} & $\overline{\mathrm{F} 81}$ & 665 & 705 & 6.0 & 0.03 \\
\hline & F83 & 675 & 705 & 5.0 & 0.03 \\
\hline \multirow[t]{3}{*}{$\mathrm{F}-82 \mathrm{H}$} & $2-1$ & 579 & 700 & 3.2 & 0.08 \\
\hline & $8-1$ & 580 & 685 & 5.2 & 0.07 \\
\hline & $15-1$ & 580 & 694 & 5.3 & 0.07 \\
\hline \multirow[t]{2}{*}{$\begin{array}{c}\text { Model } \\
\text { A533B ITI }\end{array}$} & M51 & 690 & 775 & 8.9 & \\
\hline & M52 & 685 & 780 & 8.8 & \\
\hline \multirow[t]{3}{*}{$\begin{array}{c}\text { Model } \\
\text { A533B } \\
\text { Control } \\
\end{array}$} & 4 & 540 & 650 & 8.8 & 0.08 \\
\hline & 71 & 520 & 640 & 9.3 & 0.08 \\
\hline & 72 & 525 & 630 & 8.7 & 0.08 \\
\hline \multirow[t]{3}{*}{ HT-9 } & T22 & 581 & 716 & 12.3 & 0.10 \\
\hline & T23 & 512 & 710 & 12.9 & 0.14 \\
\hline & $\mathrm{T} 24$ & 565 & 707 & 12.3 & 0.09 \\
\hline \multirow[t]{3}{*}{ A533B } & 504 & 469 & 604 & 10.2 & 0.11 \\
\hline & 505 & 469 & 610 & 9.6 & 0.11 \\
\hline & 506 & 467 & 618 & 9.9 & 0.10 \\
\hline \multirow[t]{3}{*}{ A302B } & $\overline{501}$ & 481 & 621 & 9.9 & 0.11 \\
\hline & 502 & 461 & 606 & 11.9 & 0.12 \\
\hline & 503 & 472 & 620 & 10.1 & 0.12 \\
\hline \multirow[t]{2}{*}{$\begin{array}{c}\text { Ann AISI } \\
304 \text { SS }\end{array}$} & $\overline{\mathrm{HE}}$ & 250 & $\overline{946}$ & 97.3 & 0.30 \\
\hline & $\overline{\mathrm{HG}}$ & 255 & 973 & 101.5 & 0.32 \\
\hline
\end{tabular}


The A533B model alloy microhardness specimens were in the form of 4 mm diameter disks. The disks were placed in a special holder used for handling irradiated material during polishing and microhardness testing. There were a total of 5 specimens for this alloy: 2 in the unirradiated condition (controls), 2 in the low temperature irradiation condition and 1 in the high temperature irradiation condition.

For the annealed AISI 304 SS specimens, microhardness measurements were taken on the end tabs of an untested mini-tensile specimen. The sample was glued to a metal mount in order to be polished. Specimens for the remaining materials were small rectangular samples ranging in size from approximately $0.5^{\prime \prime} \times 0.25$ " to $1.0^{\prime \prime} \times .75^{\prime \prime}$ which were mounted in epoxy.

All specimen surfaces were first wet polished with alcohol using 600 grit paper and then fine polished overnight using a vibratory polisher with 0.3 micron alumina powder and ethylene glycol. Polishing of the A533 model alloys was conducted separately in a designated area for storing and preparing activated samples.

An automated LECO microhardness tester with a Vickers-type indenter was used for all hardness tests. A minimum of 5 indents were made at loads of $200 \mathrm{~g}$ for each specimen. 
Microhardness data are summarized in Table 3.3 in terms of the both the indent diagonal and the corresponding VHN number. These hardness values generally reflect the corresponding $8 \%$ flow stress $\left(\sigma_{8}\right)$, with an average $\sigma_{8} / \mathrm{NHN}$ ratio of about 3.25 , reasonably close to the nominal value of about 3. As expected this ratio decreases with increasing strain hardening from a high of about 3.65 for the TiNb alloy to a low of about 2.4 for the AISI 302 SS. Note the nominal irradiation induced hardness increases of about 32 (LTI) and 36 (ITI) are somewhat lower than expected from the corresponding yield stress increases of 142 and $162 \mathrm{MPa}$. This may be due to the hardness of the unirradiated control $(\approx 222 \mathrm{VHN})$ which appears to be about 11 VHN higher than averages found in previous studies[29,31]. If a lower VHN value for the control is used, there is good agreement between the yield stress and hardness.changes. 
Table 3.3a Hardness values (VHN) and diagonal lengths $(\mu \mathrm{m})$ at $200 \mathrm{~g}$ for A302B, A533B, HT-9, F-82H, Nb-Ti and annealed AISI 302 SS.

\begin{tabular}{|c|c|c|c|c|c|}
\hline \multicolumn{3}{|c|}{ A302B } & \multicolumn{3}{|c|}{ A533B } \\
\hline Indent & Diagonal & $\overline{\mathrm{VHN}}$ & Indent & Diagonal & $\overline{\mathrm{VHN}}$ \\
\hline 1 & 43.2 & 199 & 1 & 41.1 & 219 \\
\hline 2 & 43.0 & 201 & $\overline{2}$ & 41.6 & $\overline{214}$ \\
\hline 3 & 42.8 & 203 & 3 & 43.3 & 198 \\
\hline 4 & 43.9 & 193 & 4 & 44.4 & 188 \\
\hline 5 & 43.6 & 195 & 5 & 44.5 & 188 \\
\hline ave & $\overline{43.3}$ & 198 & ave & 43.0 & 201 \\
\hline std dev & 0.4 & 4 & std dev & 1.3 & 12 \\
\hline \multicolumn{3}{|c|}{ HT-9 } & \multicolumn{3}{|c|}{ F.82H } \\
\hline Indent & Diagonal & $\overline{\mathrm{VHN}}$ & Indent & Diagonal & VHN \\
\hline 1 & 40.3 & 229 & 1 & 40.1 & 231 \\
\hline 2 & 39.2 & 242 & 2 & 40.6 & 225 \\
\hline 3 & 39.9 & 233 & 3 & 40.1 & 230 \\
\hline 4 & 39.8 & 234 & 4 & 40.6 & 225 \\
\hline 5 & 39.8 & 234 & 5 & 40.3 & 229 \\
\hline ave & 39.8 & 234 & ave & 40.3 & 228 \\
\hline std dev & $\overline{0.2}$ & 3 & std dev & 0.2 & 2 \\
\hline \multicolumn{3}{|c|}{$\mathbf{N b}-\mathbf{T i}$} & \multicolumn{3}{|c|}{ AISI 302 Stainless Steel } \\
\hline Indent & Diagonal & VHN & Indent & Diagonal & VHN \\
\hline 1 & 46.1 & 174 & 6 & 43.7 & 194 \\
\hline 2 & 45.3 & 181 & 7 & 43.3 & 198 \\
\hline 3 & 46.3 & 173 & 8 & 45.3 & 181 \\
\hline 4 & 46.1 & 175 & $\overline{9}$ & 43.9 & 193 \\
\hline 5 & 46.0 & 175 & $\overline{10}$ & 44.4 & 188 \\
\hline ave & 45.9 & 176 & ave & 44.1 & 191 \\
\hline std dev & 0.3 & 2 & std dev & 0.6 & 5 \\
\hline
\end{tabular}


Table 3.3b) Hardness values (VHN) and diagonal lengths $(\mu \mathrm{m})$ at $200 \mathrm{~g}$ for the A533B model alloy in the unirradiated (Control), LTI $\left(60^{\circ} \mathrm{C}\right)$, and ITI $\left(290^{\circ} \mathrm{C}\right)$ conditions

\begin{tabular}{|c|c|c|c|c|c|c|c|c|}
\hline \multicolumn{3}{|c|}{$\begin{array}{l}\text { A533B Model Alloy } \\
\text { Control }\end{array}$} & \multicolumn{3}{|c|}{ A533B Model Alloy LTI } & \multicolumn{3}{|c|}{ A533B Model Alloy ITI } \\
\hline Indent & Diagonal & VHN & Indent & Diagonal & VHN & Indent & Diagonal & VHN \\
\hline$T$ & 41.6 & 214 & $T$ & 38.2 & 254 & $\bar{T}$ & 38.1 & 256 \\
\hline 2 & 40.2 & 230 & 3 & 36.7 & 275 & $\overline{3}$ & 38.1 & 255 \\
\hline$\overline{3}$ & 40.5 & 226 & 4 & 39.0 & 244 & 4 & 38.2 & 254 \\
\hline$\overline{4}$ & 41.3 & 217 & 5 & 39.7 & 235 & 6 & 37.1 & 269 \\
\hline 5 & 41.2 & 219 & 6 & 36.8 & 274 & 7 & 37.7 & 261 \\
\hline 6 & 39.6 & 236 & 7 & 37.0 & 271 & & & \\
\hline 7 & 41.4 & 216 & 10 & 40.1 & 231 & & & \\
\hline$\overline{8}$ & 41.2 & 219 & & & & & & \\
\hline 9 & 40.9 & 222 & & & & & & \\
\hline 10 & 40.2 & 229 & & & & & & \\
\hline$\overline{\text { ave }}$ & 40.8 & 223 & ave & 38.2 & 254 & ave & 37.9 & 259 \\
\hline std dev & 0.5 & 6 & std dev & 1.1 & 14 & std dev & 0.4 & 5 \\
\hline
\end{tabular}




\subsection{Characterization of the Indents Using Confocal Images}

A Technical Instruments modeI K2-IND Spinning Disk Confocal Microscope was used to generate detailed quantitative topographical images of the microhardness indentations. The system was developed by Edsinger [25]. The confocal microscope contains a rotating disk with many pinhole-sized apertures. An image of the specimen is magnified and projected through these apertures. With this arrangement, the microscope optically slices the specimen in the $z$ direction. since only the light reflected from a surface in the focal plane is allowed to pass through these small apertures. The disk rotates so that the pinholes cover the entire area being imaged. By moving the specimen relative to the disk (i.e. changing the focal plane) using a precision stage, the topography of the surface can be mapped as a function of $\mathrm{z}$.

The light intensity passing through the disk is measured by a grayscale video camera and can be viewed by an attached television monitor. In the images captured by the camera at each specimen height the dark areas represent locations which are out of the focal plane while light areas represent areas in focus (the closer the region is to being in the focal plane the more the reflected light passes through the pinholes in the spinning disk aperture). At each pixel location in the viewed area, the intensity of light is

measured as a function of focal distance or specimen height. Using 
appropriate filtering techniques the height associated with the maximum light intensity is assigned to the feature positioned at that pixel location. Hence, assigning the positions for all pixels in the image produces a detailed topographical map of the area being viewed. This topographical image file is then transferred to an IBM RS6000 workstation for further analysis [25].

If the specimen surface is not perfectly flat on the stage of the microscope an average two dimensional slope is produced in the topographical map of the indent. This slope was computationally corrected by a geometrically dictated height adjustment at each pixel point. Adobe's Photoshop's@ median filtering algorithm was then used to reduce remaining noise in the image. Finally, a zero reference height for each image was calculated by taking the average height of all the pixels forming the outer region of the image.

Confocal images were taken of the $200 \mathrm{~g}$ indents for all materials at a height resolution of about 0.05 to $0.20 \mu \mathrm{m}$. The general characteristics of the indentations are best observed by constructing topographic elevation maps from the $x-y-z$ confocal data. These maps were created using a commercial software package, Spyglass Transform $®$.

Figure 3.2 illustrates the contour plots for limiting cases of low ( $\mathrm{TiNb}$ ) and high (AISI 302SS) strain hardening material in the unirradiated condition. 
The TiNb alloy $(n \approx 0.031)$ shows relatively high pileups that are steep on both sides and that tend to peak at the center of the indent side. The contour defining the 0 height is well defined and centered on the indent. In contrast, the AISI $302 S S$ ( $n \approx 0.29$ ) has a much lower pileup height, even at isolated peak locations, and the pileup is clearly far more diffuse. Indeed, in this case the 0 height contour is irregular and in other cases forms separate pileup patches. This behavior has been previously referred to as 'sinking in', characteristic of high strain hardening materials. However, simple volume conservation in an incompressible metal dictates that a pileup must form somewhere. Hence, strain hardening influences the location and morphology, but not the existence of a pile-up. Thus, presumably, accurate measurements of the pile-ups can be related to the corresponding strain hardening behavior.

Note the contours in Figure 3.2 are not completely symmetric on all four sides of the indent. Additional asymmetries are illustrated in contour plots for another NbTi alloy and a martensitic stainless steel. HT-9 shown in Figure 3.3. The NbTi indent pile-ups are not all peaked at the center of the indent side; and on one side two peaks have formed. In the case of HT-9 one of the sides of the indent shows three peaks. 

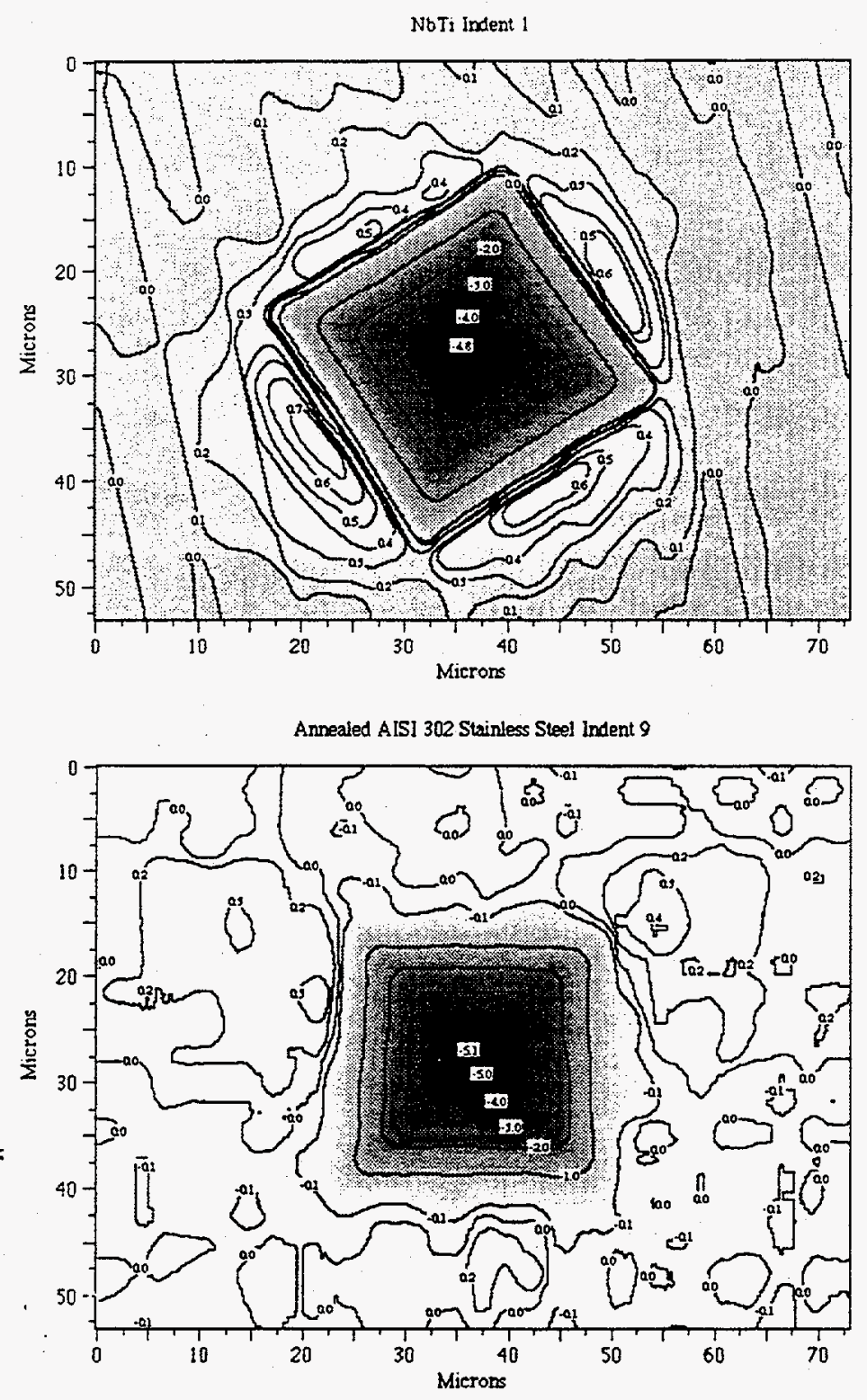

Figure 3.2 Contour plots of a) NbTi and b)annealed AISI 302 stainless steel 
NbTi Indent 3

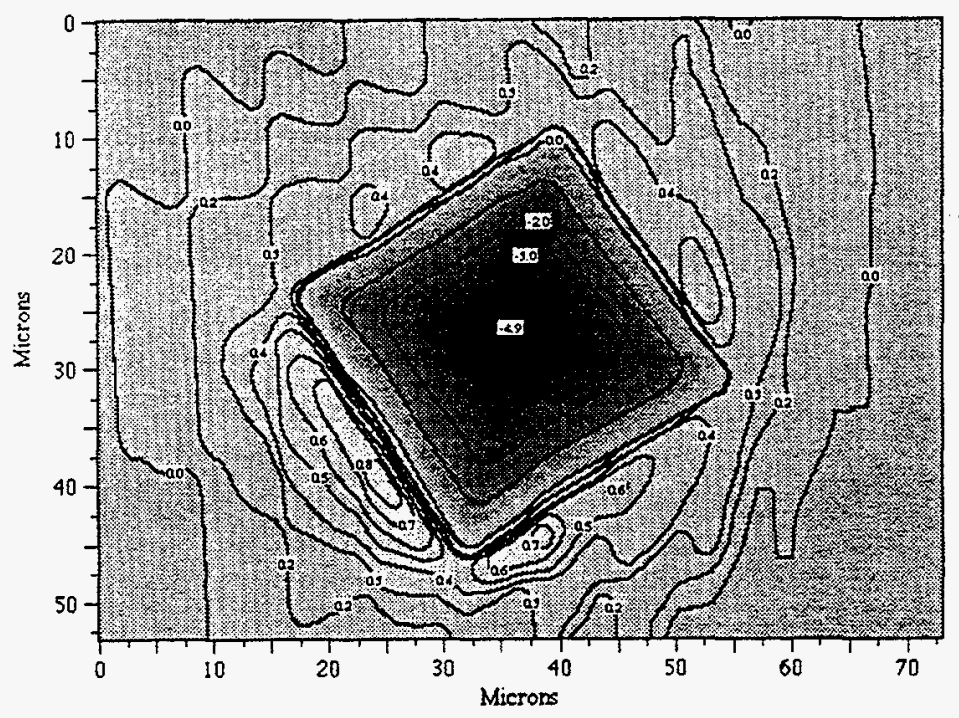

HT-9 Indent I

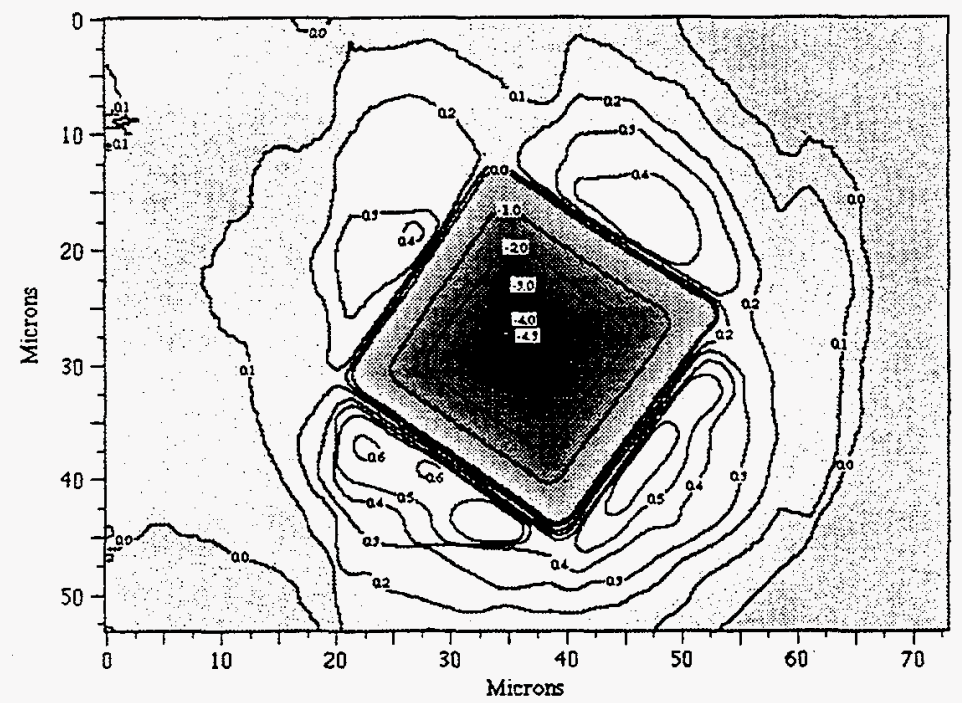

Figure 3.3 Contour plots of a) NbTi and b) HT-9 
Clearly, the contour maps contain too much local information to be used directly to quantitatively evaluate strain hardening properties. The information in these maps must be parameterized in some fashion that can be physically related to strain hardening rates. Ideally the parameterization of the pile-up location and morphology has the following characteristics:

1. A demonstrable, unique physical relation to strain hardening;

2. applicability to a wide range of conditions including variations in the absolute value of the yield and flow stresses of a metal (e.g., apply to a wide range of strength levels), indent loads and even types of indents.

3. ability to account for inevitable asymmetries and variations in indents and indent pile-ups;

4. is amenable to relatively easy and precise measurement.

Given all the complexities of metal flow controlled by real constitutive laws under conditions with high stress/strain gradients and local heterogeneities and imperfect test conditions. meeting these ideal requirements is very difficult. The initial efforts in this work were directed at using the volume conservation principle to characterize the shapes of the indentations in terms 
of the spatial distribution of material lying below and above the zero-height pre-indent plane. One objective was to verify that, indeed, volume conservation could be observed. Although it is worthy of additional effort, it was found that the volume distribution methods were difficult to apply in practice, since in many cases conservation was approached but not fully achieved. In large part, this was due to the difficulty in characterizing small pileup heights that gradually approach zero at fairly large distances from the indent. While the heights are small, the in-plane areas are large; thus, the net volumes may be significant in this region, but measurements are subject to uncertainties associated with resolution and the accumulation of small errors.

Thus another approach was developed that is more robust and insensitive to the accumulation of small measurement errors. This involved creation of averaged pseudo height profiles. An idealized version of construction of such profiles is illustrated in Figure 3.4. In this case the pile-ups are completely symmetric and peaked at the center of the indent edge. Thus a profile along the line $\mathrm{ABCDE}$ would produce a symmetric profile that might be sufficient to provide the first level of characterization of the indent and pile-up. However, as illustrated in Figure 3.5 real pile-ups are neither symmetric nor peaked at the center. Thus some sort of averaging along the length of the pile-up, parallel to the indent side, is needed; indeed, this might be desirable even if the indents were completely symmetric. 
Topographical Map of Indent

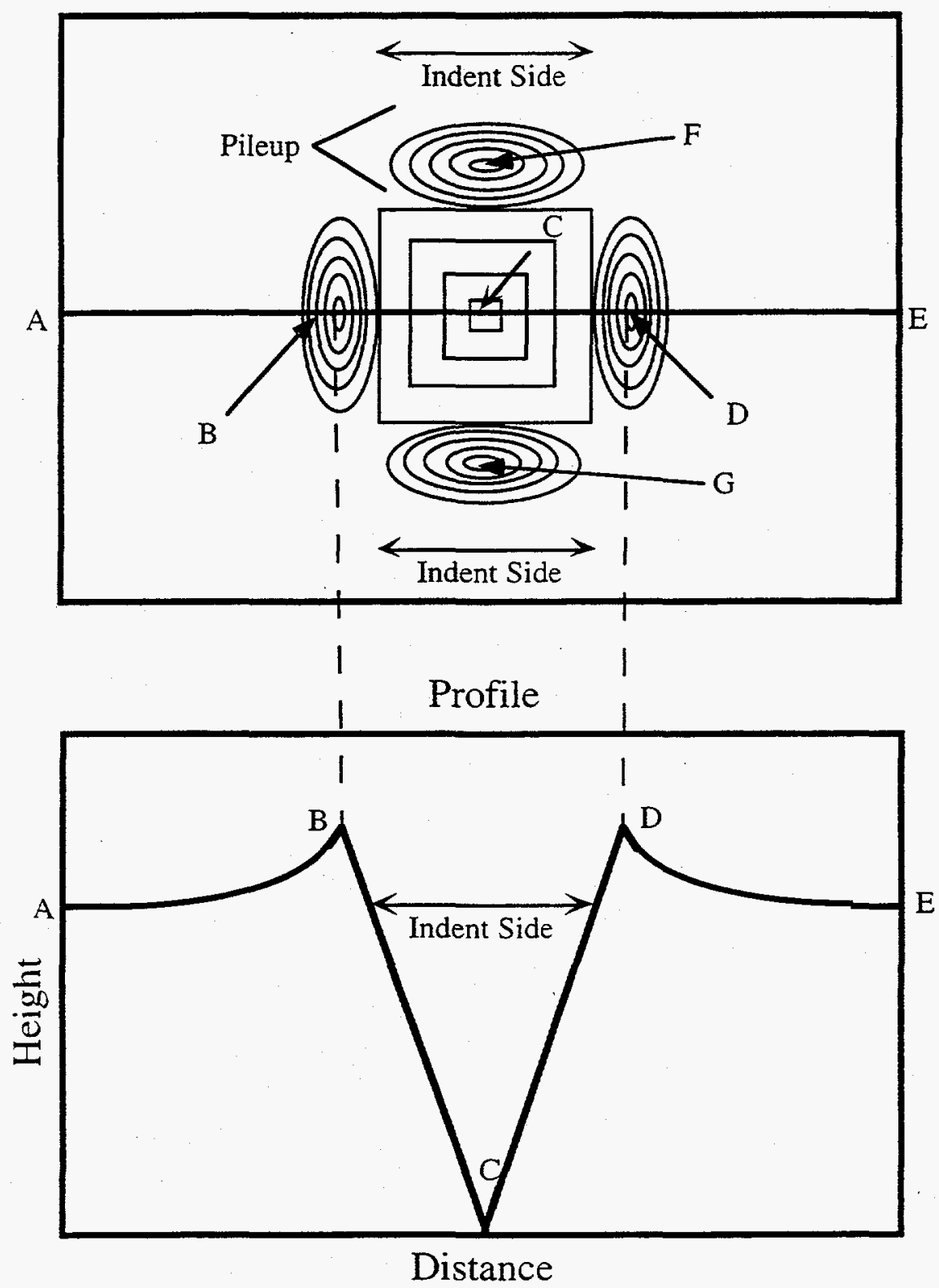

Figure 3.4 Illustration of a) idealized topographical map of an indent and $b$ ) a corresponding profile 

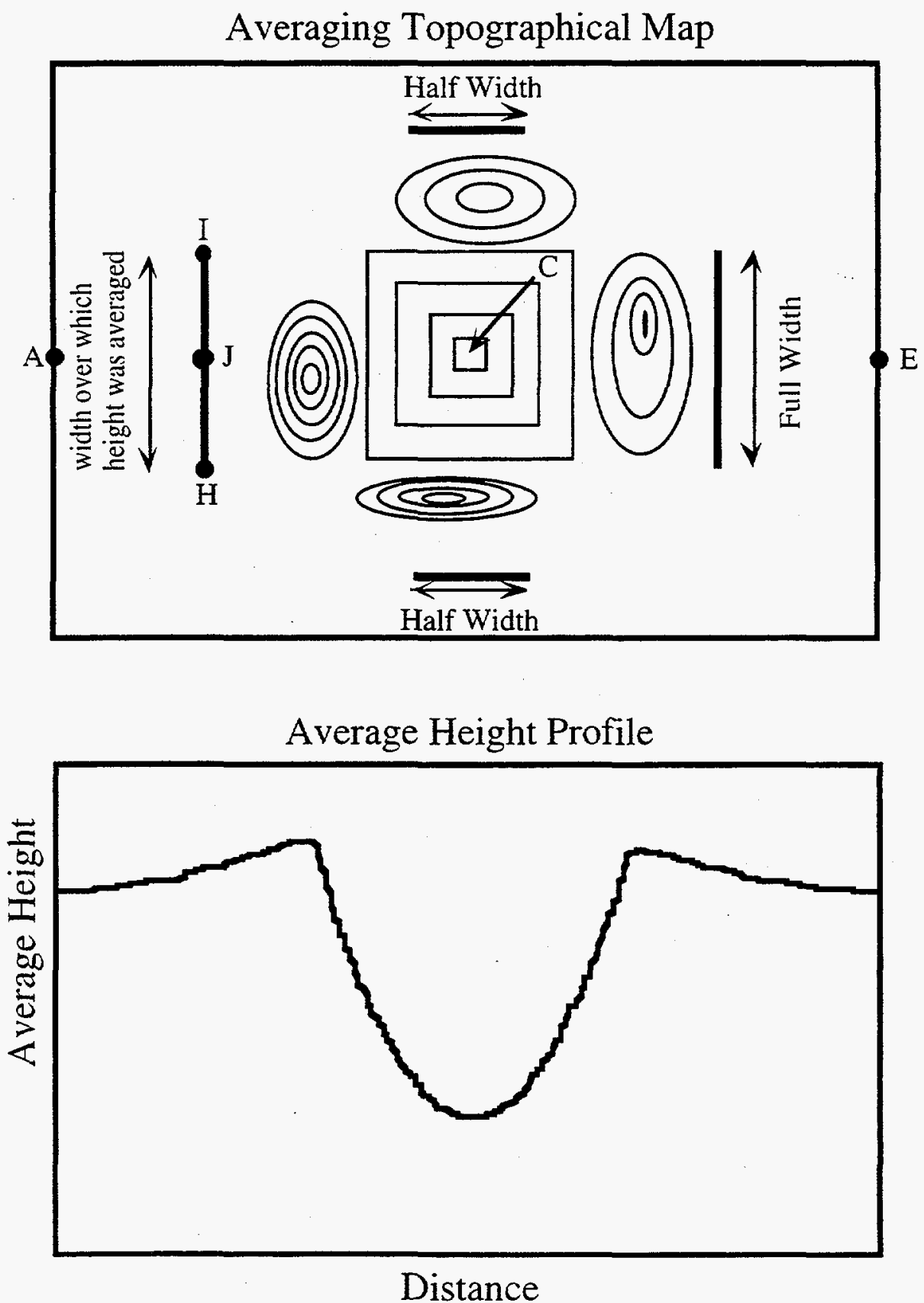

Figure 3.5 Illustration of a) typical topographical map of an indent and b) a corresponding average height profile 
The procedure adopted in this work involved averaging heights along either one half length or a full length of the indent side, defined by the zero height contour. Of course other averaging lengths could be chosen. These averaging lengths were applied both inside and outside the indent to maintain some spirit of volume conservation. Thus, below the zero height plane the profiles represent a pseudo or average indent depth. Thus the halflength averaging profiles are deeper than those for full length averaging, but differences are much less pronounced above the zero plane - the region of interest for characterizing the pile-up itself.

Figure 3.6 shows a full length profile for $\mathrm{F}-82 \mathrm{H}$ which is fairly symmetric on all sides. Here the $c$ and $d$ plots are magnifications of the pile-up profiles in plots a and b. A similar plot for another F-82H indent is shown in Figure 3.7. In this case the pile-up profiles are different for each side. Figure 3.8 shows a contour plot and the corresponding profiles for the $\mathrm{A} 302 \mathrm{~B}$ pressure vessel steel for both half (dashed line) and full (solid line) length averaging. Note the half width averaging is both deeper in the indent itself and slightly higher in the pile-up region. Figure 3.9 shows similar plots for the A533B pressure vessel steel with blown-up views of the pile-up profiles. In this case due to the formation of multiple peaks, the half length average is actually lower in the pile-up on one side. 


\section{F82h Indent 5}
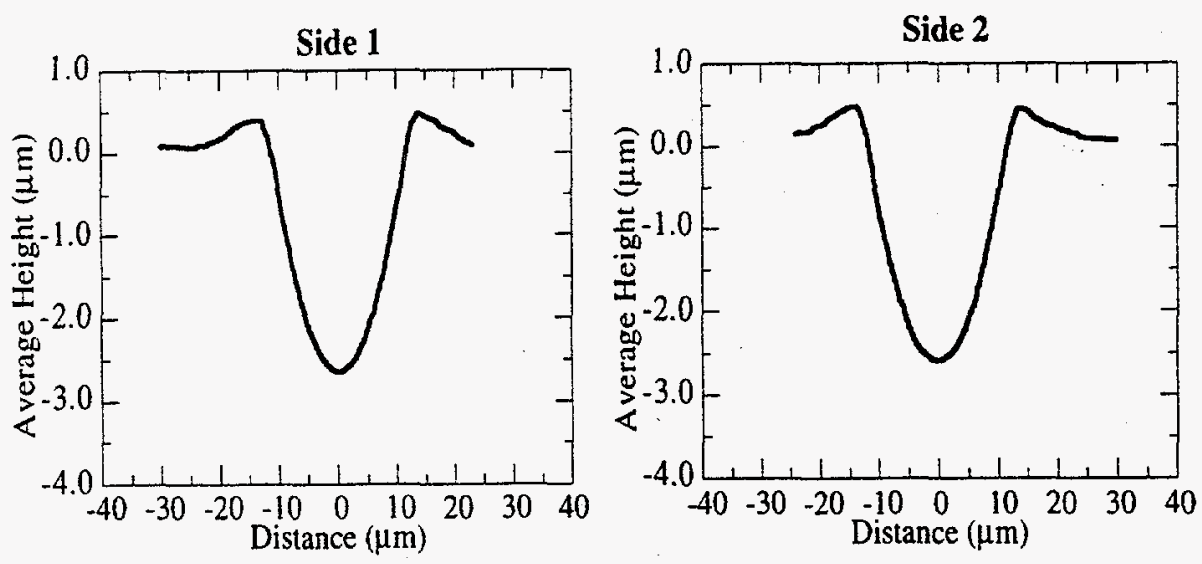

Side 1
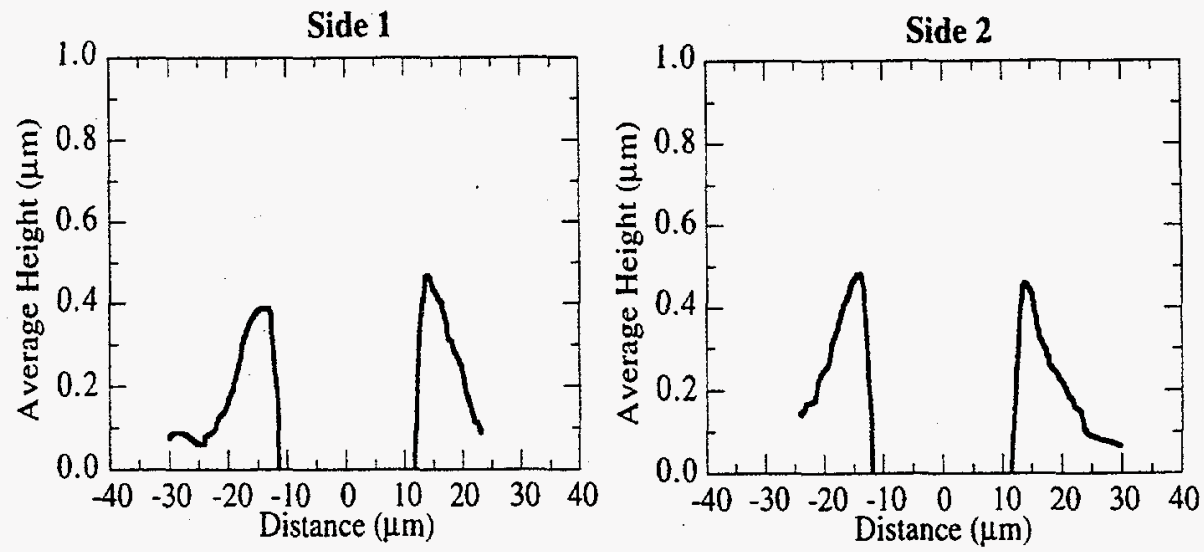

Fig 3.6 Full length average height profiles for F-82H indent 5 along a) side 1 showing the entire range of heights $b$ ) side 2 showing the entire range of heights c) side 1 showing only the heights above $0 \mathrm{~d}$ ) side 2 showing only the heights above 0 


\section{F82h Indent 1}

Side 1
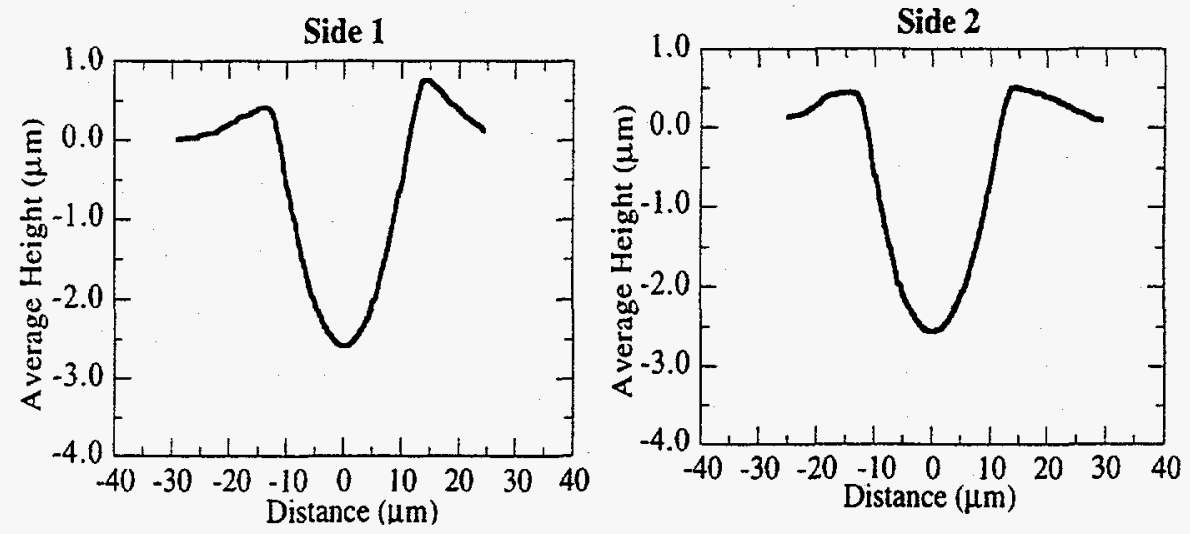

Side 1

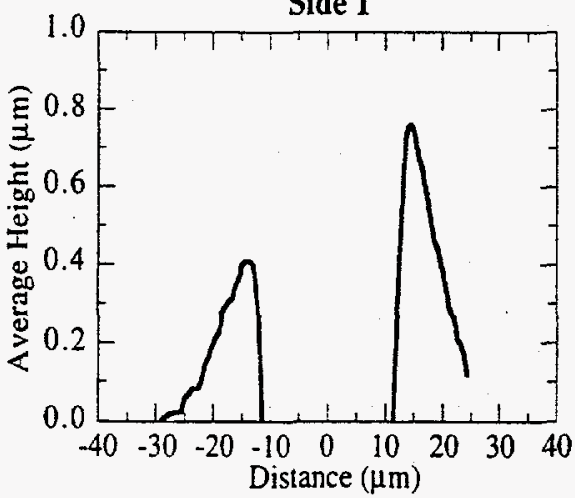

Side 2

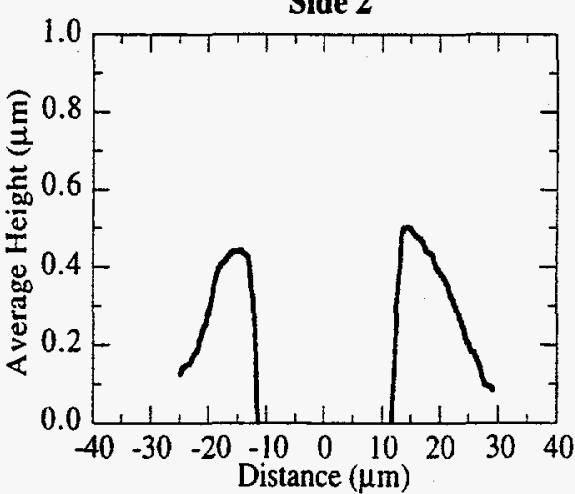

Fig 3.7 Full length average height profiles for $\mathrm{F}-82 \mathrm{H}$ indent 1 along a) side 1 showing the entire range of heights $b$ ) side 2 showing the entire range of heights $c$ ) side 1 showing only the heights above $0 \mathrm{~d}$ ) side 2 showing only the heights above 0 

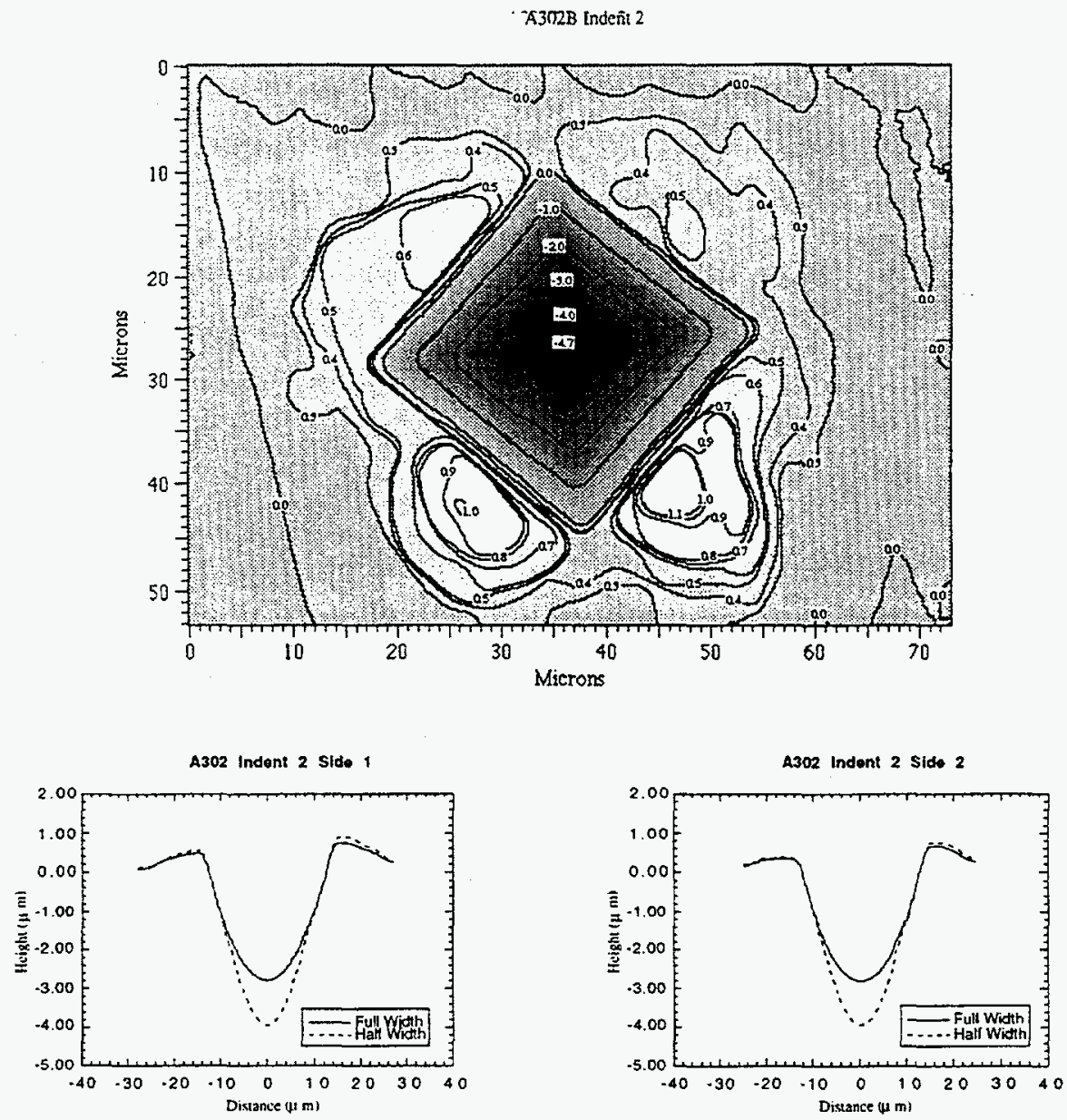

Fig 3.8 a) Contour plot of $A 302 B$ indentation with the coresponding average height profiles along $b$ ) side 1 and $c$ ) side 2 of the indent 

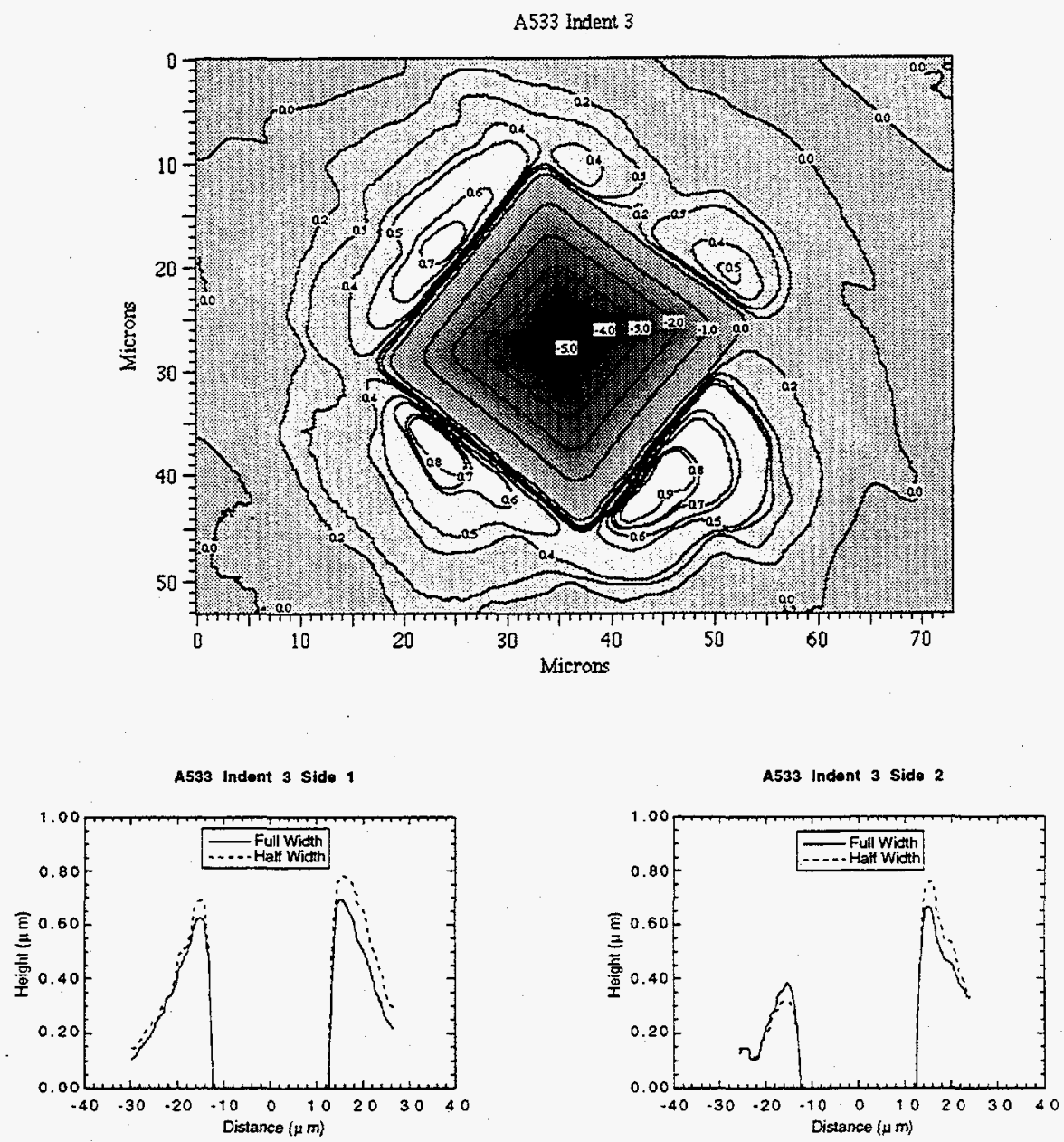

Fig 3.9 a) Contour plot of A533B indentation with the coresponding average height profiles along $b$ ) side 1 and $c$ ) side 2 of the indent 
Given this variability, averaging of the profiles was carried out for all four sides of a given indent and for all five indents in the same material. The full and half length averages are shown in Figure 3.10. A comparison of the limiting cases of NbTi and AISI 302SS shows the NbTi has a high narrow pile-up profile while the AISI 302 SS is much lower and broader. The other material conditions fall in between. These profiles form the basis for further parameterization of the indent/pile-up and it relationship to strain hardening behavior. 


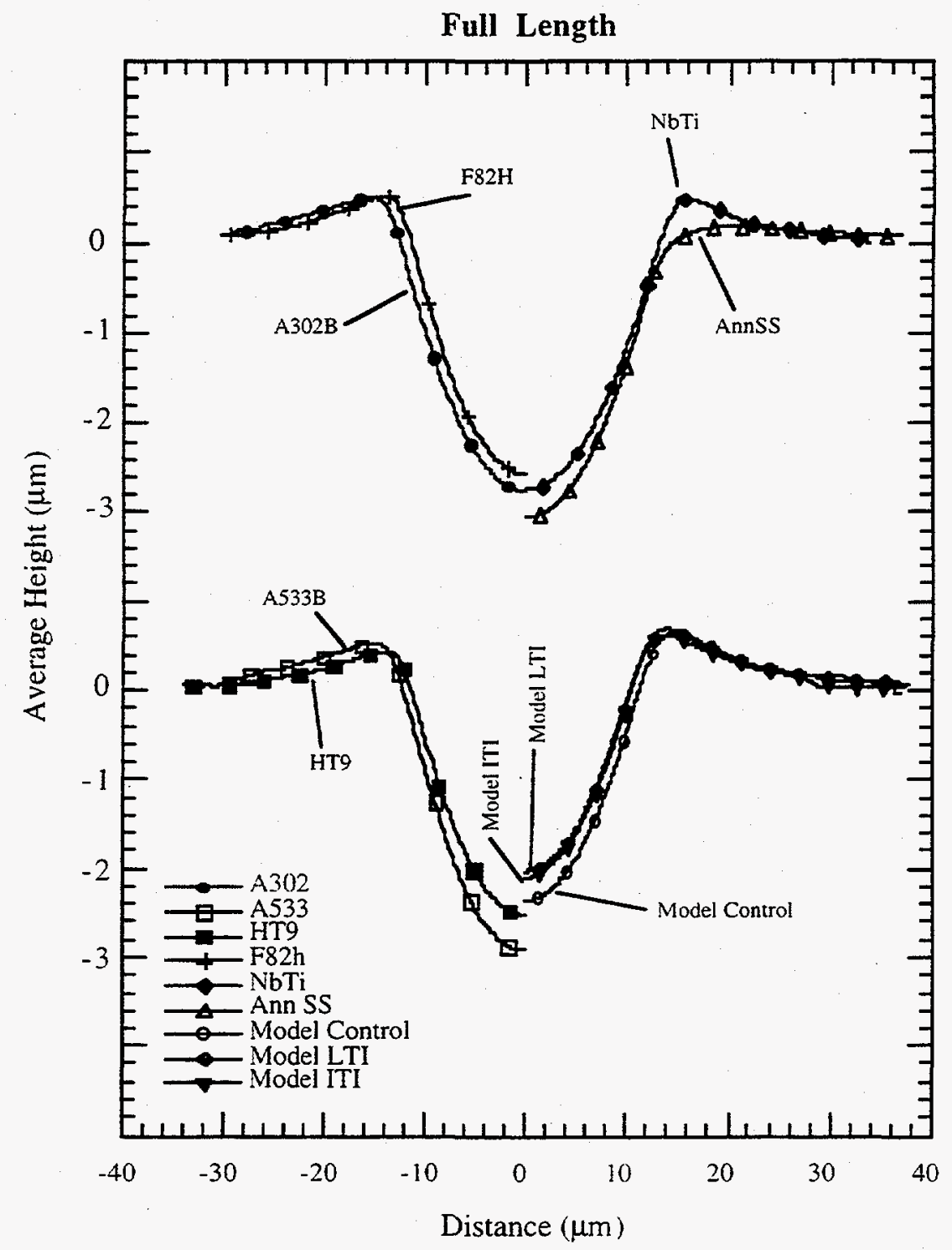

Figure 3.10 a) Characteristic full length average height profiles. 


\section{Full Length}

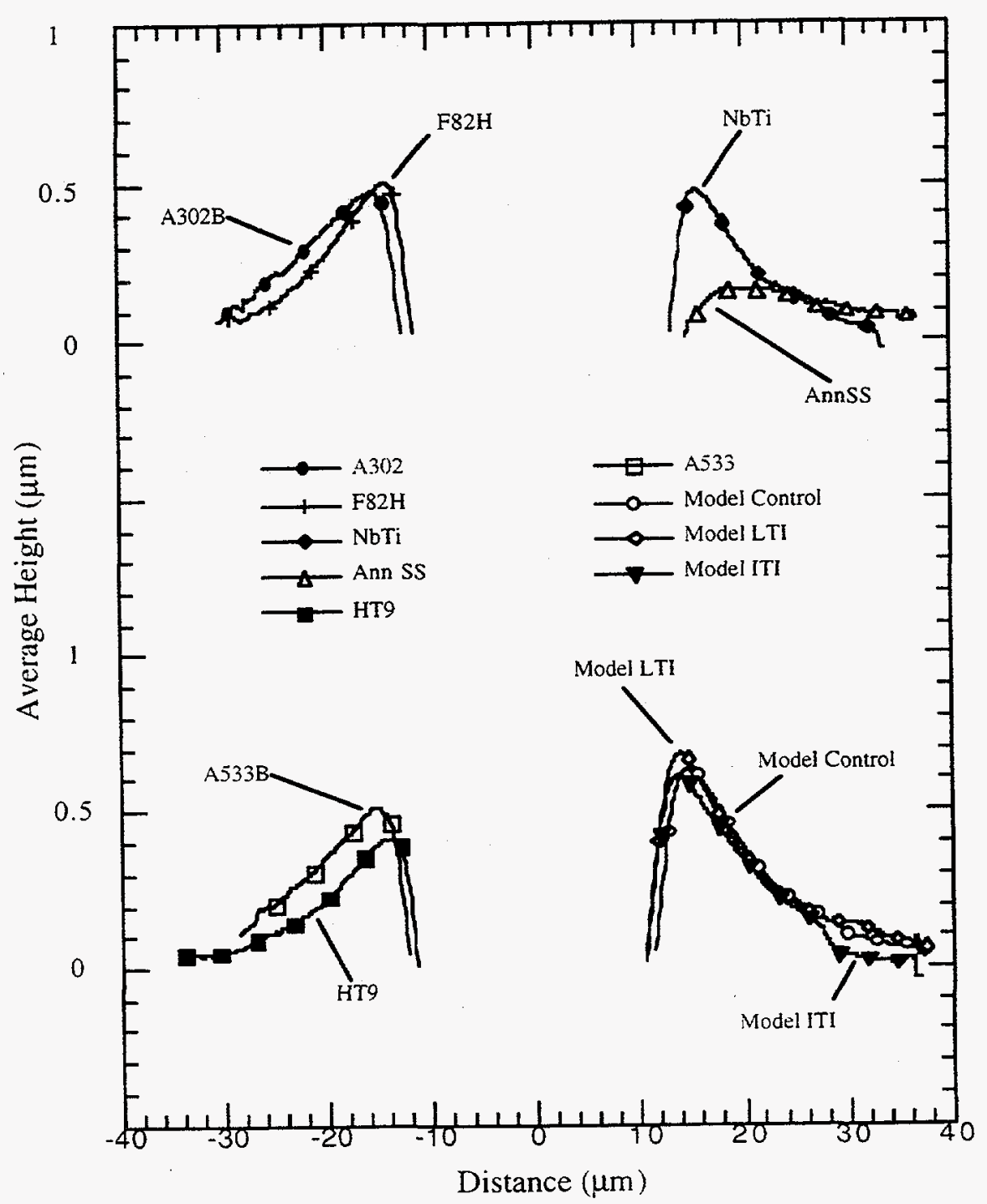

Figure 3.10 b) Characteristic Full Length Average Height Profiles for heights between 0 and $1 \mu \mathrm{m}$. 


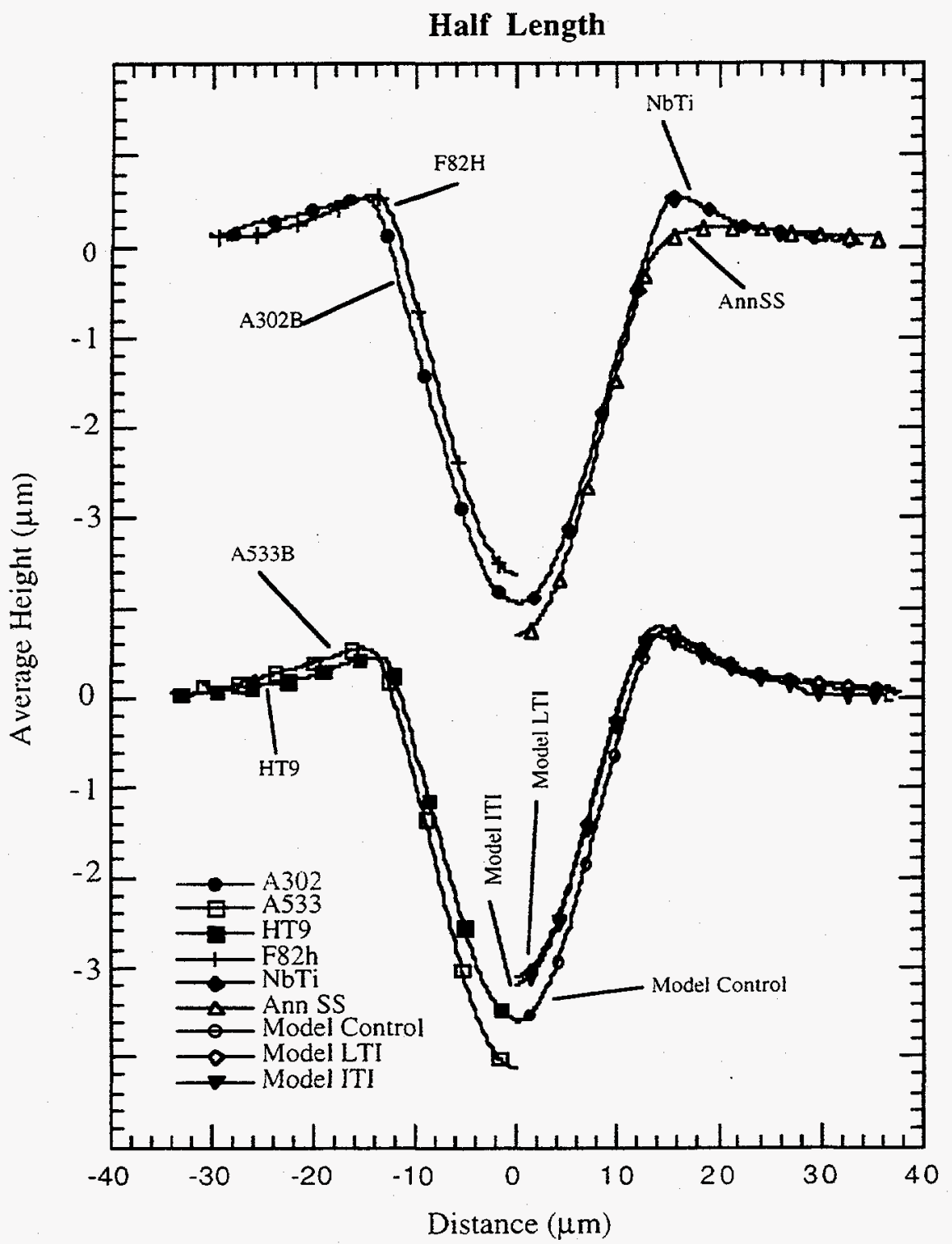

Figure 3.10 c) Characteristic Half Length Average Height Profiles. 
Half Length

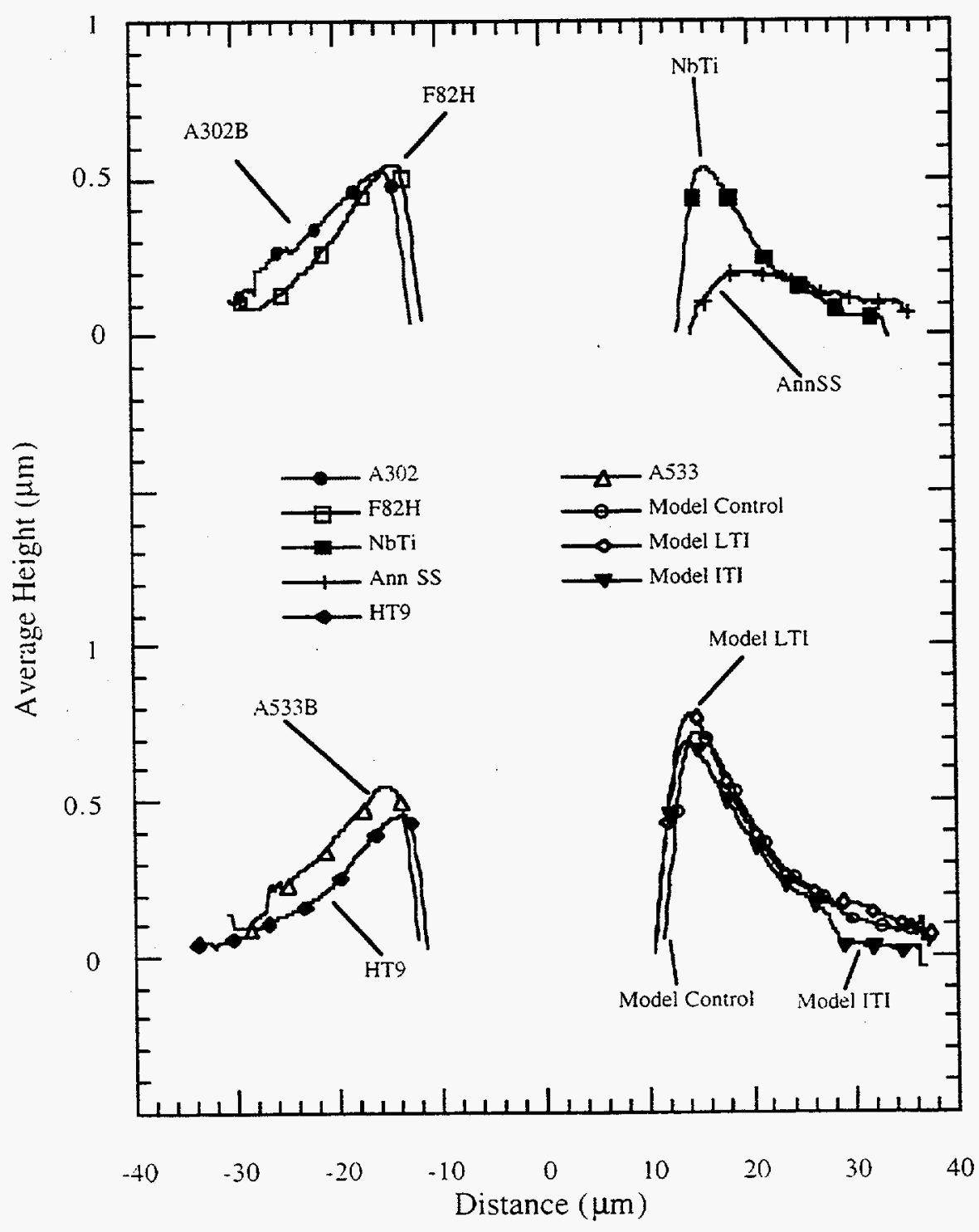

Figure 3.10 d) Characteristic Half Length Average Height Profiles between 0 and $1 \mu \mathrm{m}$. 


\subsection{Indent/Pile-Up Profile Parameters}

The profiles described in the last section can be most simply characterized by the following set of dimensional parameters illustrated in Figure 3.11: a) the profile depth $\left(h_{d}\right)$; the distance from the center to the zero-height at the edge of the indent $\left(\mathrm{L}_{\mathrm{mo}}\right)$; $\left.\mathrm{c}\right)$ the peak height of the pile-up $\left(\mathrm{h}_{\mathrm{p}}\right)$; the distance from the center of the indent to the peak $\left(\mathrm{L}_{\mathrm{mp}}\right)$; d) the distance from the inner to outer zero height crossing $\left(\mathrm{L}_{\mathrm{oo}}\right)$; e ) the distance from the peak to the counter zero level $\left(\mathrm{L}_{\mathrm{po}}\right)$. The pile-up profile only gradually approaches the outer zero-height level, while the region of initial drop off following the peak is approximately linear down to about one half the peak height. Thus it is more effective to define $\mathrm{L}_{\infty}$ and $\mathrm{L}_{\mathrm{po}}$ in terms of the distance to a outer zero crossing of a least square fit line to the pile-up profile in the linear region, indicated by the dashed line in Figure 3.11a. These parameters for all of the average indent profiles are summarized in Table 3.4 for both full and half width lengths. The indent/pile-up parameters are rounded to three significant figures and the corresponding strain hardening coefficient to two significant figures. 

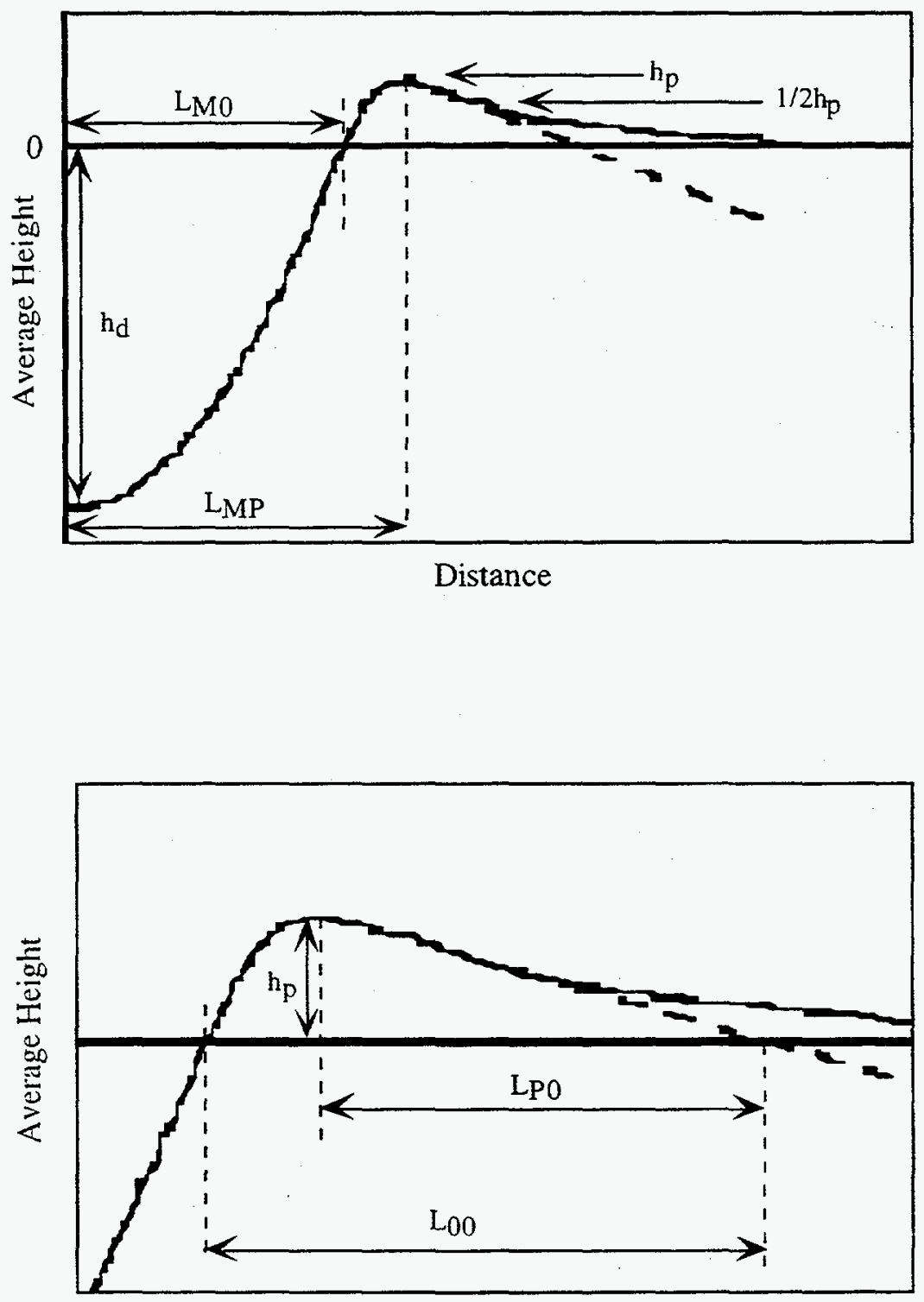

Distance

Figure $3.11 \mathrm{a}$ and b) Parameters used to characterize average height profiles. 
Table 3.4 Half-profile parameters for the full width and half width average height profiles and average work hardening exponent for each material.

\begin{tabular}{|c|c|c|c|c|c|c|c|}
\hline \multicolumn{8}{|c|}{ Full Width } \\
\hline Material & $\mathrm{L}_{(x)}(\mu \mathrm{m})$ & $\mathrm{L}_{\rho\}}(\mu \mathrm{m})$ & $\mathrm{L}_{\mathrm{mit}}(\mu \mathrm{m})$ & $\mathrm{L}_{\mathrm{mp}}(\mu \mathrm{m})$ & $h_{p}(\mu m)$ & $\mathrm{d}(\mu \mathrm{m})$ & $n$ \\
\hline $\mathrm{NbTi}$ & 12.8 & 10.0 & 13.2 & 16.0 & 0.47 & 2.75 & 0.03 \\
\hline $\begin{array}{c}\text { Model } \\
\text { A533B LTI } \\
\end{array}$ & 15.6 & 11.9 & 10.4 & 14.1 & 0.68 & 2.05 & 0.03 \\
\hline $\mathrm{F}-82 \mathrm{H}$ & 15.1 & 12.3 & 11.3 & 14.1 & 0.50 & 2.59 & 0.07 \\
\hline $\begin{array}{c}\text { Model } \\
\text { A533B ITI } \\
\end{array}$ & 16.6 & 13.4 & 10.6 & 13.8 & 0.61 & 2.13 & 0.07 \\
\hline $\begin{array}{c}\text { Model } \\
\text { A533B Control }\end{array}$ & 16.0 & 12.5 & 11.4 & 14.8 & 0.63 & 2.39 & 0.08 \\
\hline HT-9 & 15.5 & 12.9 & 11.2 & 13.8 & 0.41 & 2.54 & 0.11 \\
\hline A533B & 18.6 & 15.5 & 12.1 & 15.3 & 0.51 & 2.94 & 0.11 \\
\hline A302B & 18.7 & 15.7 & 12.5 & 15.5 & 0.47 & 2.78 & 0.12 \\
\hline AISI 304 SS & 31.7 & 26.3 & 14.6 & 20.0 & 0.16 & 3.07 & 0.30 \\
\hline \multicolumn{8}{|c|}{ Half Width } \\
\hline Material & $L_{(x)}(\mu m)$ & $\mathrm{L}_{\mathrm{m} \mathbf{1}}(\mu \mathrm{m})$ & $\mathrm{L}_{\mathrm{m} 0}(\mu \mathrm{m})$ & $\mathrm{L}_{\mathrm{mp}}(\mu \mathrm{m})$ & $h_{p}(\mu m)$ & $d(\mu \mathrm{m})$ & $\mathrm{n}$ \\
\hline $\mathrm{NbTi}$ & 13.5 & 10.6 & 13.0 & 16.0 & 0.53 & 3.95 & 0.03 \\
\hline $\begin{array}{c}\text { Model } \\
\text { A533B LTI } \\
\end{array}$ & 15.5 & 11.6 & 10.4 & 14.3 & 0.78 & 3.12 & 0.03 \\
\hline $\mathrm{F}-82 \mathrm{H}$ & 15.7 & 12.9 & 11.3 & 14.1 & 0.54 & 3.63 & 0.07 \\
\hline $\begin{array}{c}\text { Model } \\
\text { A533B ITI }\end{array}$ & 16.2 & 12.6 & 10.6 & 14.1 & 0.69 & 3.20 & 0.07 \\
\hline $\begin{array}{c}\text { Model } \\
\text { A533B Control } \\
\end{array}$ & 16.1 & 12.6 & 11.4 & 14.8 & 0.72 & 3.62 & 0.08 \\
\hline HT-9 & 15.8 & 13.2 & 11.2 & 13.8 & 0.45 & 3.58 & 0.11 \\
\hline A533B & 18.7 & 15.6 & 12.1 & 15.3 & 0.55 & 4.14 & 0.11 \\
\hline$\overline{\mathrm{A} 302 \mathrm{~B}}$ & 20.0 & 17.1 & 12.5 & 15.5 & 0.52 & 3.94 & 0.12 \\
\hline AISI 304 SS & 31.0 & 25.2 & 14.3 & 20.0 & 0.19 & 4.31 & 0.30 \\
\hline
\end{tabular}




\subsection{Evaluation of Indent/Pile-Up Parameter Combinations}

As noted previously the primary objective of this work is to relate the strain hardening behavior, characterized as an average power law exponent, to an indent/pile-up parameter. Clearly this parameter must be non-dimensional to achieve any hope of providing a general, self-similar relationship that is relatively independent of such details such as the load and overall strength level of the material. Previous studies [24] using a $120^{\circ}$ diamond cone indenter at high loads have shown that that the parameter defined as the pile-up height divided by the radius of the pile-up peak (similar to $h_{p} / L_{m p}$ in this study) decreases with increasing uniform strain $\left(e_{u}\right)$ and n. Figure 3.12 shows these results (assuming $e_{u} \approx n$ ) and the corresponding values of $h_{p} / L_{m p}$ versus $n$ in this study. The current results follow a similar trend but the absolute values of $h_{p} / L_{m p}$ are about 3 to 4 times lower for a specified value of $\mathrm{n}$. Further the NbTi falls below the trend of the data for steels. Further $n$ versus $h_{p} / L_{m p}$ as shown in Figure 3.12 decreases approximately linearly with $h_{p} / L_{m p}$ for the martensitic and pressure vessel steels, but the $\mathrm{NbTi}$ point falls well below the other data and the AISI 302SS falls somewhat above a linear trend line. 

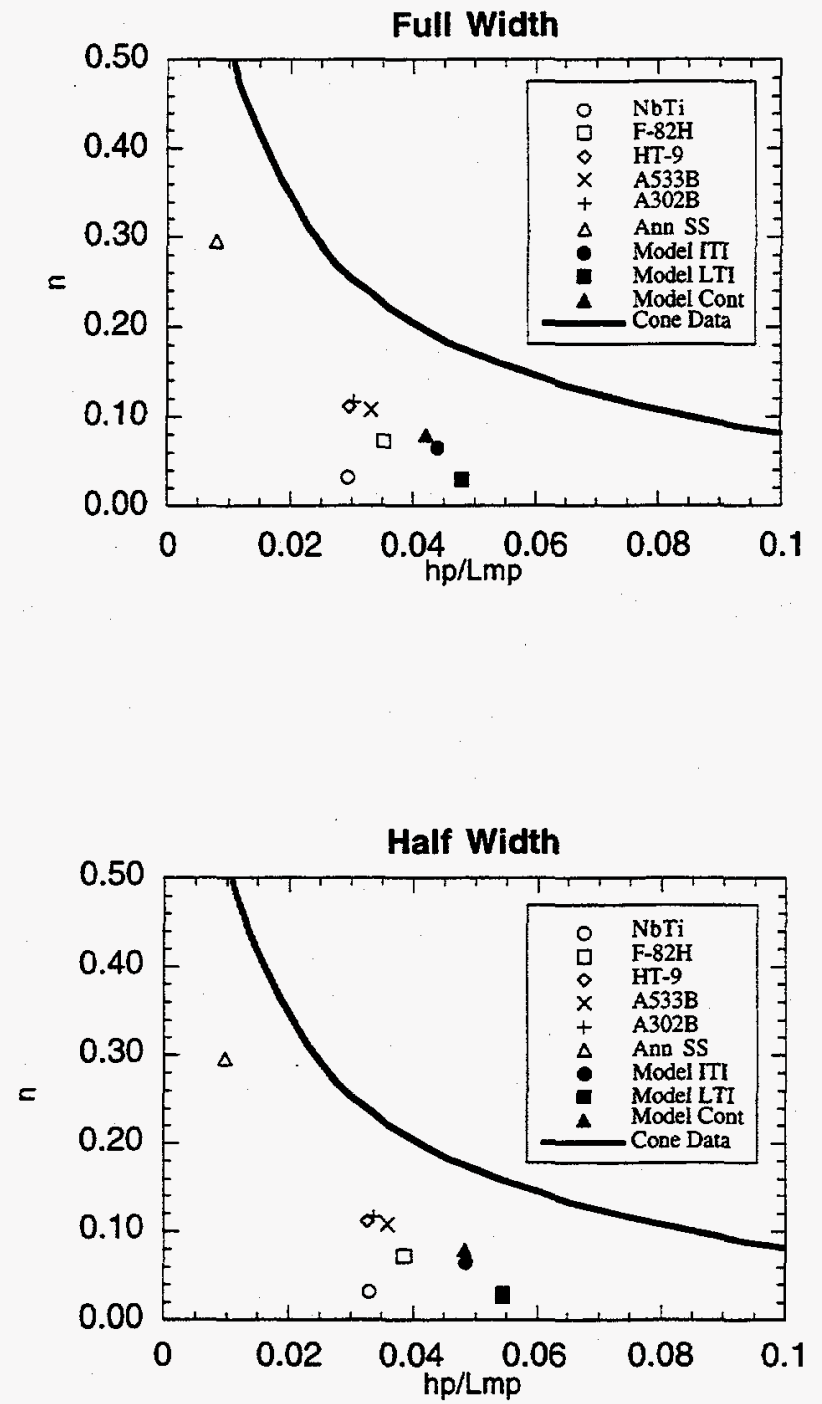

Figure 3.12 Correlation between $\mathrm{n}$ and $\mathrm{h}_{\mathrm{p}} \mathrm{L}_{\mathrm{mp}}$ from conical and pyramidal indenters. Pyramid indenter results were taken from average height profiles taken over a) the full width and b) half width. The cone results were taken from work done by Maliyakal Jayakumar [24]. 
A number of other indent/pile-up combinations were examined in a similar fashion, including: $h_{p} / h_{d}, L_{m o} / L_{m o}, h_{p} / L_{p o}, L_{p} / L_{m 0}, L_{00} / L_{m 0}$, and $h_{p} / L_{o o}$. The $h_{p} / L_{0 o}$, shown in Figure 3.13, was judged to provide the best fit since it approximately followed a simple linear relation (solid line) and also provided the best ordering of the individual data. However, even in this case the NbTi fell below and the AISI 302 SS fell above the line fit to only the steel data (dashed line). A possible explanation for these deviations is that the martensitic and pressure vessel steels share a common bi-linear log $\sigma_{\mathfrak{t}}-\log \varepsilon_{\mathrm{t}}$ behavior, while the NbTi is approximately linear and the AISI 302SS is most strongly bilinear or even tri-linear.

The physical justification for the use of the $h_{p} / L_{o o}$ versus the other parameters is not clear, and is best provided by the FEM studies that are discussed in the next section. However, this parameter, which is an overall base-to-height aspect ratio for the triangular pile-up cross section, contains information on slopes on both sides of the indent, which decrease with increasing $\mathrm{n}$ and well as the indent height, which increases with increasing $\mathrm{n}$. Thus the parameter is a very sensitive integral measure of the pile up profile.

In the future additional studies will be carried out for other materials, loads, indenter shapes to evaluate the generality of the $n$ versus $h_{p} / L_{o o}$ relationship found in this work. However, a potentially extremely useful complement to 
additional measurements is modeling indent/pile-up characteristics using FEM codes. The initial progress in this modeling is described in the next section. 


\section{Full Width}

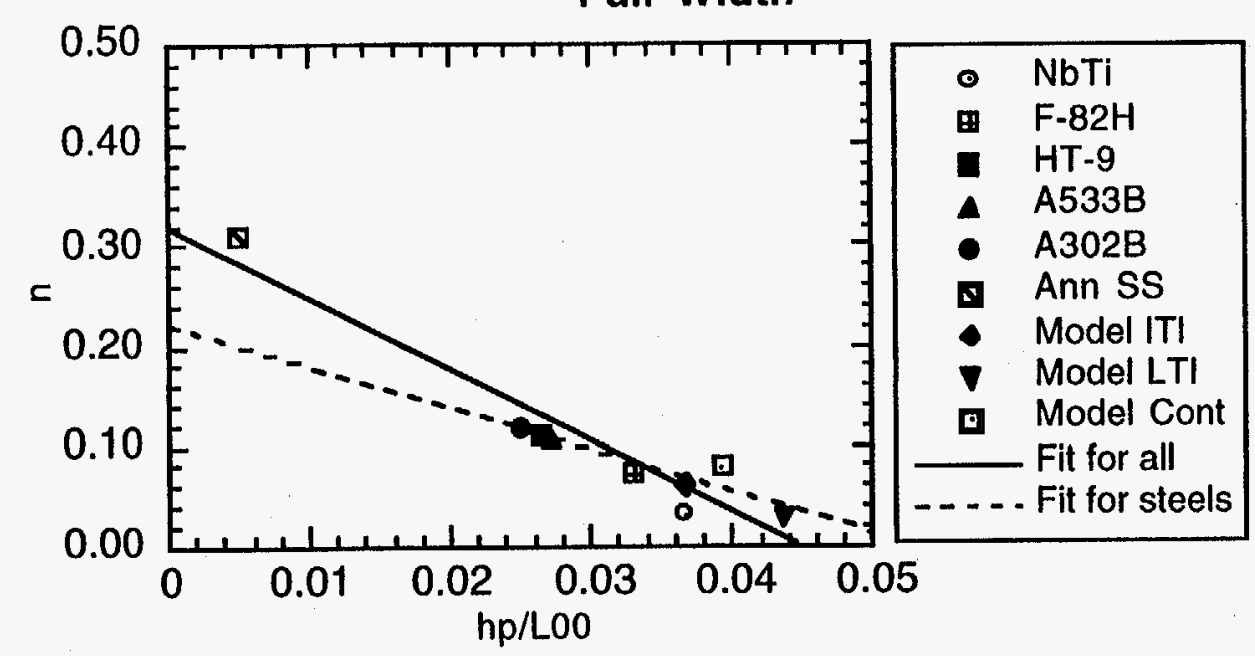

Figure 3.13 Correlation between $\mathrm{n}$ and $\mathrm{hp} / \mathrm{L} 00$ using the full width average height profile for all the materials considered in this study. The solid line shows a least squares fit to all the data points. The dashed line represents the best fit to the materials except $\mathrm{NbTi}$ and annealed stainless steel. 


\section{Chapter 4}

Finite Element Analysis

\subsection{Finite Element Model}

Three-dimensional finite element analyses of a Vickers indentation test were conducted for a range of strain hardening behavior. The analyses were run on a Silicon Graphics workstation using ABAQUS@ version 5.6. The mesh model was created by Takuya Yamamoto, of Tohoku University, Japan. Figure 4.1 shows a top view of the indenter and specimen surface. Because of the symmetry in a Vickers indentation only one eighth of the indentation is modeled. A complete Vickers indenter is shown as a diamond in the lower left corner of the figure. The shaded triangular area of the indenter defines the portion of the indenter modeled in the analysis.

The test specimen mesh is composed of 3,220 3-dimensional brick continuum elements. Figure 4.2 shows the specimen and indenter in the undeformed state. The specimen was divided into 6 layers of elements: layer 1 (the surface layer) consisted of 27 noded elements, layers 2,3 and 4 consisted of 20 noded elements and layers 5 and 6 (the bottom layer) consisted of 8 noded elements for a total of 7,882 nodes. The finer 
elements were concentrated on the surface toward the center of the indent.

The approximate running time for one analysis is 25 hours. 


\section{Top View}

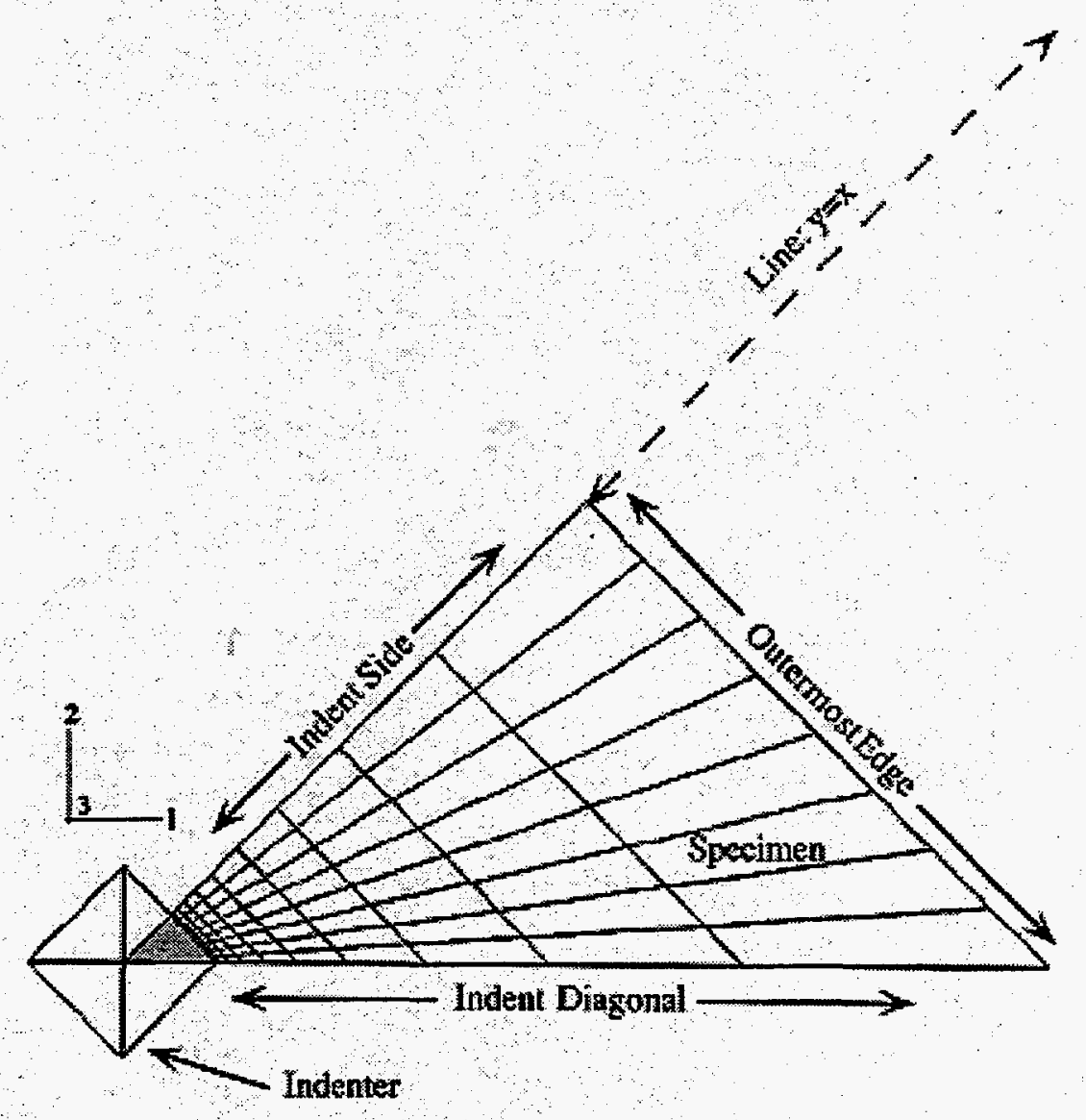

Figure 4.1 Top View of Finite Element Model. 
Undeformed Mesh

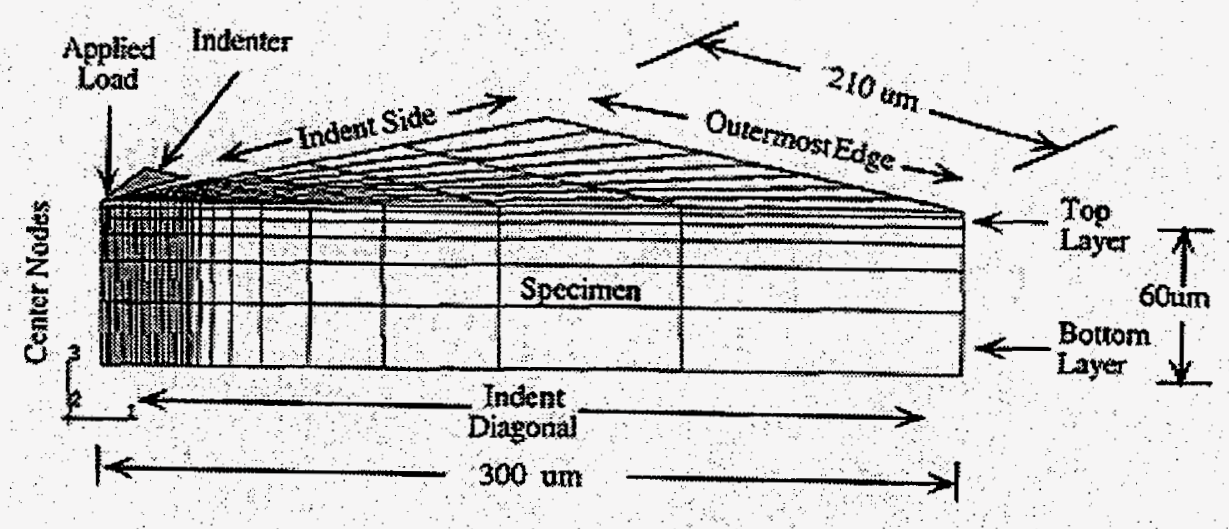

Figure 4.2 Finite Element Model in the Undeformed Condition. 
The indenter itself was modeled as a $1 / 8$ section rigid body pyramid oriented to simulate a Vickers indenter. Since the indenter is defined as a rigid body the indentation load was applied as a concentrated force on the tip the indenter. The location and direction of this applied load is shown in Figure 4.2. Figure 4.3 shows the indenter and specimen in the deformed configuration.

\section{Deformed Mesh}

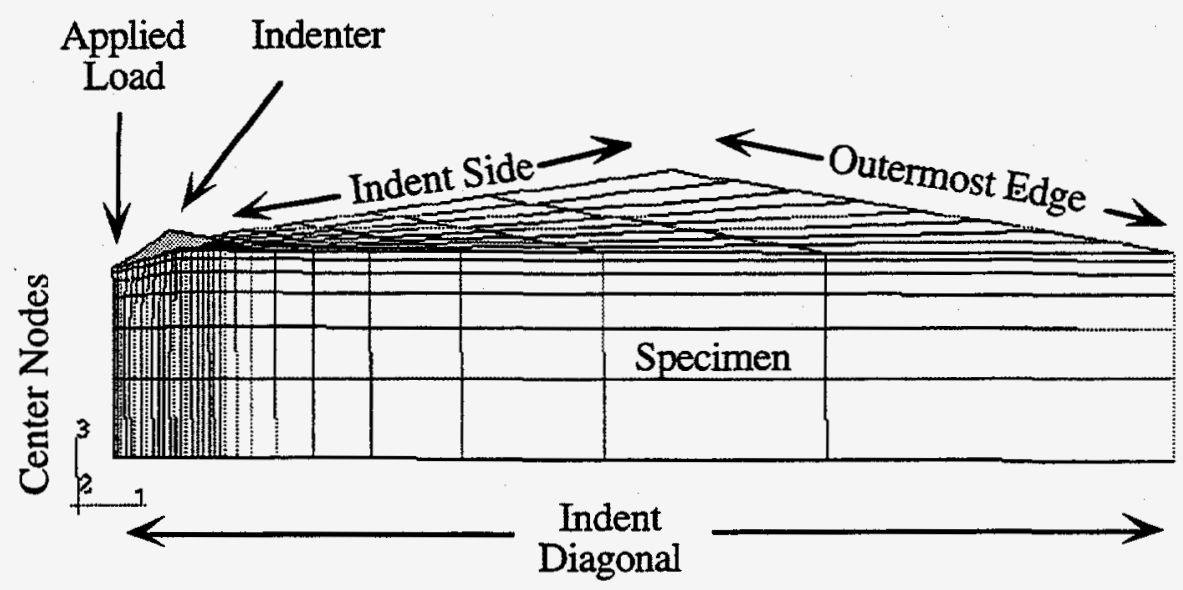

Figure 4.3 Finite Element Model in the Deformed Condition.

The model used the following specimen boundary conditions. The line of nodes along the indentation center as well as the plane forming the outermost edge of the test specimen were also only allowed to move in the $z$ direction. The bottom plane of the specimen was fixed in the $\mathrm{z}$ direction. The planes along the indent diagonal were fixed in the $y$ direction. The 
plane extending out from the indent side could move along the line $\mathrm{y}=\mathrm{x}$ or in the $\mathrm{z}$ direction. The $\mathrm{y}=\mathrm{x}$ line is shown as a dashed line near the top of Figure 4.1.

A variety of surface contact coefficients of friction and maximum shear stresses were examined. The nominal coefficient of friction between the indenter and specimen surface was taken as 0.125 , and the maximum allowable shear stress between these surfaces was taken as $\sigma_{\mathrm{y}} / \sqrt{3}$.

The work hardening exponents of these materials covered a range from 0.00 to 0.30 with a fixed flow stress of $670 \mathrm{MPa}$ at a true strain of 0.08 . The corresponding yield stresses at 0.002 strain ranged from 270 to $670 \mathrm{MPa}$. Poisson's ratio was taken as 0.3 and Young's modulus as $200 \mathrm{GPa}$.

\subsection{Results}

The detailed results of the ABAQUS analysis was used to determine height profiles and profile parameters in the same way as the experimental data but with a higher resolution of $0.02 \mu \mathrm{m}$.

Figure 4.4 compares the predicted profile (solid line) for a strain hardening exponent of 0.11 and an $8 \%$ strain flow stress of $670 \mathrm{MPa}$ to the experimental profile (dashed line) for A302B steel with similar properties. The agreement is 
generally good with almost exact agreement for the indent depth. However, the overall predicted profile is shifted slightly to smaller distances and has a slightly higher peak pile-up height. Figure 4.5 shows the predicted profile for a $\mathbf{n}=$ 0.05 and an 0.08 strain flow stress of $670 \mathrm{MPa}$ (solid line) compared to experimental profiles for the model pressure vessel steel in the unirradiated (dashed line) and low temperature irradiated (dotted line) conditions. In this case the predicted indent depth is larger than observed for both the unirradiated ( $\mathrm{n}=$ $0.08)$ and irradiated $(n=0.03)$ steels; in part this is due to their greater strength (= 700 and $740 \mathrm{MPa}$ at 0.08 strain, respectively) and in the case of the unirradiated steel a larger strain hardening exponent compared to the simple power law hardening model used in the FEM calculation. Further, the predicted profile is again shifted slightly to smaller distances; and the predicted peak is slightly higher than observed for the unirradiated steel. However, considering the uncertainties associated with the measured profiles (see below) and the approximate material model used in the FEM predictions, the overall agreement is very encouraging. 


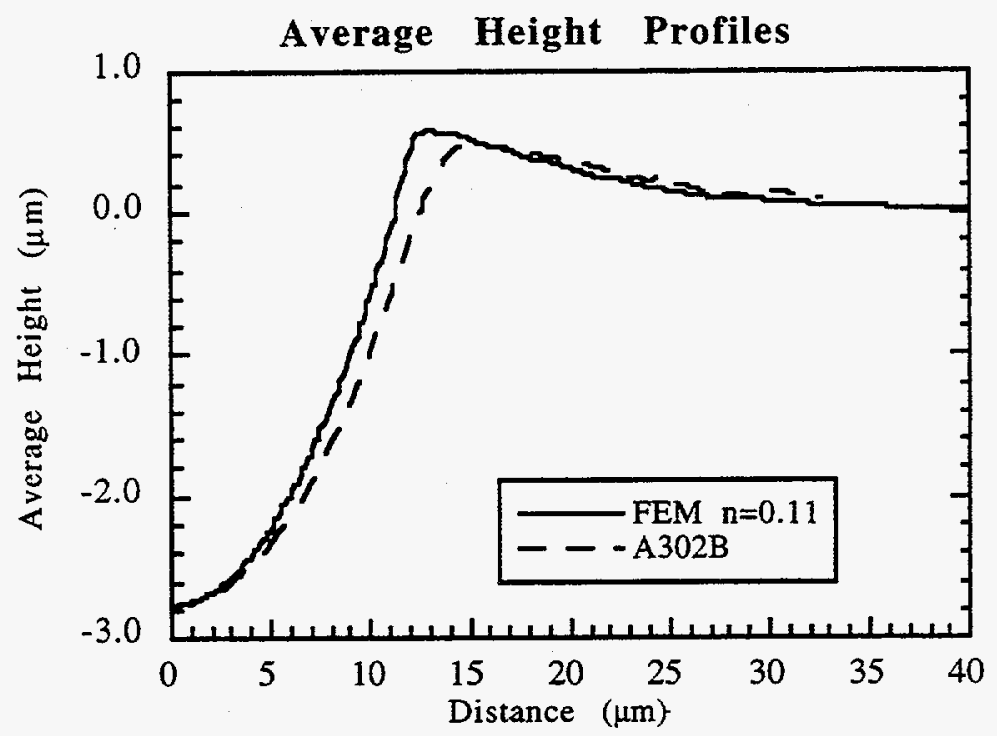

Figure 4.4 Average height profile for FEM $\mathrm{n}=0.1$ and A302B. 


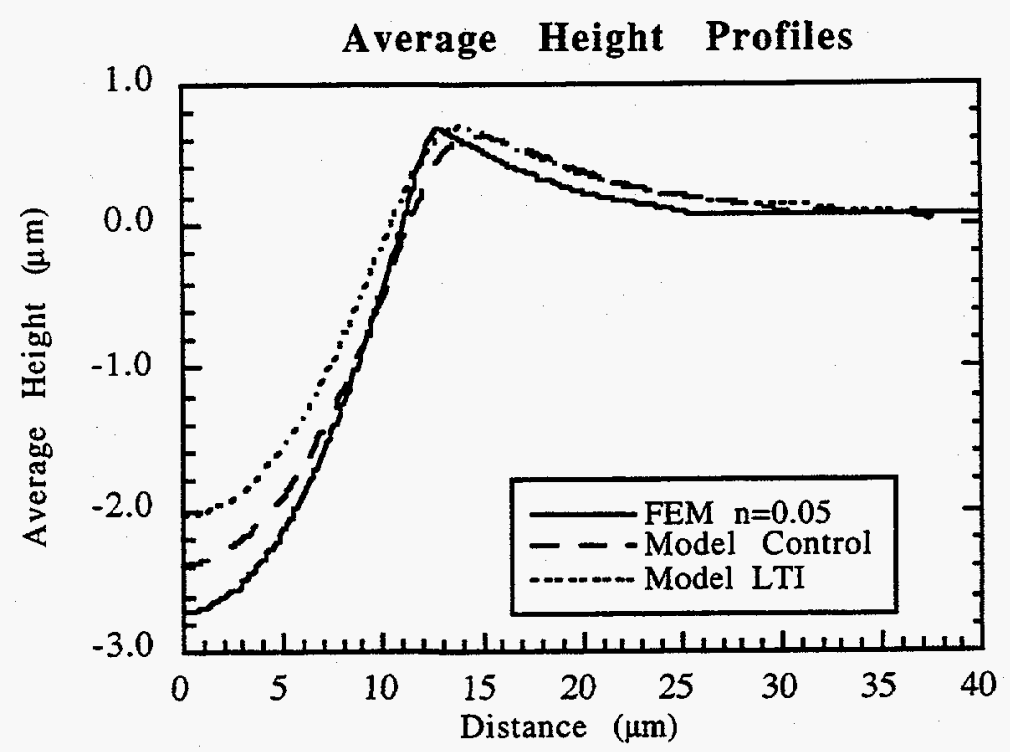

Figure 4.5 Average height profiles for FEM n=0.05, A533B Model alloy control and A533B Model alloy LTI. 
Figure 4.6 compares the predicted profiles for $\mathrm{n}=0.3,0.2,0.11,0.05$, and 0.00 , showing the trend toward lower, broader pile-ups with increasing strain hardening rates.

Figure 4.7 shows the experimentally observed (crossed circles) and FEM predictions (filled diamonds) of $n$ versus $h_{p} / L_{o o}$. The trends are in good general agreement with the experimental observations. However, the predicted $h_{p} / L_{00}$ are greater than the observed values particularly at low $n$ values. Some of these differences are probably due to limits in experimental resolution. Both height (z) and planar $(\mathrm{x}, \mathrm{y})$ resolution limits will intrinsically result in systematically lower peak heights. The maximum $\mathrm{z}$ resolution is estimated to be $0.05 \mu \mathrm{m}$. However, the steep and asymmetric (x,y) profiles also result in lower observed heights by amounts estimated to be on the order of $0.1 \mu \mathrm{m}$. The higher-steeper (sharper) profiles result in larger deviations between the actual and observed peak pile-up height. The ratio of the measured to actual peak height is an approximately constant factor where $h_{p o}$ and $h_{p a}$ are the observed and actual peak pileup heights. For similar reasons limited resolution decreases the slope in the post-peak regime resulting in observed $L_{00}$ values that are larger than the actual extrapolated zero to zero crossing length. Again the relative deviation is expected to increase with increasing pile-up height. The effect of an $h_{p}$ bias factor of observed to actual of $0.8 h_{p}$ (FEM) and increase in L00 by $2.5 h_{p}$ (FEM) is shown as the filled 
diamonds in Figure 4.7. The resolution adjusted FEM predictions are in excellent agreement with the experimental results.

FEM Average Height Profiles

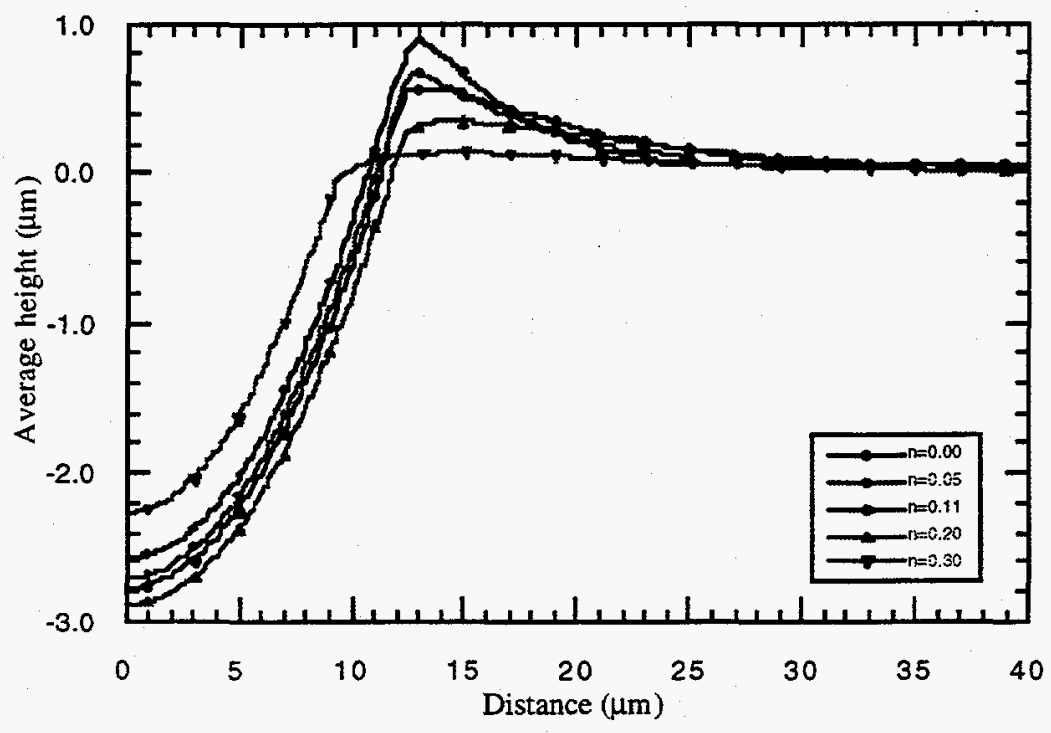

Figure 4.6 Average height profiles for FEM models with $n$ equal to $0.00,0.05$, $0.11,0.20$, and 0.30 . 


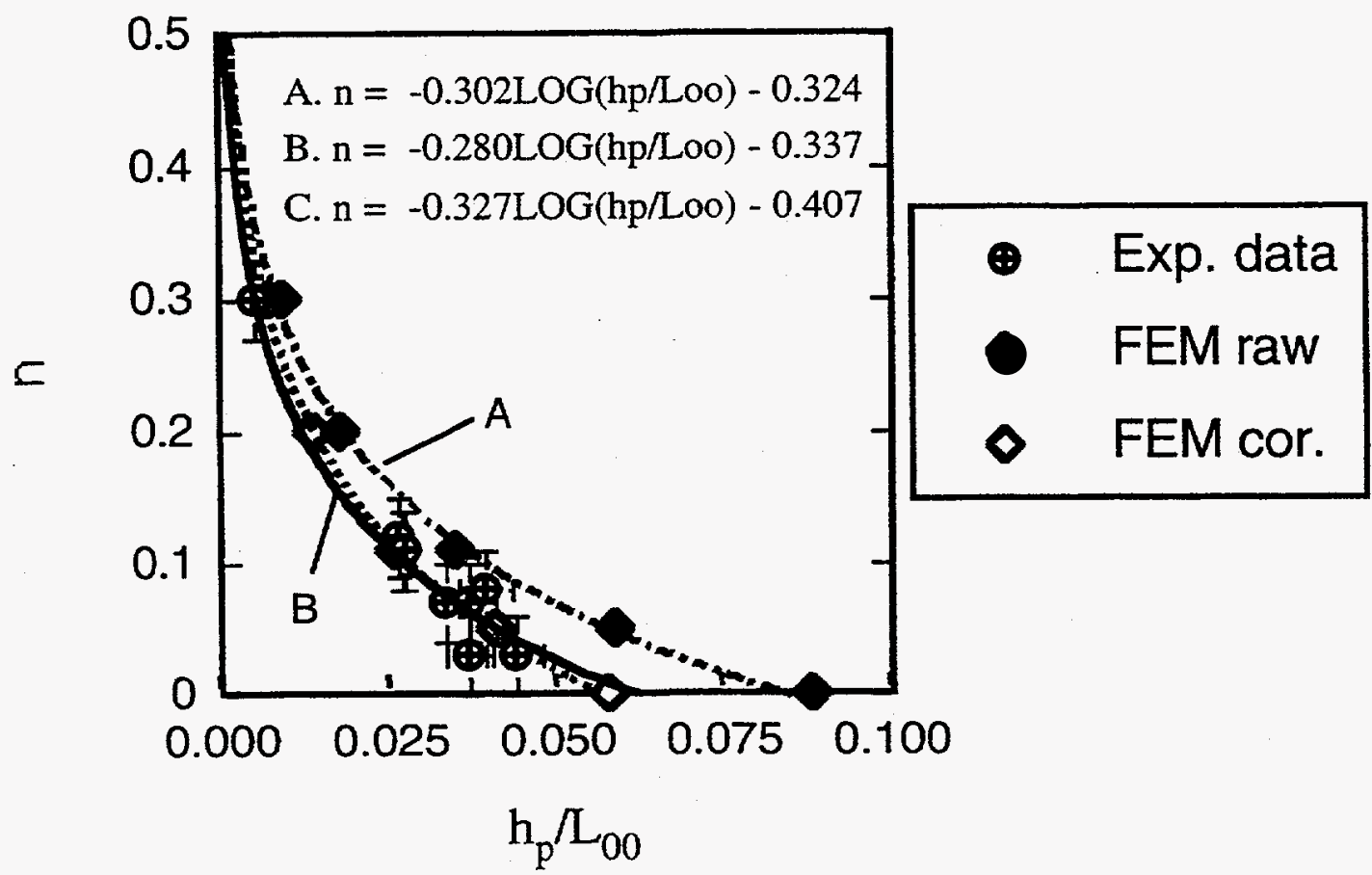

Figure 4.7 Correlation between $n$ and $h_{p} / L_{(x)}$ for both experimental and FEM results. See text for explanation of symbols and lines. 
While these results are encouraging, the assumptions regarding the effects of experimental resolution limits remain to be confirmed. One good approach would be to use atomic force microscopy to characterize the indent and pile-up profiles.

Figure 4.7 also shows an expression in the form $n=C_{1}+C_{2} \log \left(h_{p} / L_{00}\right)$ that least square fits to both the raw FEM results (dashed-dotted line, $C_{1}=-0.324$, $C_{2}=-0.302$ ) and the experimental data (solid line, $C_{1}=-0.337, C_{2}=-0.280$ ) where the latter has a standard error in $\mathrm{n}$ of \pm 0.017 . A similar fit to the corrected FEM data (dashed line, $C_{1}=-0.407, C_{2}=-0.327$ ) also provides a good fit to the experimental data with a standard error of \pm 0.02 .

Future FEM studies will also be directed at examining other factors like details of the constitutive $\sigma(\varepsilon)$ model, the effects of finite indenter compliance, mesh and noding schemes, treatment of contact boundary, the size of the overall simulation cell and the like. Preliminary studies using both 2 and 3 dimensional FEM models have suggested that most of these details will have a limited influence on predicted pile-up profiles. However, these studies have shown a much larger effect of details of the constitutive model. For example, cutting-off the flow stress at a (low) finite strain (saturation) results in higher steeper pile-ups than predicted by the simple 
power law strain hardening models. Although the effects have not been systematically examined to date, a low strain hardening regime at low strains (e.g., a bilinear $\log \sigma_{\mathrm{t}}-\log \varepsilon_{\mathrm{p}}$ curves) may also result in somewhat different pile-up profiles than found for the simple power law hardening models.

Indeed, the good logarithmic fit may suggest that $h_{p} / L_{00}$ decreases as a simple function of a flow stress ratio over an effective low-to-high strain range sampled by the indent, or a flow stress gradient. Preliminary studies show that the square of this flow stress ratio over a strain range of about 100 correlates with $h_{p} / L_{00}$. While we do not yet have a fundamental rationale for this correlation, it further suggests that the pile-up is sensitive to a large range of strain (say 0.005 to 0.5 ). As a corollary, deviations from simple power law behavior over this strain range may be reflected in the indent profile and corresponding profile parameters. 


\section{Chapter 5}

Conclusions and Future Work

Vickers microhardness tests and static room temperature tensile tests were conducted on a various materials exhibiting a wide range of strain hardening behavior. The strain hardening exponents, $n$, were estimated from the tensile tests assuming a simple power law constitutive relationship. Spatial parameters defining the geometry (aspect ratio) of the indentation pileups showed the expected relationship with strain hardening exponent. This correlation was also verified from 3dimensional finite element modeling. Based on these results an entire flow curve of a material could be estimated from simple microhardness tests. The VHN sets the flow stress at $8 \%$ strain while the topographical features of the indentation defines the strain hardening exponent.

This could ultimately be useful in developing a device to perform seminondestructive evaluations of components in service to monitor aging. Currently indentation tests using spherical indenters are used to generate stress-strain curves of a material. However, converting to pyramidal or even conical indenters would allow the use of much smaller loads thereby damaging a much smaller volume of material. 
The initial results of this work are encouraging, but much work must still be done: The surface topography strain hardening exponent relationship must be verified with additional materials in various conditions ( $\mathrm{n}$ values $\approx 0.20$ ) as well as with conical indenters. Atomic Force Microscopy (AFM) could also be used to characterize topographical features at a higher resolution than that attainable from confocal microscopy. In resolving the discrepancy between the observed and FEM results it could be useful to conduct compression tests on materials to generate constitutive relationships which could be used in the computational analysis. 


\section{REFERENCES}

1. J.H. Westbrook and H. Conrad eds., The Science of Hardness Testing and It's Research Applications, American Society for Metals, Metals Park, Ohio, 1973.

2. Hugh O'Neill, Hardness Measurement of Metals and Alloys, 2nd ed., Chapman and Hall LTD, 11 New Fetter Lane, London, 1967.

3. George E. Dieter, Mechanical Metallurgy, McGraw-Hill Inc., 3rd ed., San Francisco, 1986.

4. J.R. Cahoon, W. H. Broughton, A. R. Kertzak, "The Determination of Yield Strengths From Hardness Measurements", Metallurgical Transactions, Vol 2, 1980.

5. M.O. Lai, and K. B. Lim, "On the Prediction of Tensile Properteis from Hardness Tests", Journal of Material Science, Vol 26, 1991.

6. J. Gubicza, A. Juhasz, P. Tasnadi, P. Arato, and G. Voros, "Determination of the Hardness and Elastic Modulus from Continuous Vickers Indentation Testing", Journal of Material Science, Vol 31, 1996.

7. B. Taljat, T. Zacharia, F.M. Haggag, "Analysis of Ball-Indentation Load- Depth Data: Part I. Determining Elastic Modulus," Journal of Materials Research, Vol. 12, No. 4, 1997.

8. Robert A. George, Subimal Dinda, Arthur S. Kasper, "Estimating Yield Strength From Hardness Data," Metal Progress, May 1976.

9. M. Jayakumar and G. E. Lucas, "The Determination of Flow Distribution by Analysis of Indent Geometry" Journal of Nuclear Materials, 122\&123, 1984.

10. P. Au, G. E. Lucas, J.W. Sheckherd, and G.R. Odette, "Flow Property Measurements From Instrumented Hardness Tests", Conference Proceedings International Conference on Nondestructive Evaluation in the Nuclear Industry, ASM, Metals Park, OH, 1981.

11. K. Shinohara, "Relationship Between Work-Hardening Exponent and Load Dependence of Vickers Hardness in Copper" Journal of Material Science, Vol 28, 1993. 
12. K. Yasuda, K. Shinohara, M. Yamada, M. Kutsuwada, and C. Kinoshita, "A New Method for Evaluating the Stress-Strain Properties of Metals Using Ultra-Microhardness Technique", Journal of Nuclear Materials, Vol 187, 1992.

13. K. Shinohara, K. Yasuda, M. Yamada, C. Kinoshita, "Universal Method for Evaluating Work-Hardening Exponent of Metals Using Ultra-Microhardness Tests", Acta Metallurgica Materialia, Vol 42, No, 11, 1994.

14. J.R. Matthews, "Indentation Hardness and Hot Pressing", Acta Metallurgica. Vol. $28,1980$.

15. Qing Ma, David R. Clarke, "Size Dependent Hardness of Silver Single Crystals," Journal of Materials Research. Vol. 10, No. 4, 1995.

16. John H. Underwood, "Residual-Stress Measurement Using Surface Displacements Around an Indentation," Presented at the Third SESA International Conference on Experimental Mechanics, Los Angeles, 1973.

17. F.E. Kennedy, F.F. Lang, "Elasto-Plastic Indentation of a Layered Medium," Journal of Engineering Materials and Technology, Trans. ASME, Series H, 1974.

18. K.L. Johnson, "The Correlation of Indentation Experiments," J. Mech. Phys. Solids, Vol. 18, 1970.

19. Y. Tirupataiah, G. Sundararajan, "A Dynamic Indentation Technique for the Characterization of the High Strain Rate Plastic Flow Behaviour of Ductile Metals and Alloys," J. Mech. Phys. Solids, Vol. 39, No. 2, 1991.

20. Y. Tirupataiah, G. Sundararajan, "The Volume of the Crater Formed by the Impact of Ball Against Flat Target Materials -- The Effect of Ball Hardness and Density," International Journal of Impact Engineering, Vol. 9, No. 2, 1990. 
21. G.E. Lucas, C. Pendleton, "Time-Dependent Flow Properties from Indentation Tests," Journal of Nuclear Materials, 103 \& 104 (1981) 1539-1544.

22. Fahmy M. Haggag, Glenn E. Lucas, "Determination of Luders Strains and Flow Properties in Steels from Hardness/Microhardness Tests," Metallurgical Transactions, Vol 14A, 1983.

23. Kazuo Furuya, John Moteff, "Deformation Behavior of Neutron Irradiated Molybdenum in Tensile and Harness Tests," Journal of Nuclear Materials 99 (1981) 306316.

24. Maliyakal D. Jayakumar, "Characterization of Plastic Flow Distribution by Indentation Techniques", Master's Thesis. University of California at Santa Barbara, 1983.

25. Kurt Edsinger, "Fracture Reconstruction and Advanced Micromechanical Modeling of Structural Steels", PhD Thesis, UC Santa Barbara, 1995.

26. T.H. Courtney, Mechanical Behavior of Materials, McGraw-Hill Inc., San Francisco, 1990.

27. D.H. Porter, and K.E. Easterling, Phase Transformations in Metals and Alloys, 2nd ed., Chapman and Hall, Boundary Row, London, 1992.

28. Metals HandbookDesk Edition, edited by Howard E. Boyer and Timothy L. Gall, (1985), ASM International, Materials Park, OH 44073-0002 (fromerly American Soceity for Metals, Metals Park, $\mathrm{OH}$ 44073).

29. G.R. Odette and G.E. Lucas, An Experimental Investigation of Kinetic Aspects of Neutron Irradiation Embrittlement of Light Water Reactor Pressure Vessel Steels, EPRI, RP-1021-7, RP-2455-11, 1989.

30. G.E. Lucas, G.R. Odette, K. Edsinger, B. Wirth, J.W. Sheckherd, "On the Role of Strain Rate, Size, and Notch Acuity on Toughness: A Comparison of Two Martensitic Stainless Steels", Effects of Radiation on Materials: 17th International Symposium, ASTM STP 1270, American Society for Testing and Materials, 1996. 
31. E. Mader, "Kinetics of Irradiation Embrittlement and the Post-Irradiation Annealing of Nuclear Reactor Pressure Vessel Steels", PhD Thesis, Department of Materials, UC Santa Barbara, 1995.

32. James D. Redmond, "Stainless Steels" Metals Handbook Desk Edition. American Soceity for Metals, Metals Park, Ohio, 1985.

33. D.S. Dugdale, "Experiments with Pyramidal Indenters - Part I", Journal of the Mechanics and Physics of Solids, Vol 8, 1955.

34. D.S. Dugdale, "Experiments with Pyramidal Indenters - Part II", Journal of the Mechanics and Physics of Solids. Vol 8, 1955.

35. G.E. Lucas and N. F. Panayotou, "Microhardness Tests for High Energy Neutron Source Experiments", Journal of Nuclear Materials, 103\&104, 1981.

36. D.S. Dugdale, "Cone Indentation Experiments", Journal of the Mechanics and Physics of Solids, Vol 2, 1954.

37. Giles F. Carter, "Mechanical, Physical and Chemical Properties of Metals", Metals Handbook Desk Edition. American Soceity for Metals, Metals Park, Ohio, 1985.

38. A. Kimura, H. Matsui, "Neutron Irradiation Effects on the Microstructure of LowActivation Ferritic Alloys", Journal of Nuclear Materials, 212-215 (1994) 701-706

39. Y. Kohno, D.S. Gelles, A. Kohyama, M. Tamura, A. Hishinuma, "Irradiation Response of a Reduced Activation Fe-8Cr-2W Martensitic Steel (F82H) After FFTF Irradiation," Journal of Nuclear Materials, 191-194 (1992) 868-873.

40. M. Tamura, H. Hayakawa, A. Yoshitake, A. Hishinuma, T. Kondo, "Phase Stability of Reduced Activation Ferritic Steel: $8 \% \mathrm{Cr}-2 \%$ W-0.02\%V-0.04\%Ta-Fe," Journal of Nuclear Materials, 155-157 (1988) 620-625.

41. Y. Tirupataiah, G. Sundararajan, "On the Constraint Factor Associated with the Indentation of Work-Hardening Materials with a Spherical Ball," Metallurgical Transactions, Vol 22A, 1991. 
42. H.A. Francis, "Phenomenological Analysis of Plastic Spherical Indentation," Journal of Engineering Materials and Technology, Transactions of the ASME, July 1976. 
Appendix A

Raw Tensile Data and Least Squares Power Law Fits 


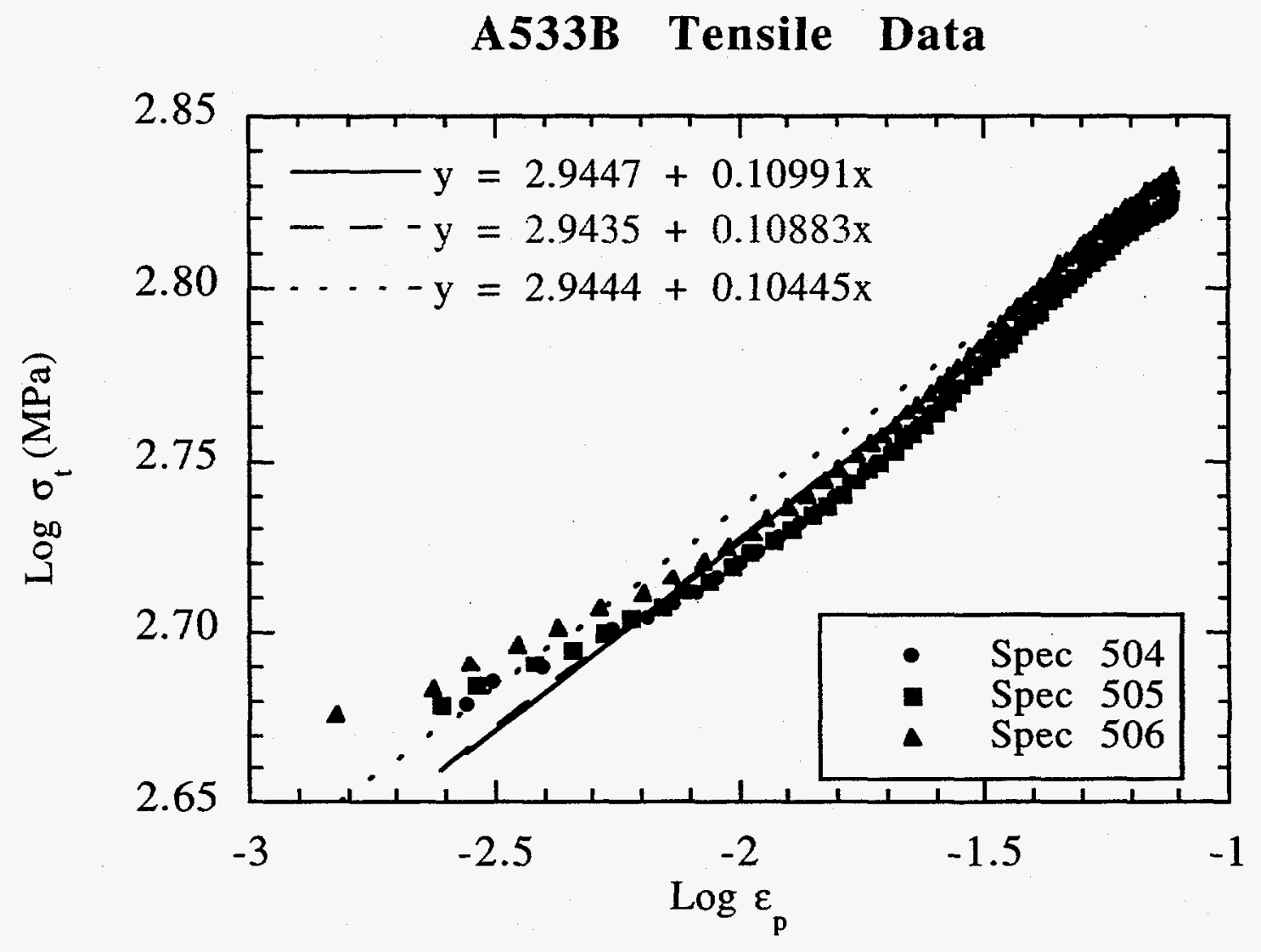




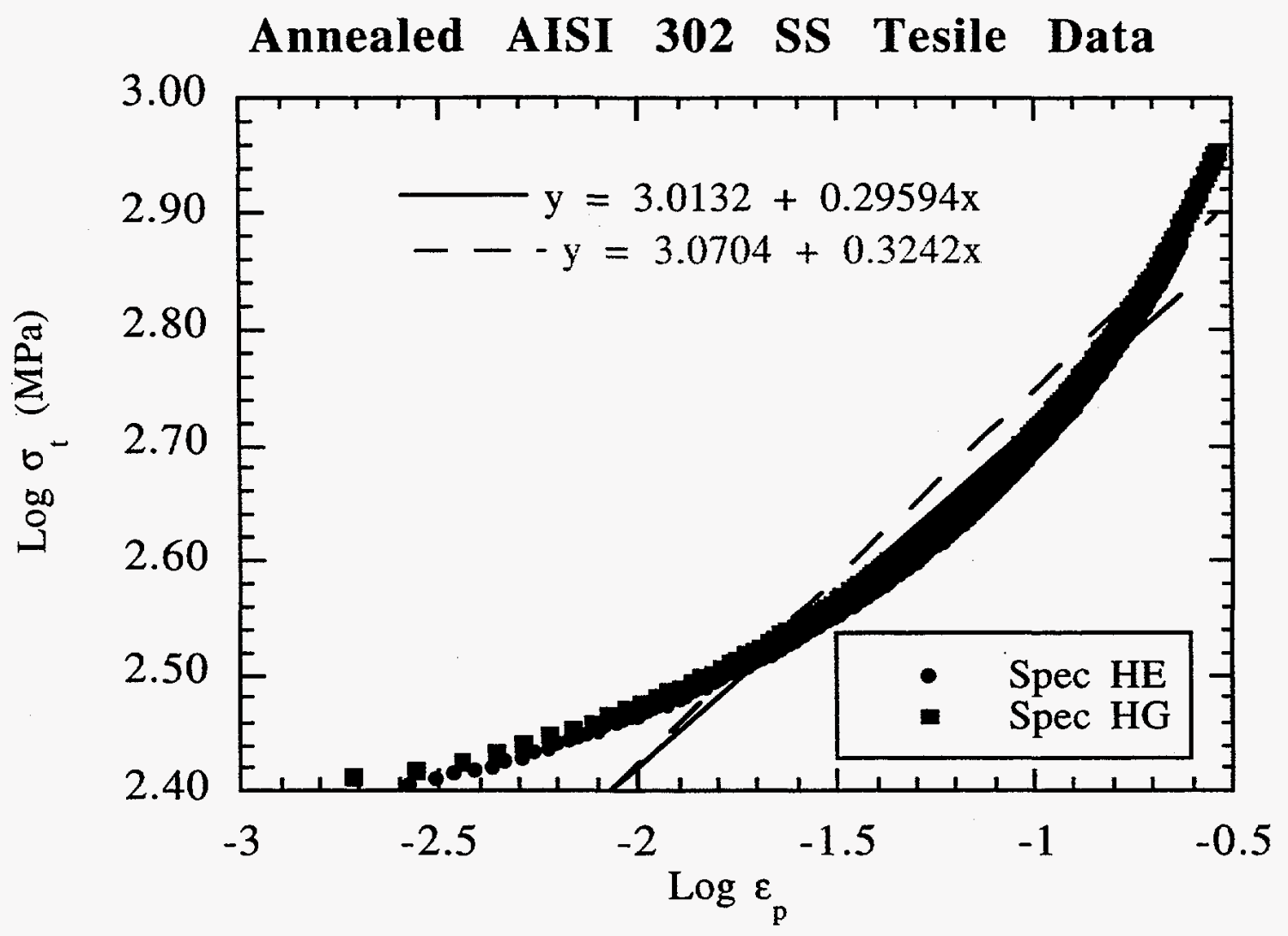




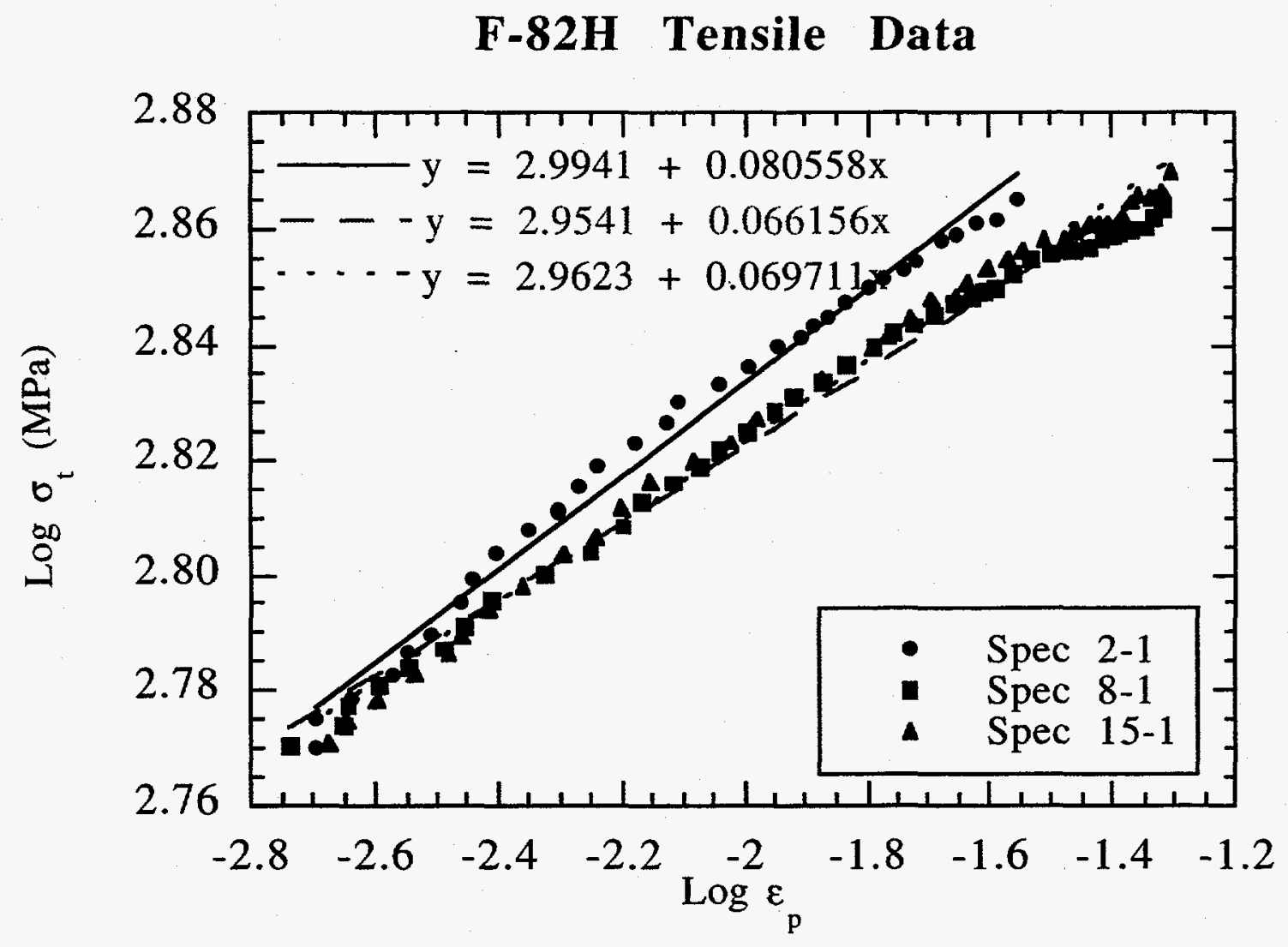




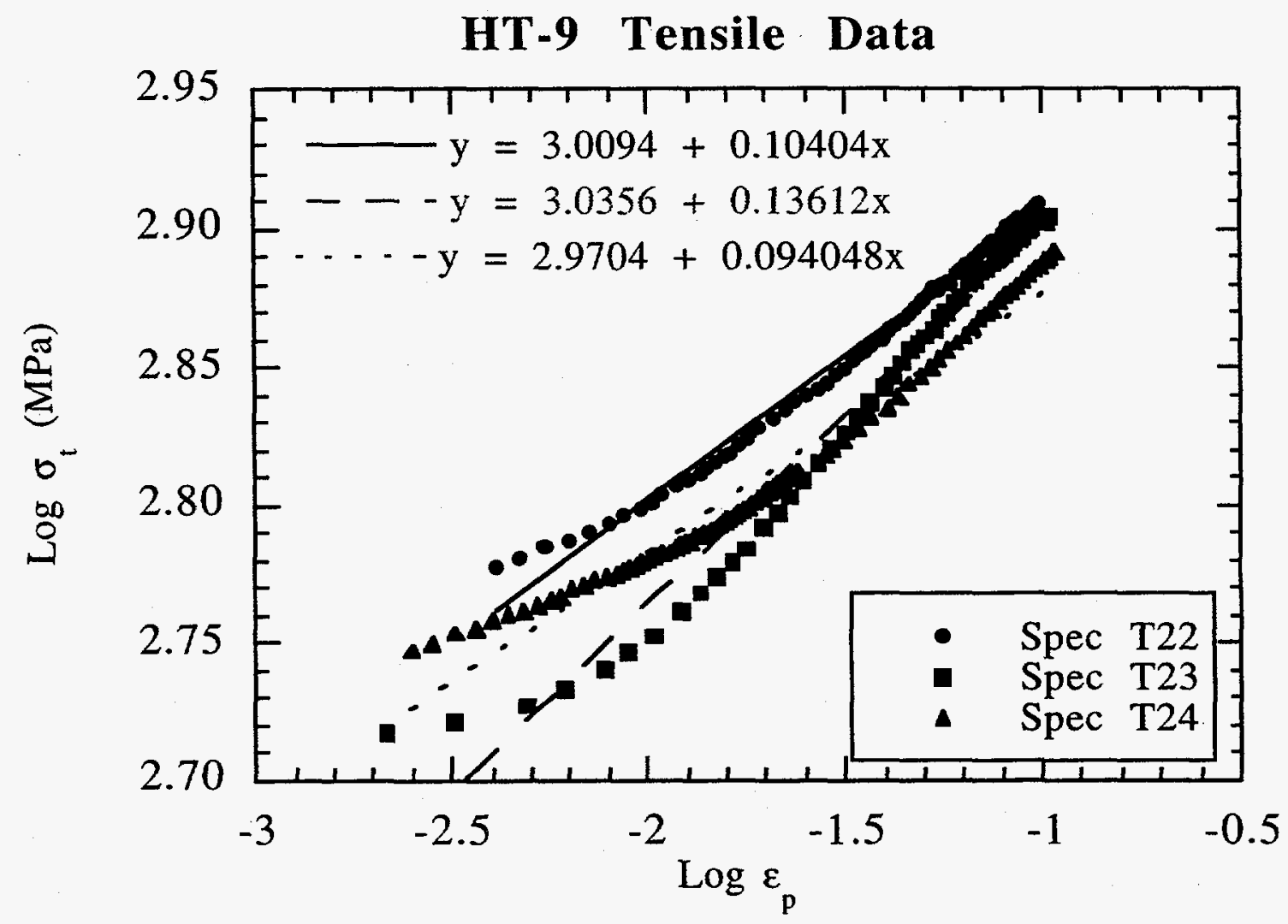




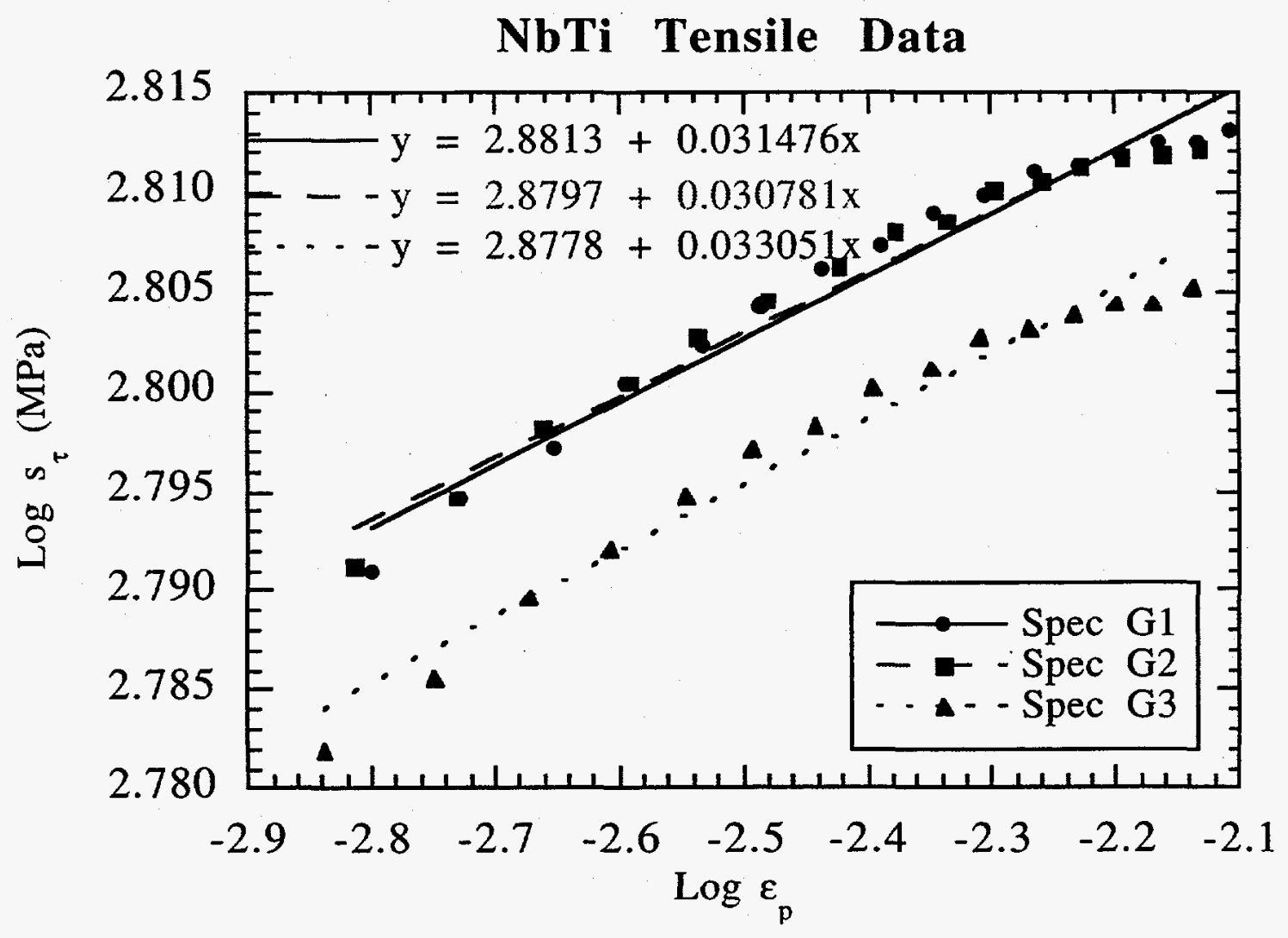




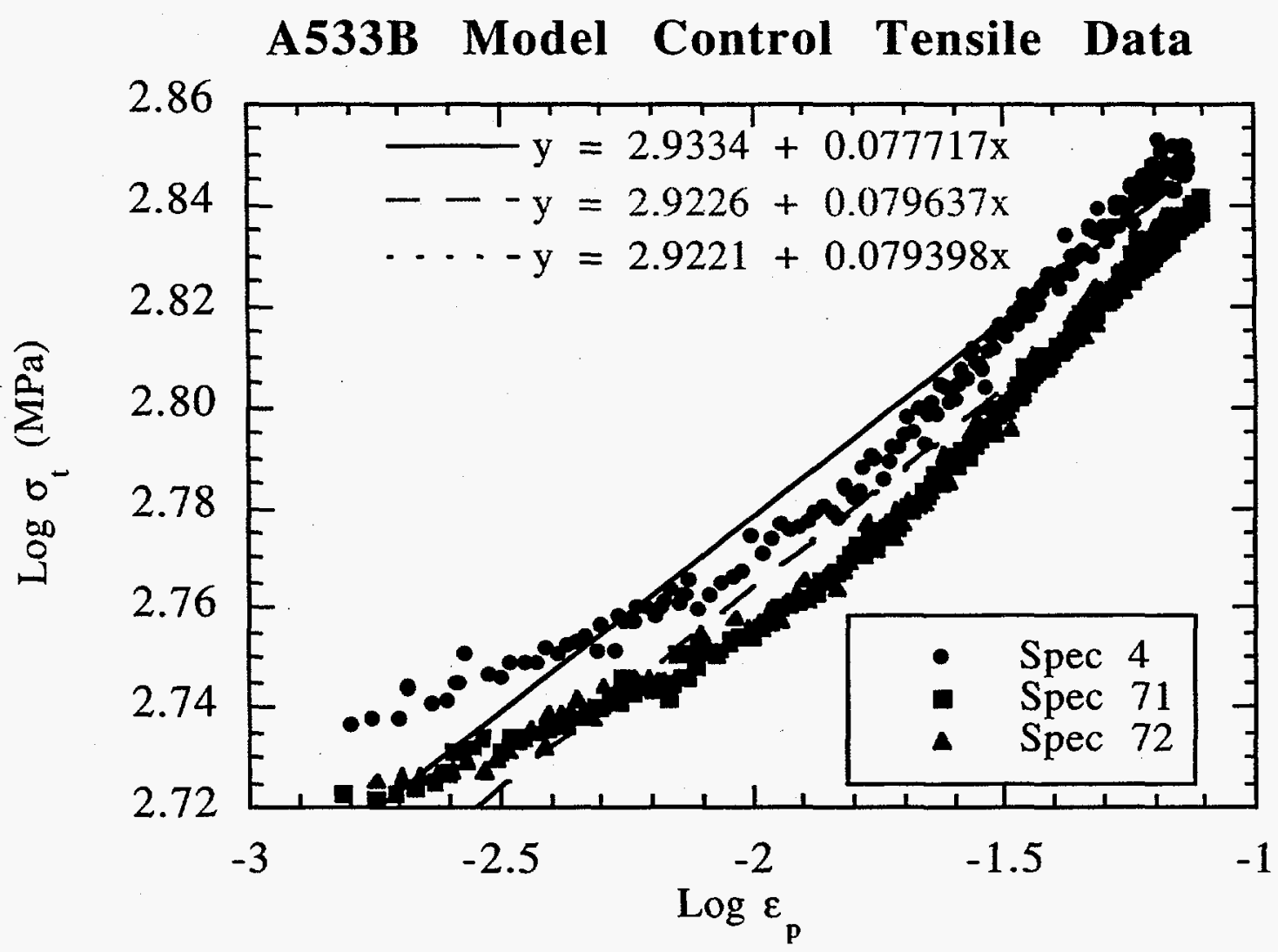




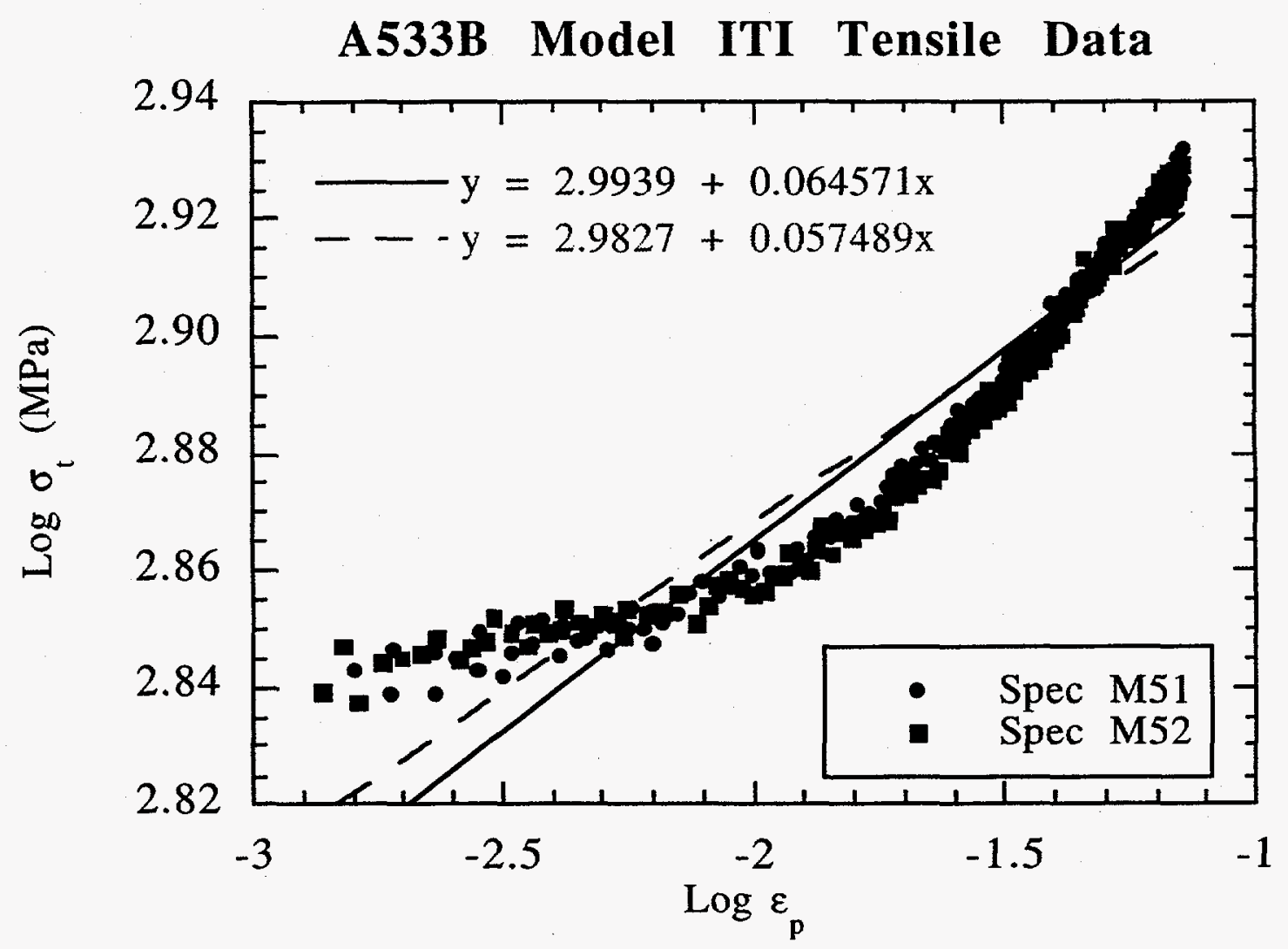




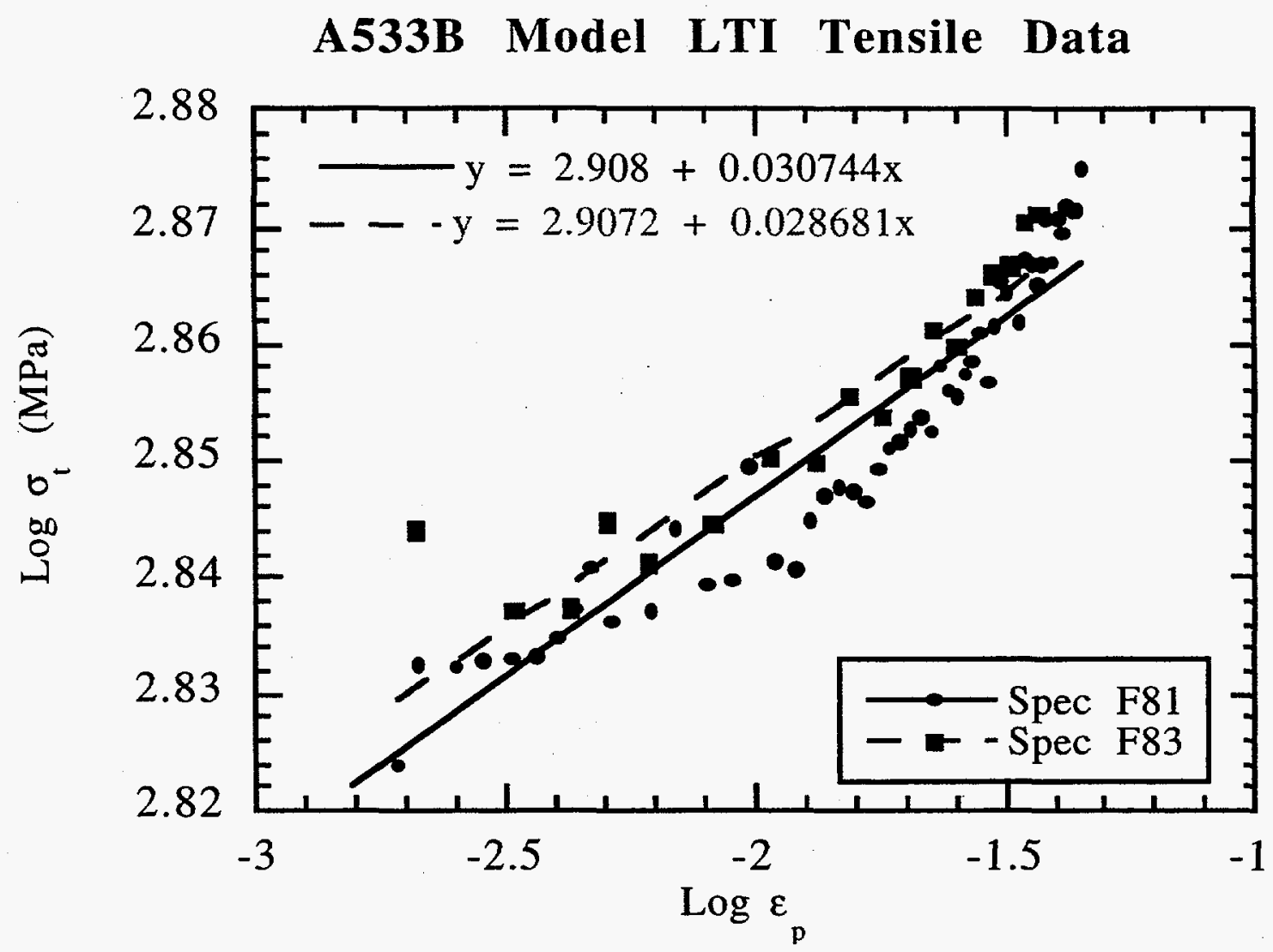




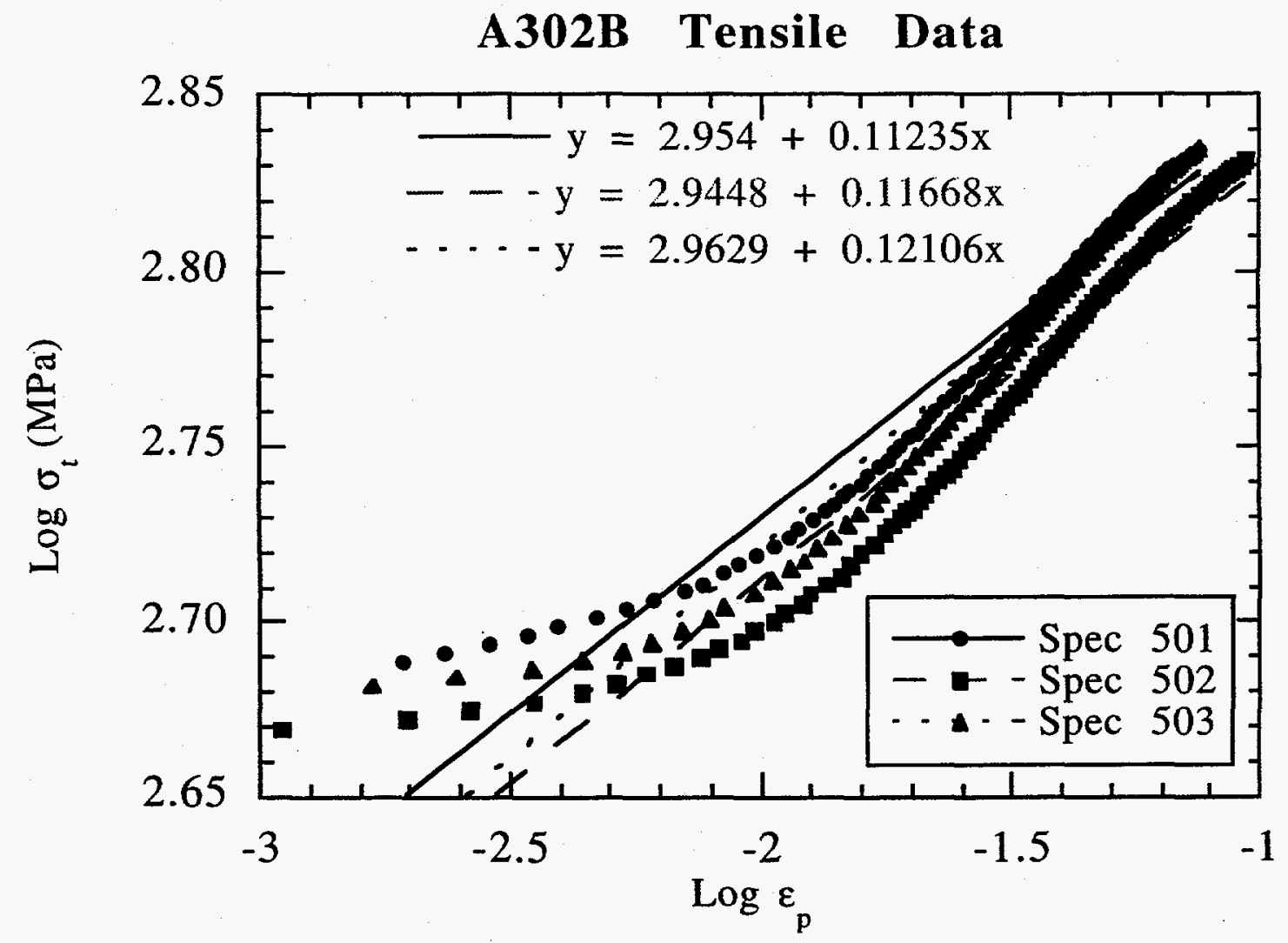





\section{Appendix B}

\section{Topographical Maps of Indentations}


Contour Plot: A302 $200 \mathrm{~g}$ load -- Indent 1

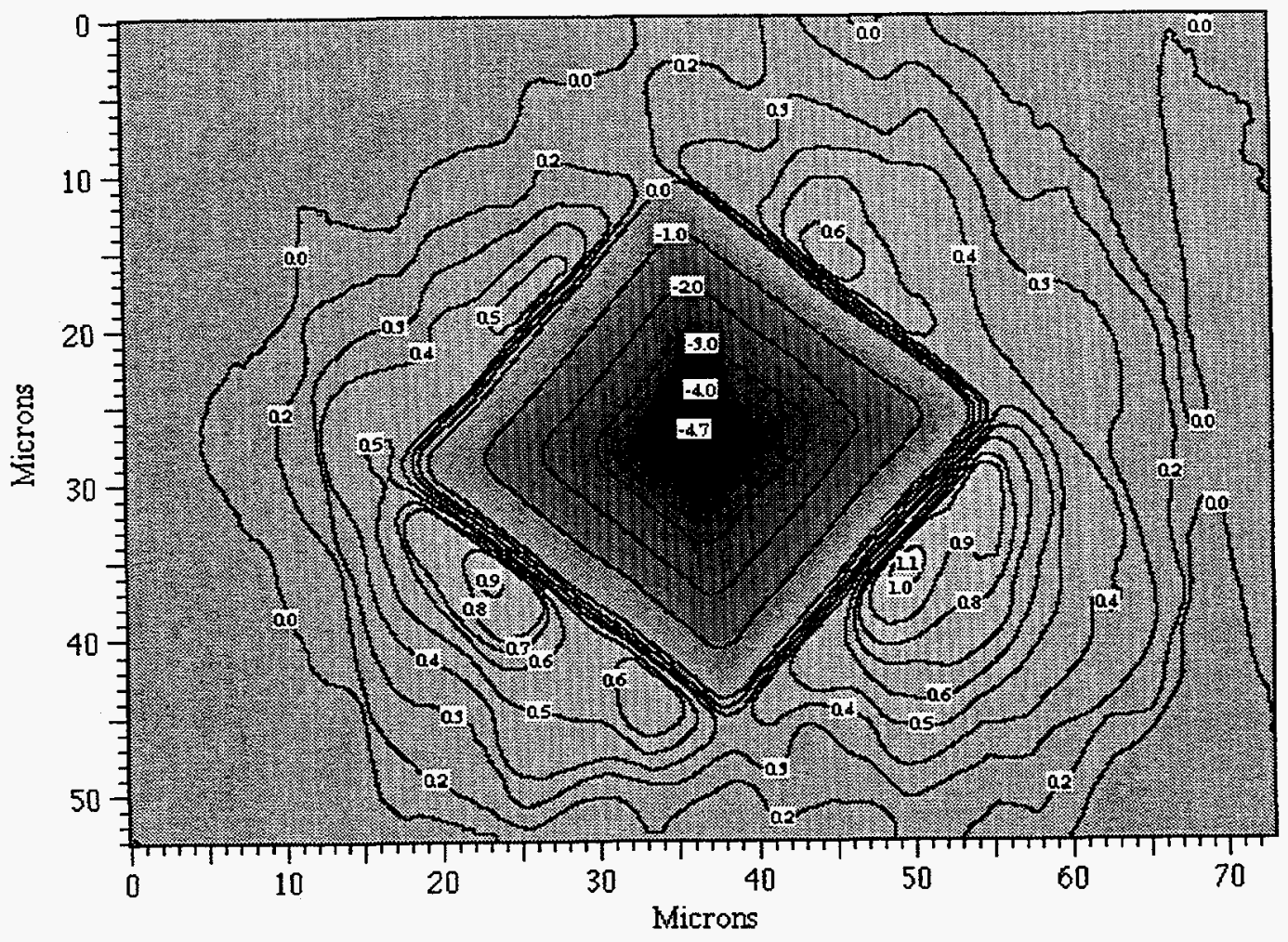


Contour Plot: A302B $200 \mathrm{~g}$ load -- Indent 2

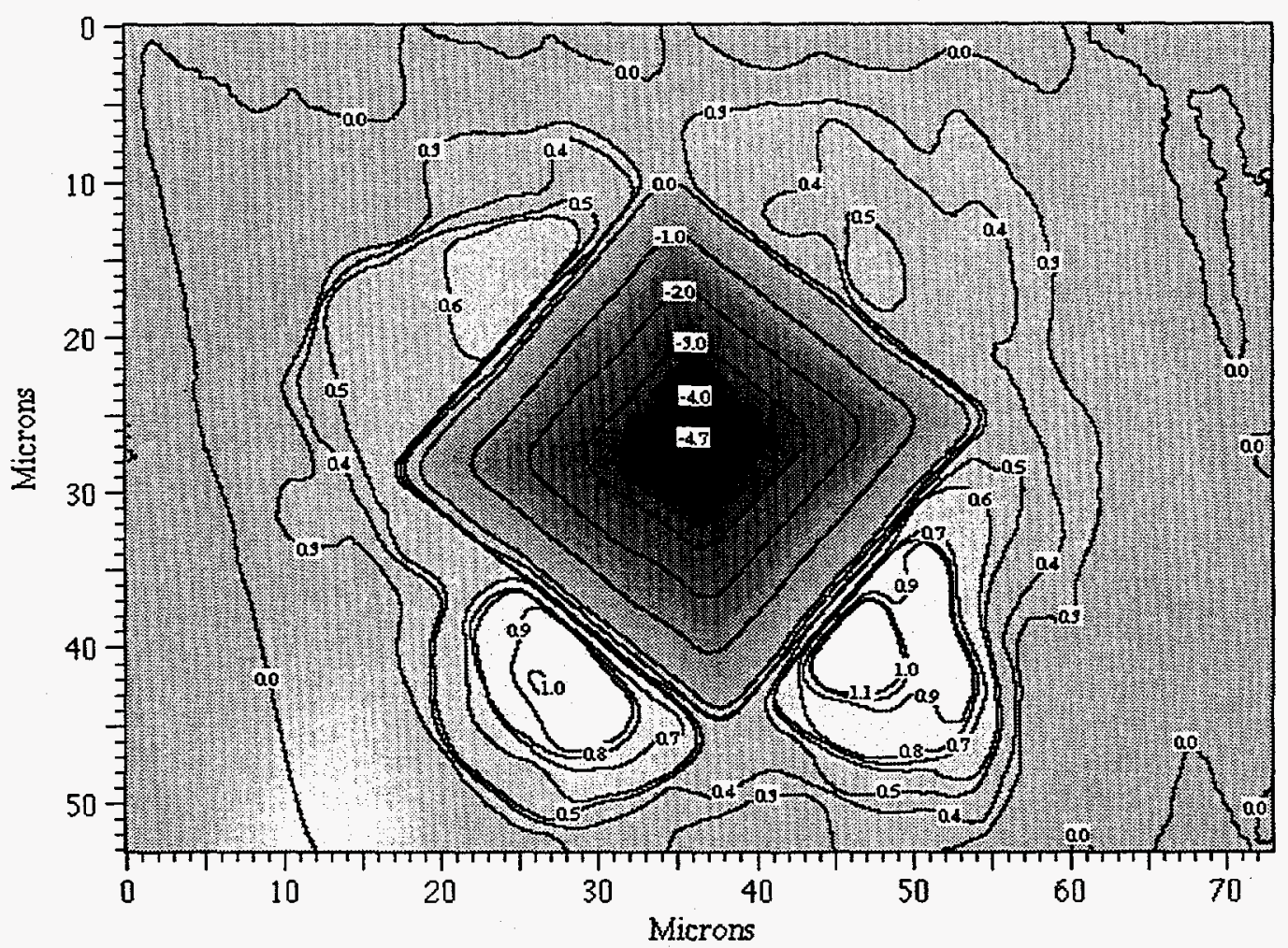


Contour Plot: A302B $200 \mathrm{~g}$ load -- Indent 3

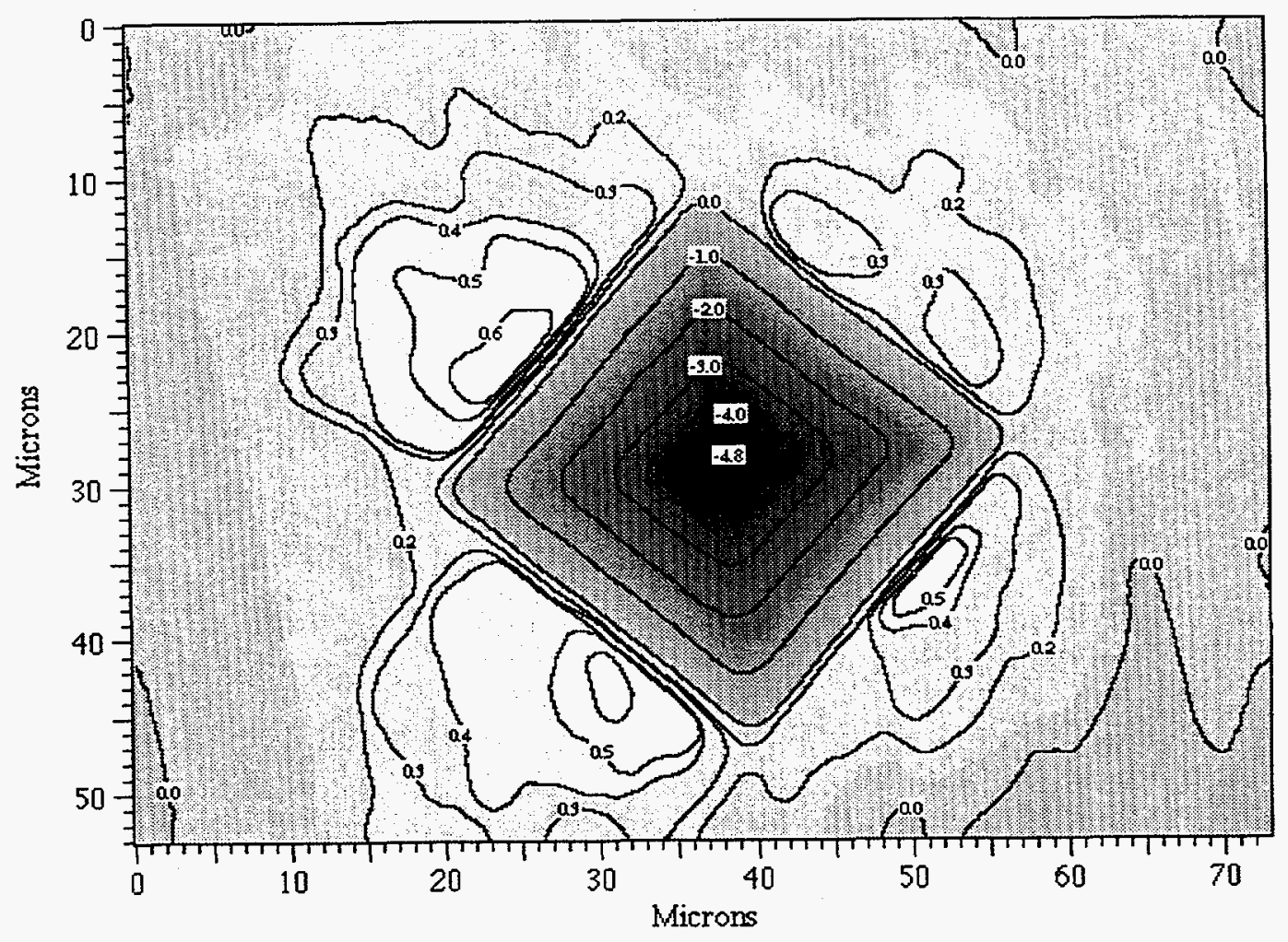


Contour Plot: A302B $200 \mathrm{~g}$ load -- Indent 4

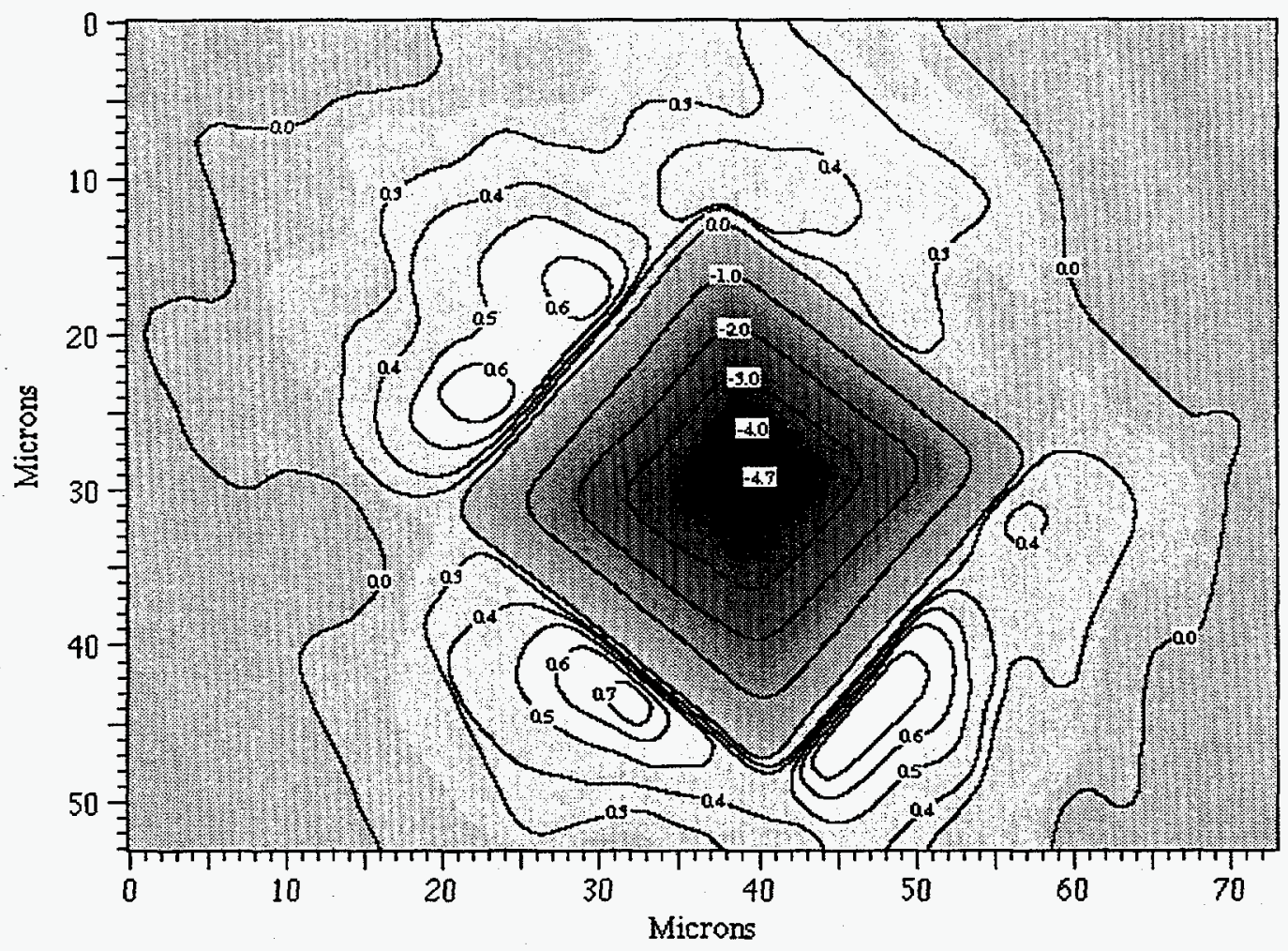


Contour Plot: A302B 200 g load -- Indent 5

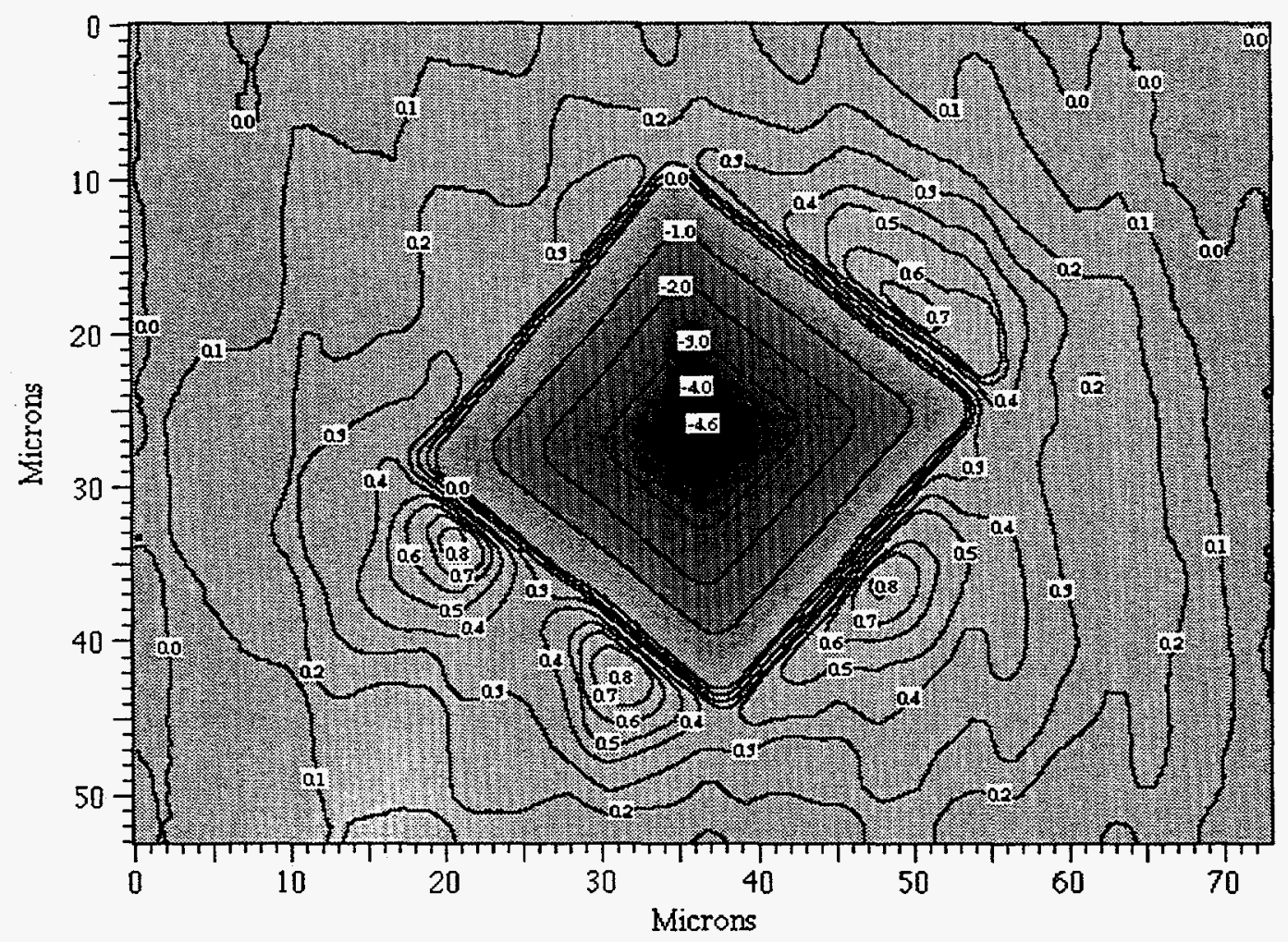


Contour Plot: A533B $200 \mathrm{~g}$ load - Indent 1

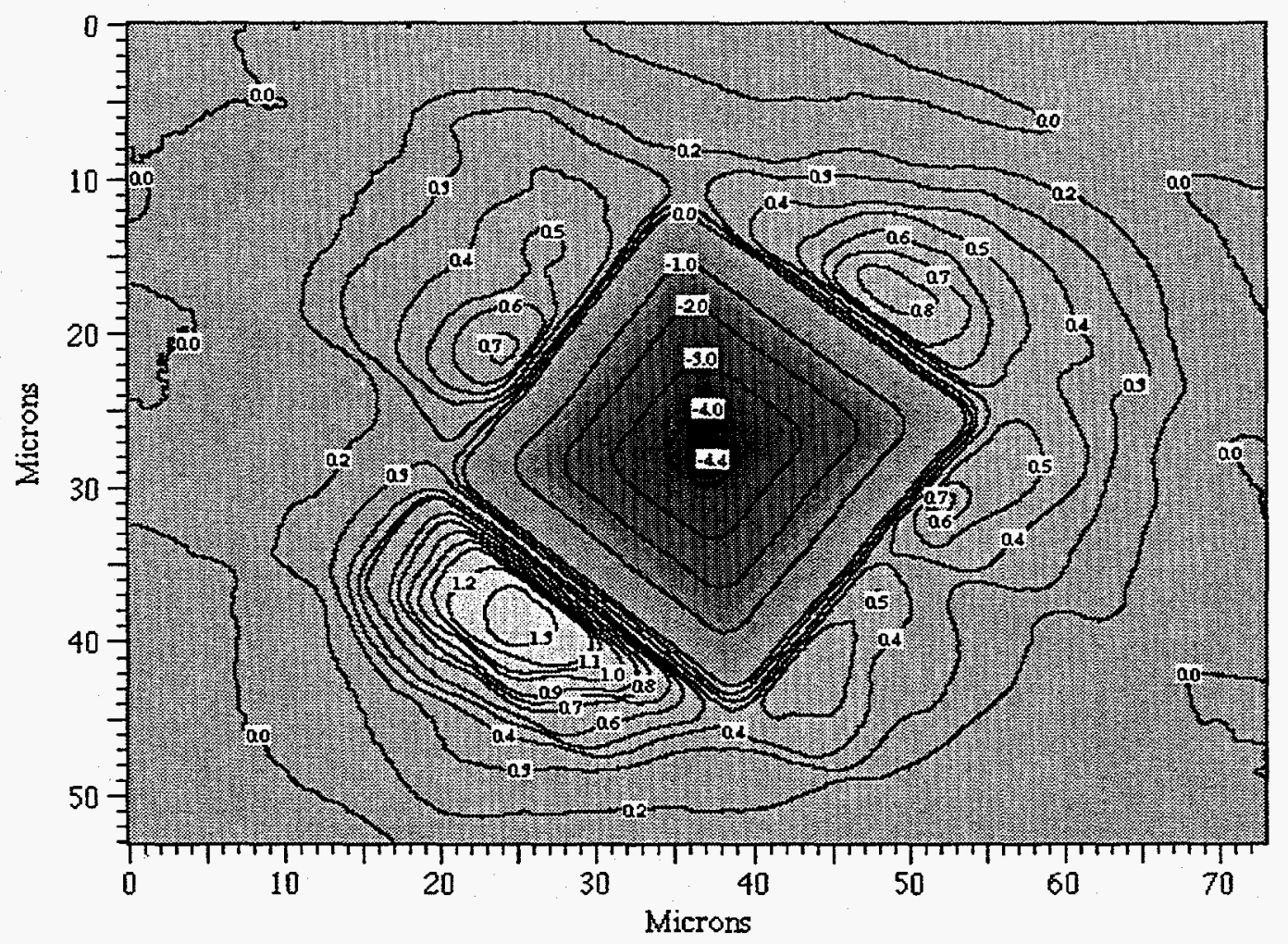


Contour Plot: A533B $200 \mathrm{~g}$ load -- Indent 2

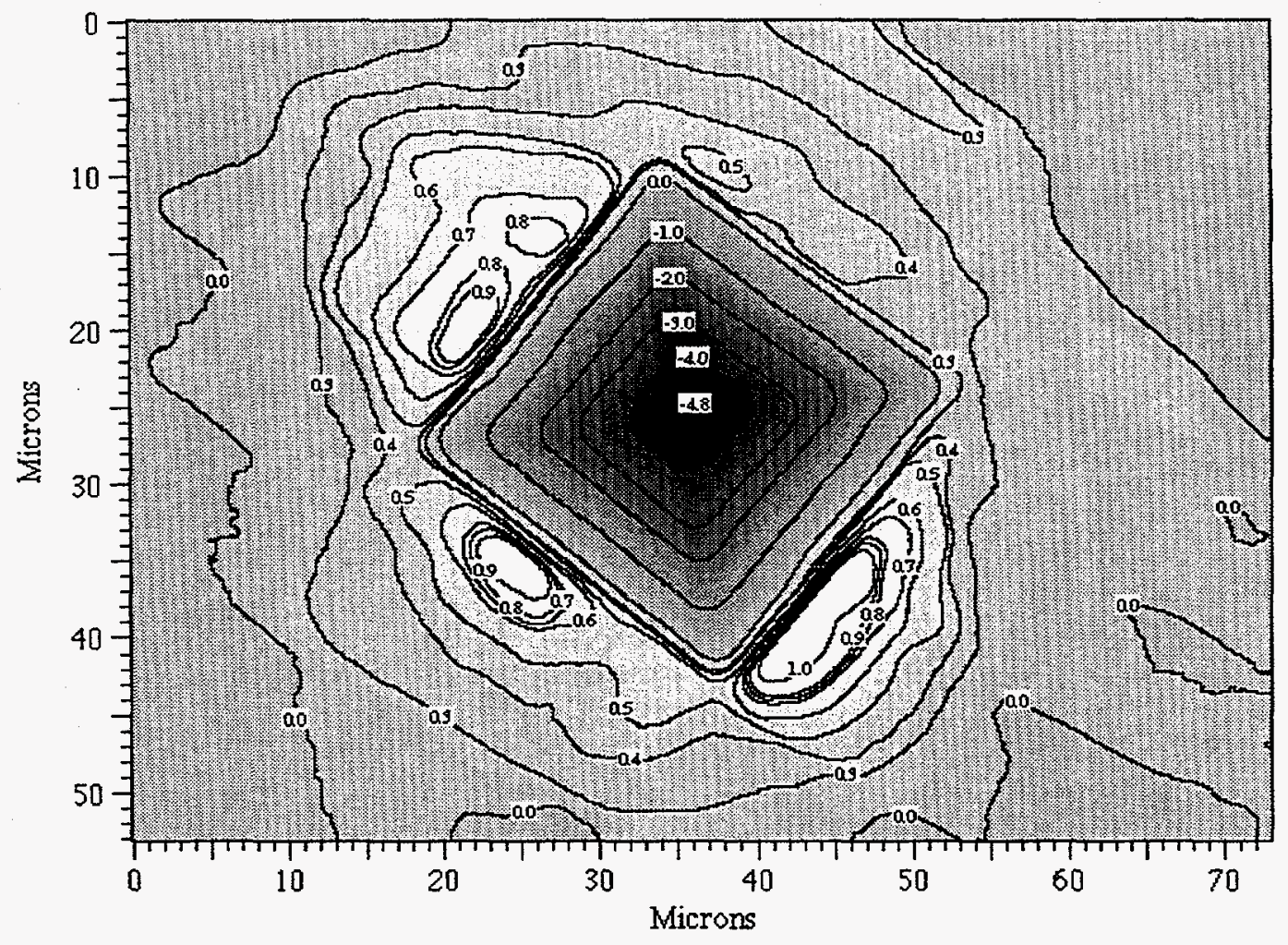


Contour Plot: A533B 200 g load -- Indent 3

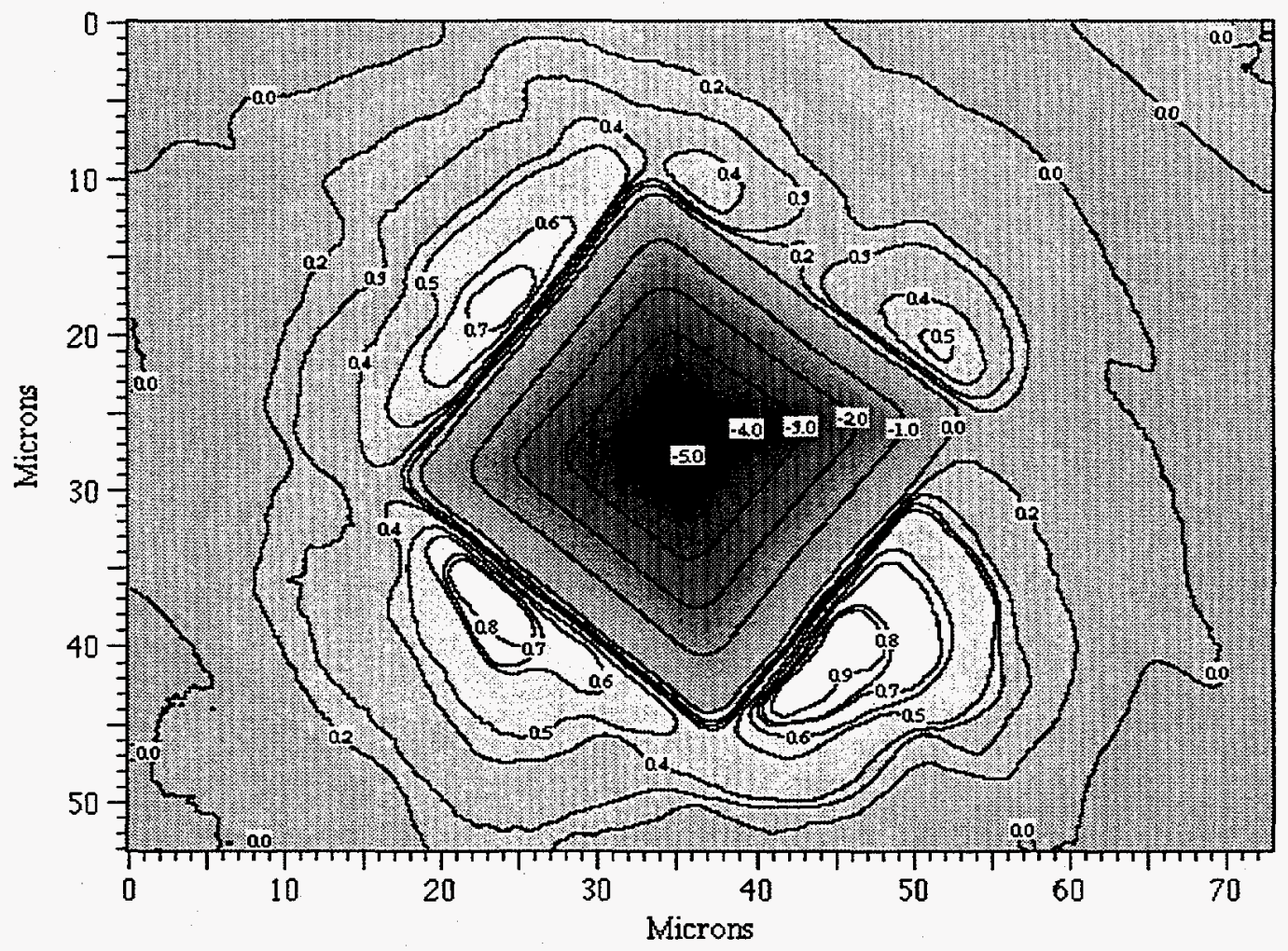


Contour Plot: A533B $200 \mathrm{~g}$ load - Indent 4

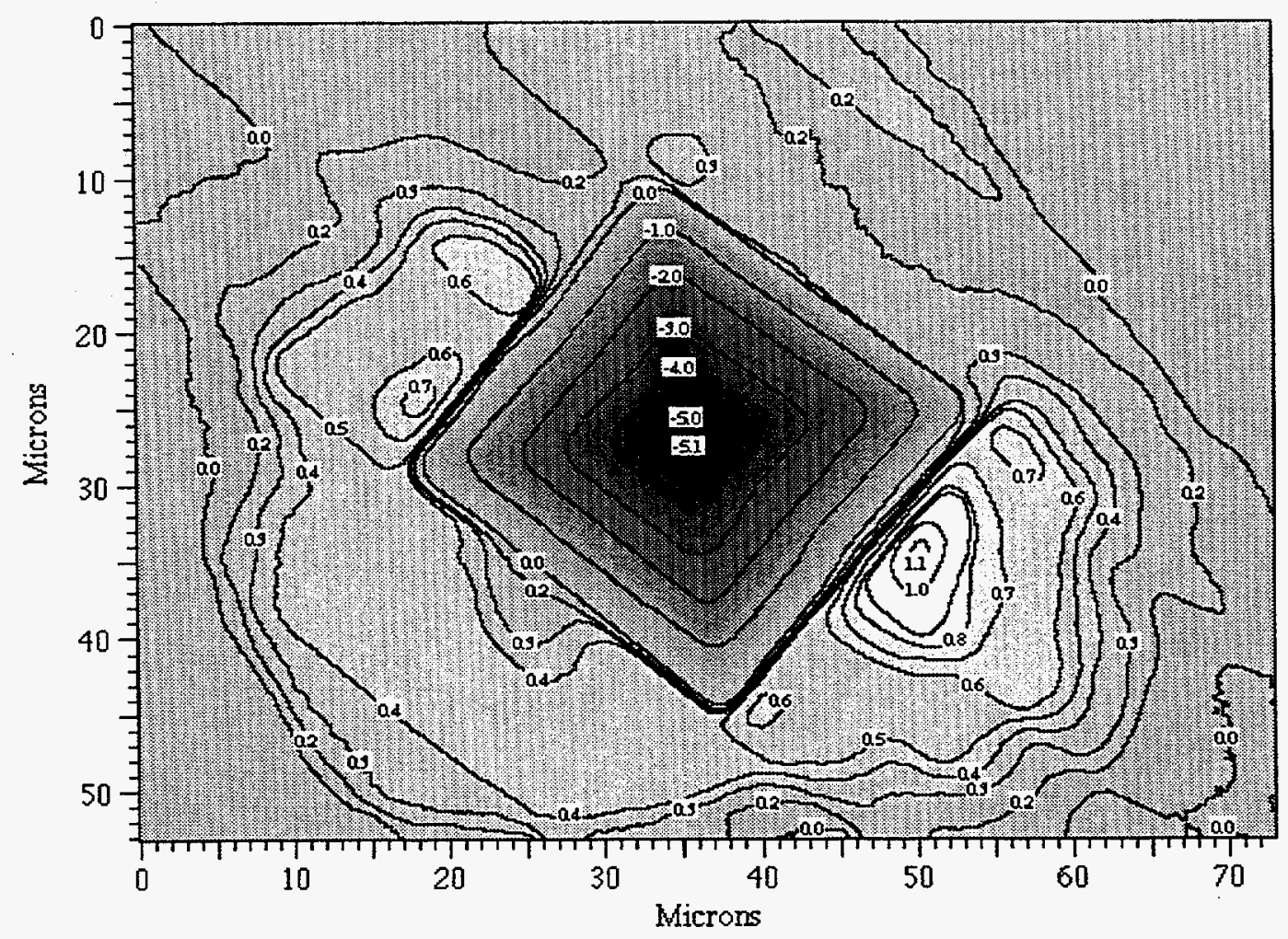


Contour Plot: A533B $200 \mathrm{~g}$ load -- Indent 5

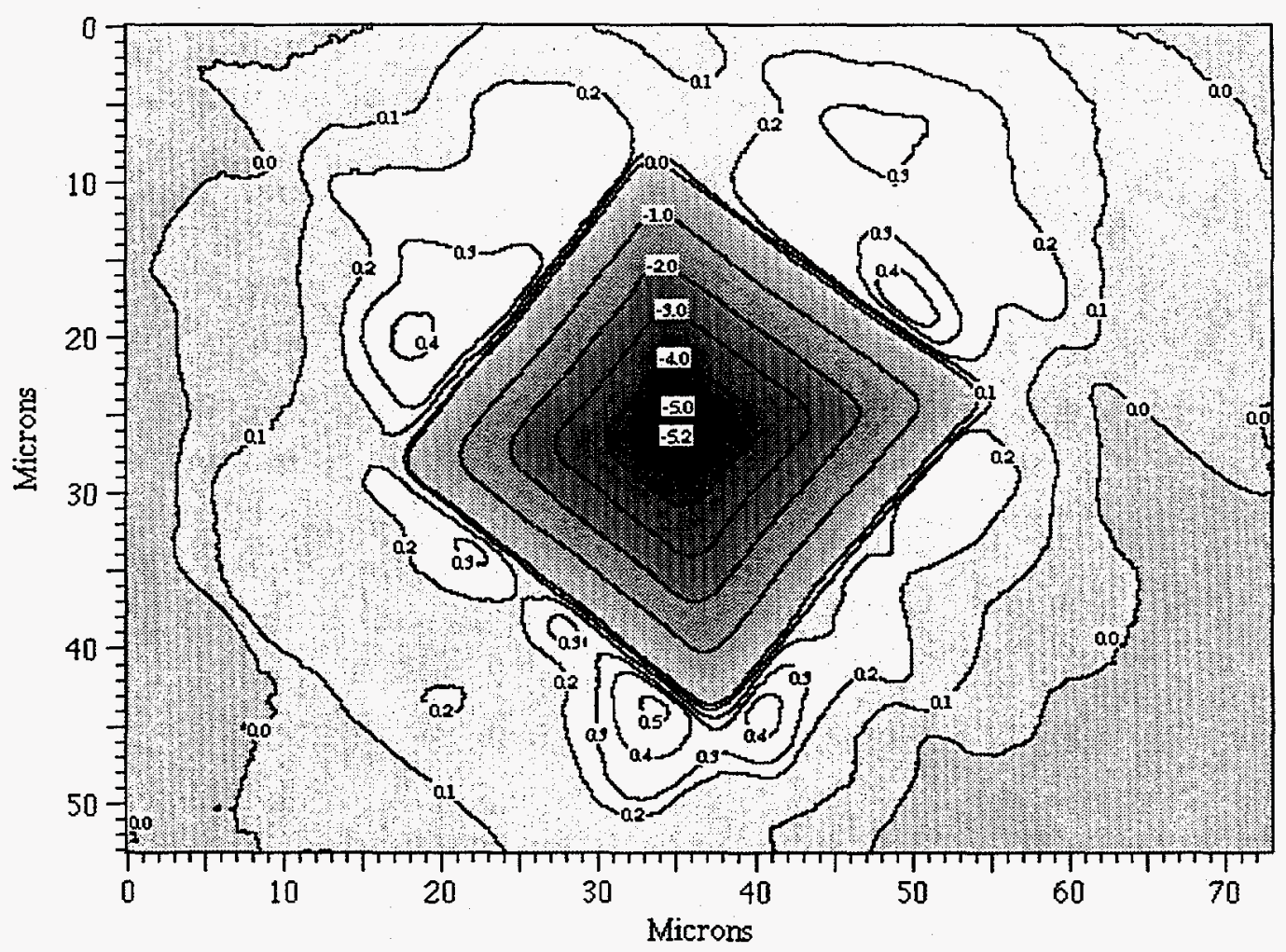


Contour Plot: F82H $200 \mathrm{~g}$ load -- Indent 5

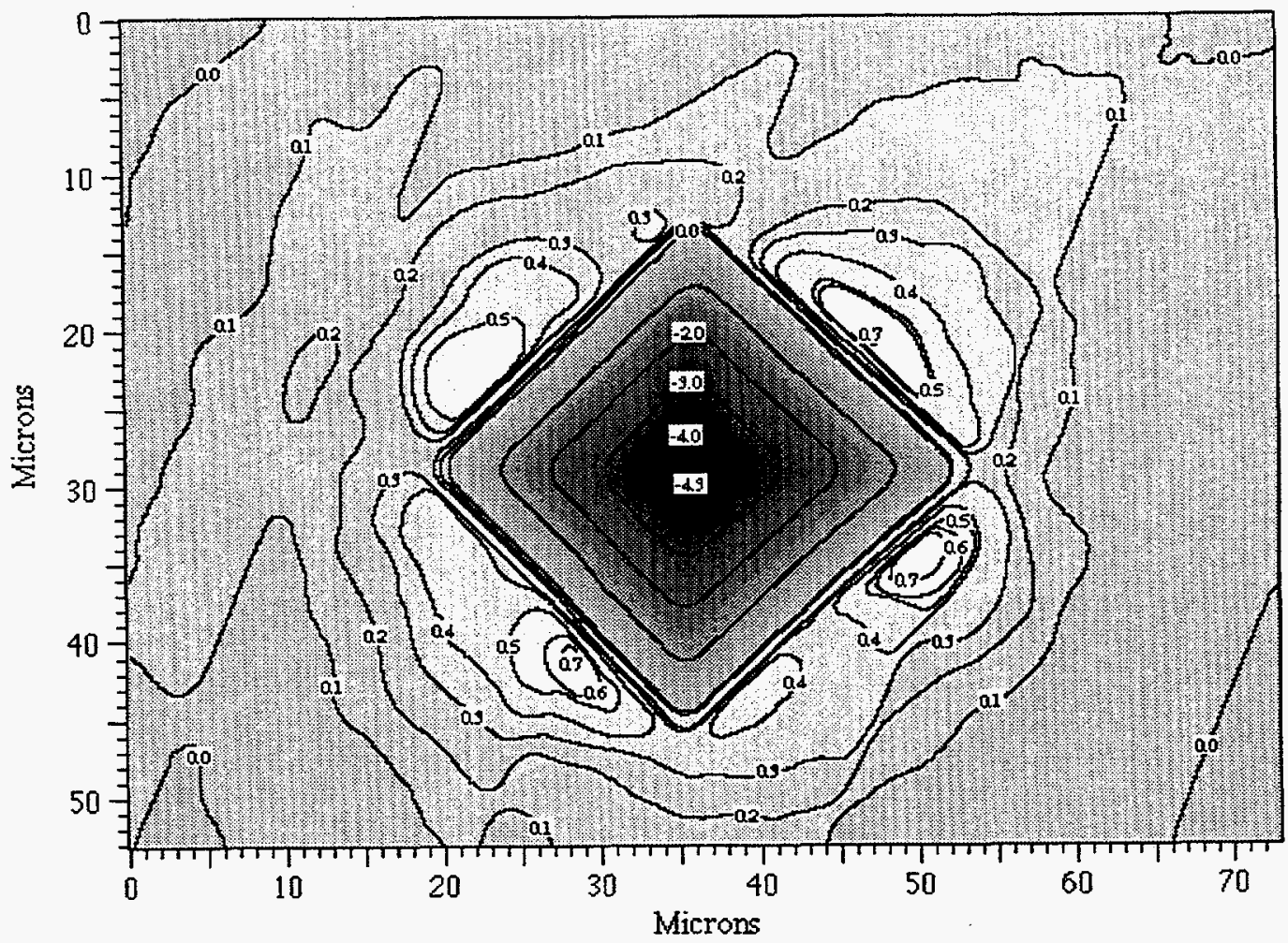


Contour Plot: F82H $200 \mathrm{~g}$ load -- Indent 1

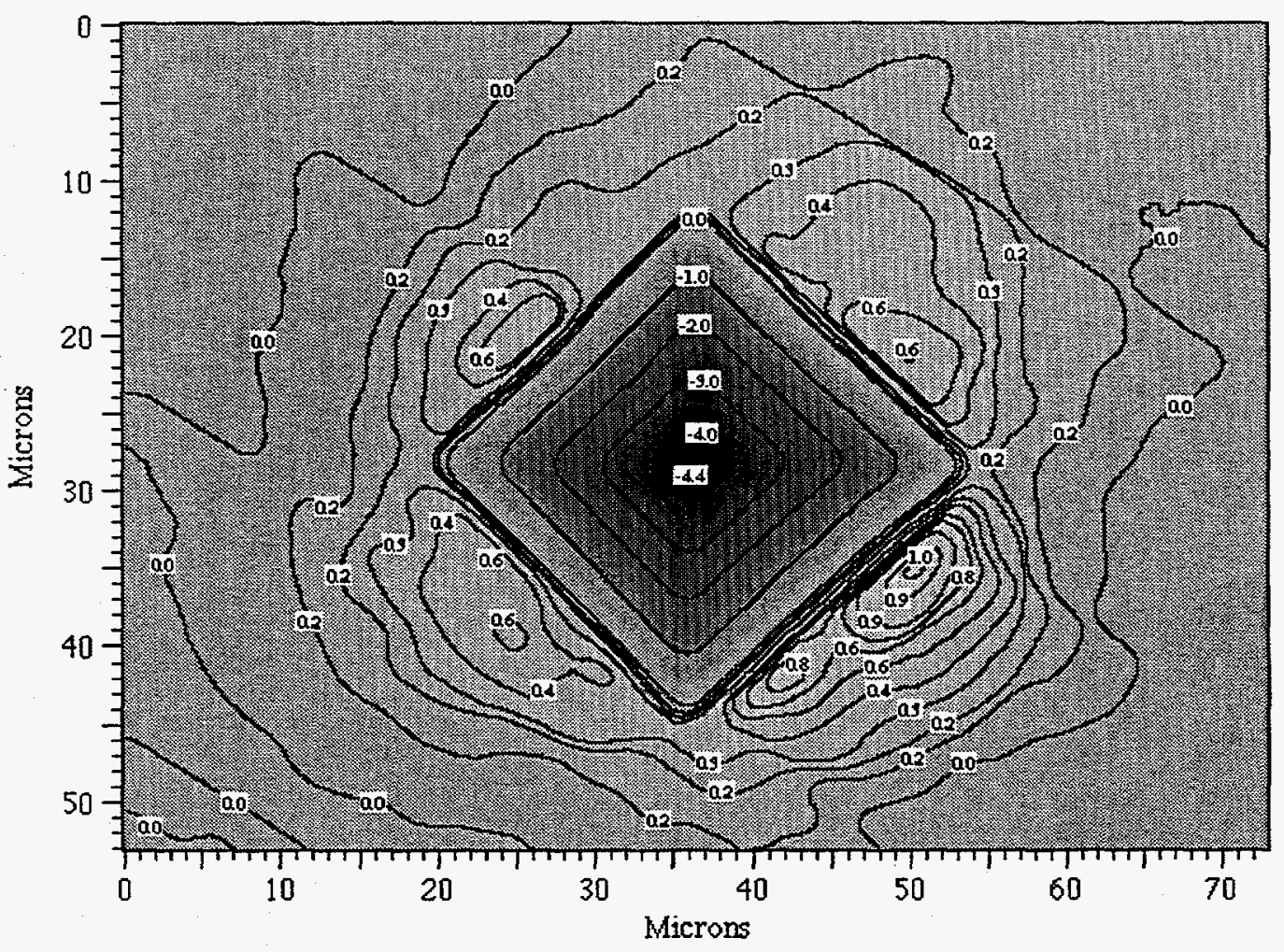


Contour Plot: F82H $200 \mathrm{~g}$ load -- Indent 2

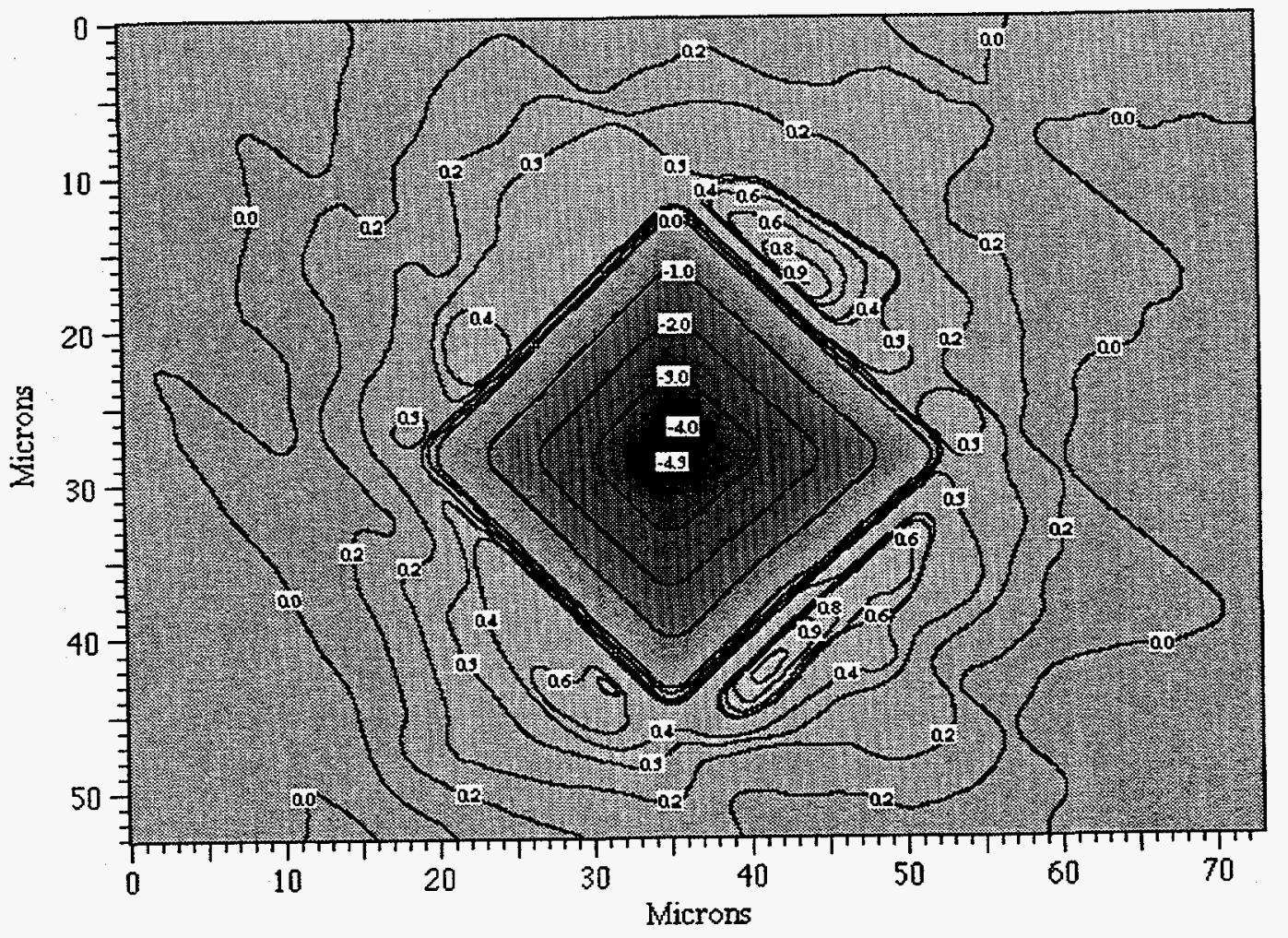


Contour Plot: $\mathrm{F} 82 \mathrm{H} 200 \mathrm{~g}$ load -- Indent 3

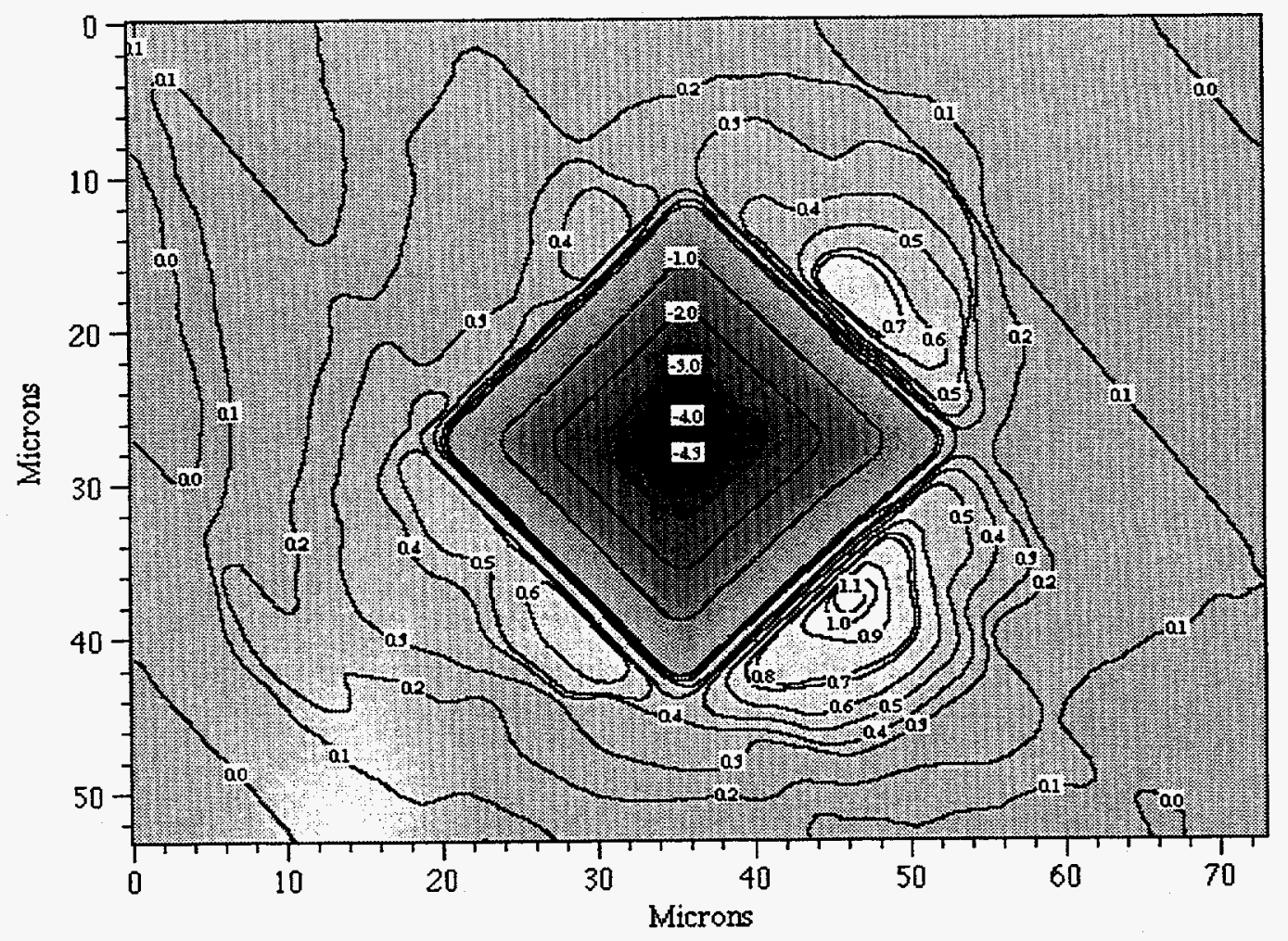


Contour Plot: F82H 200 g loat -- Indent 4

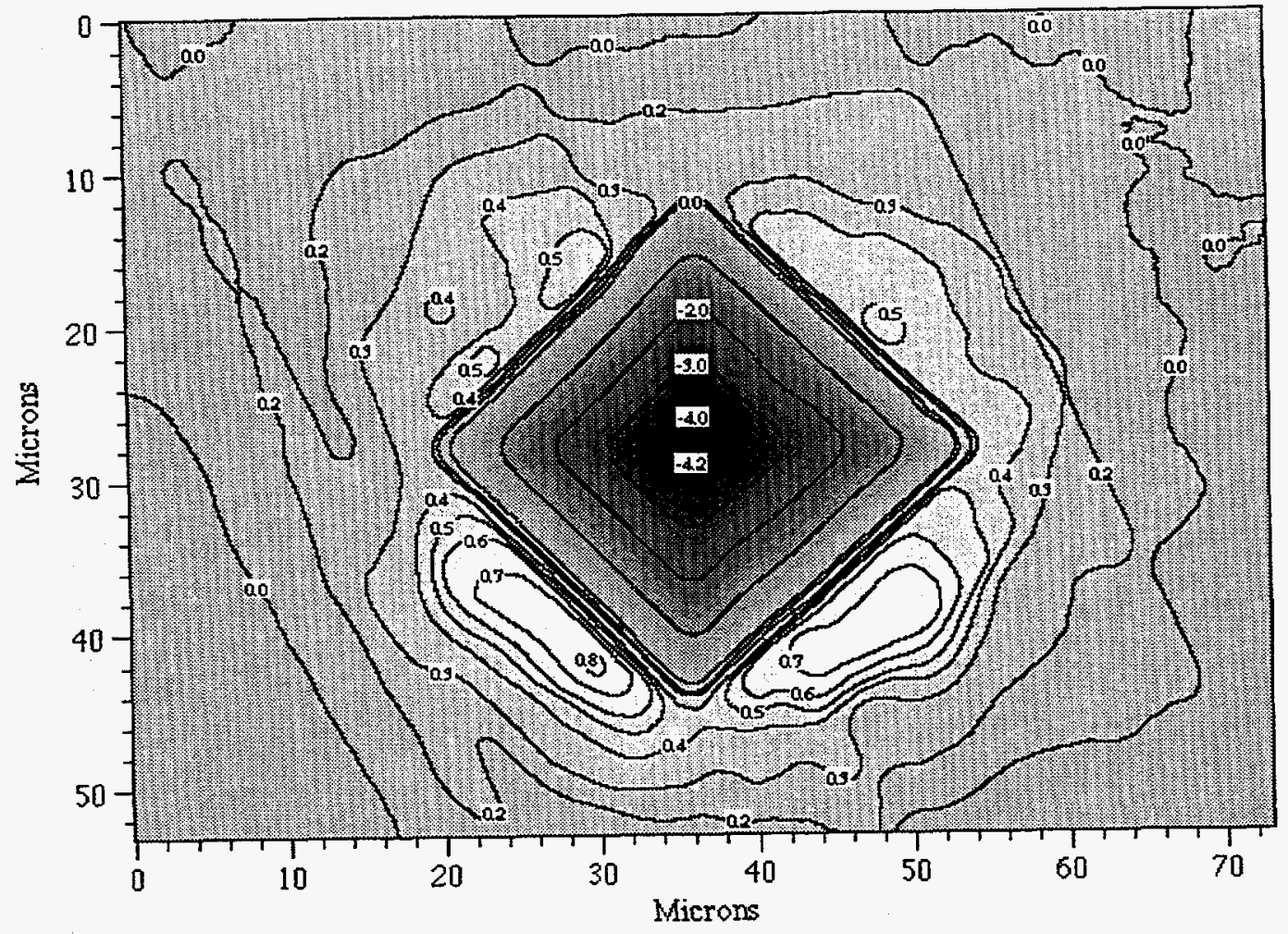


Contour Plot: Ann SS 200g - Indent 6

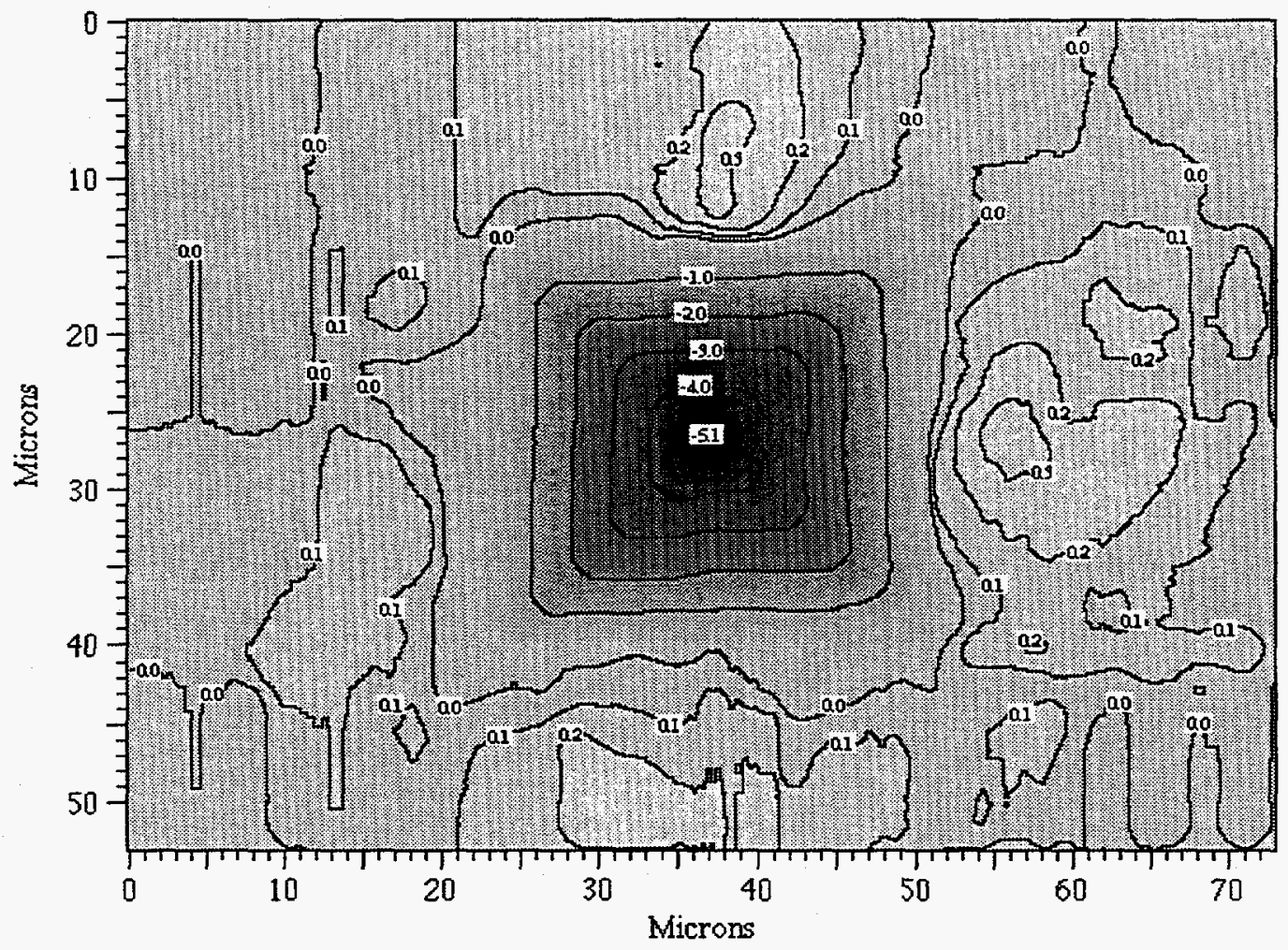


Contour Plot: Ann SS 200g -- Indent 7

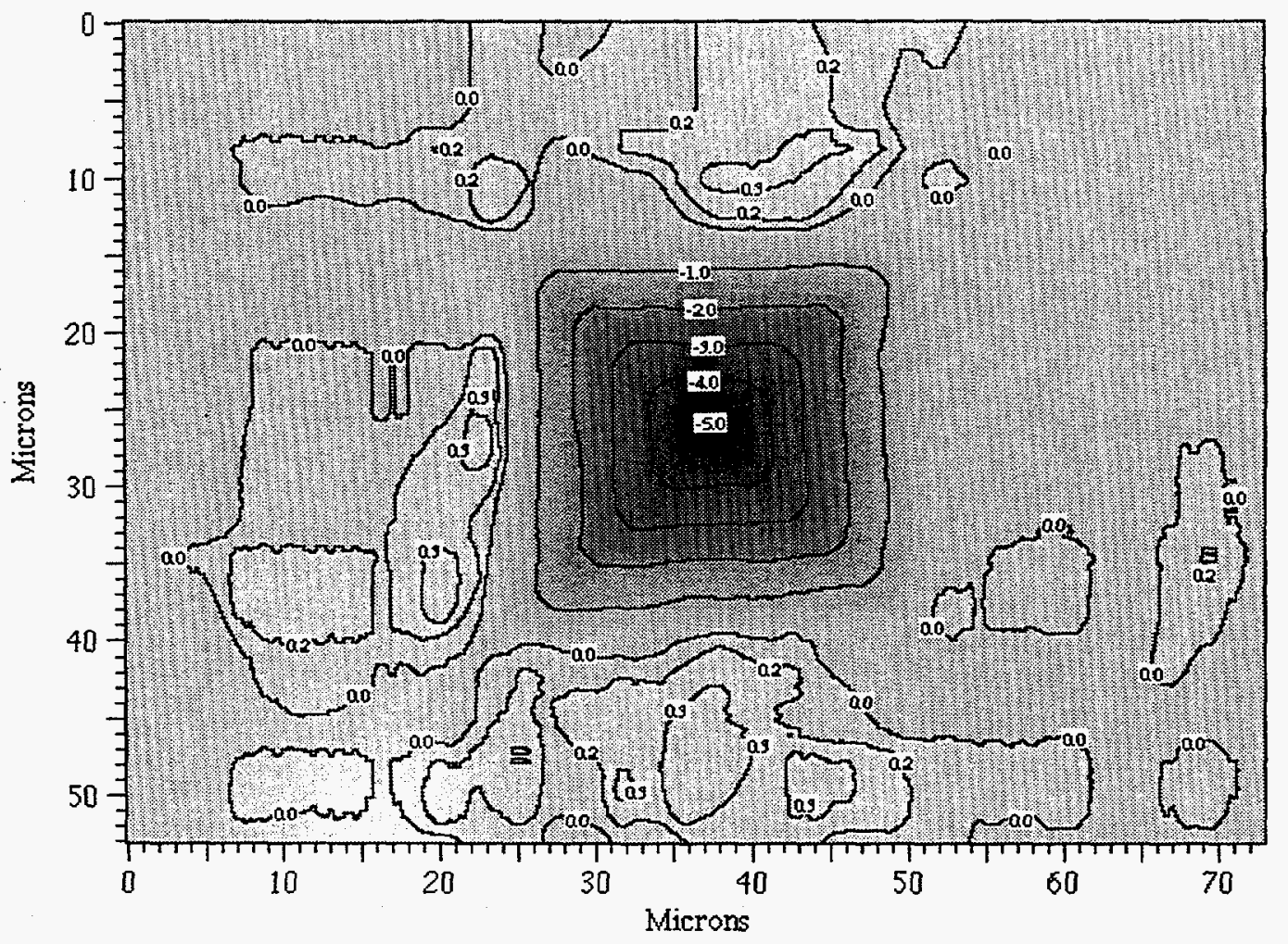


Contour Plot: Ann SS 200g -- Indent 8

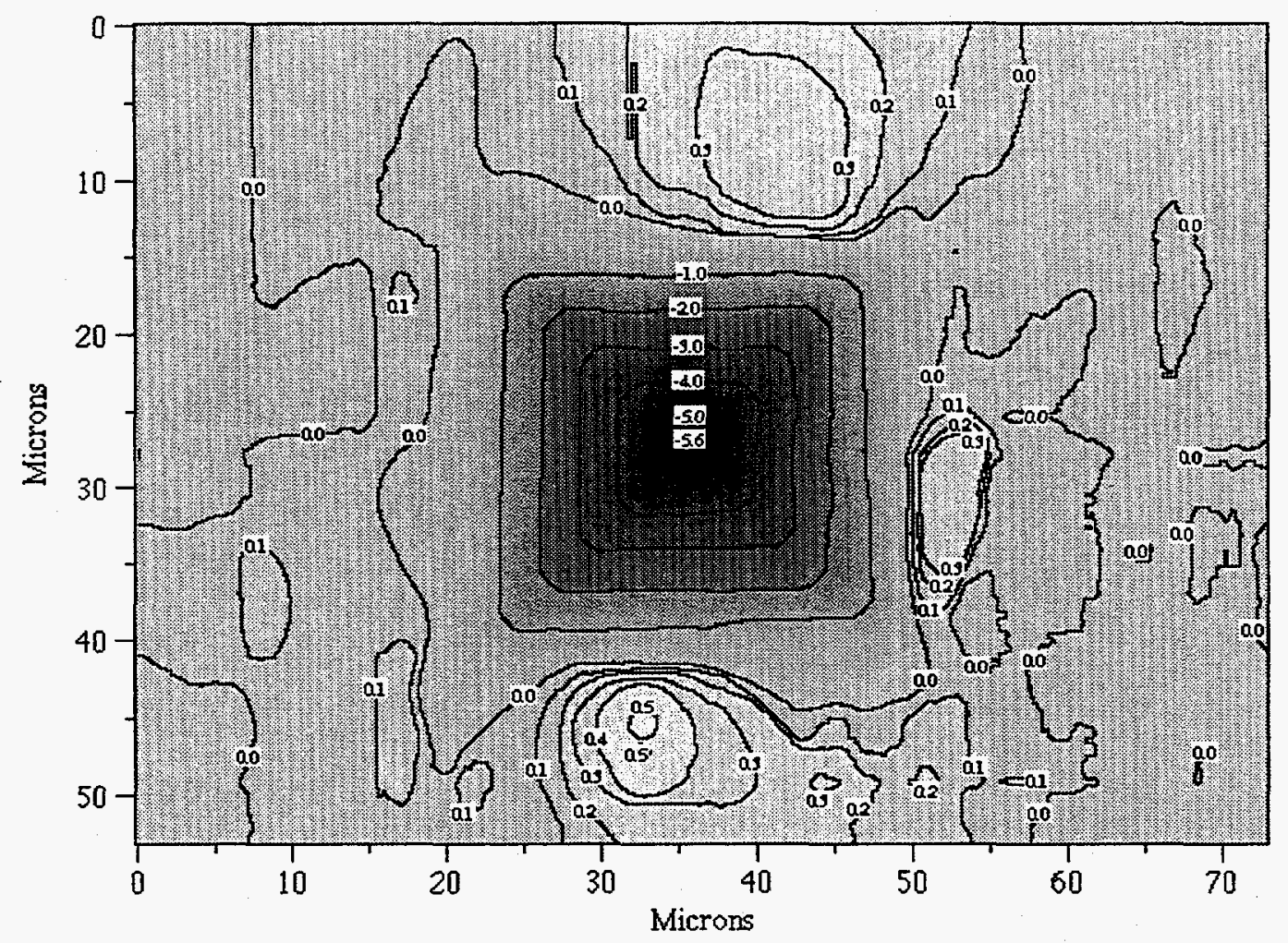


Contour Plot: A.m SS 200g - Indent 9

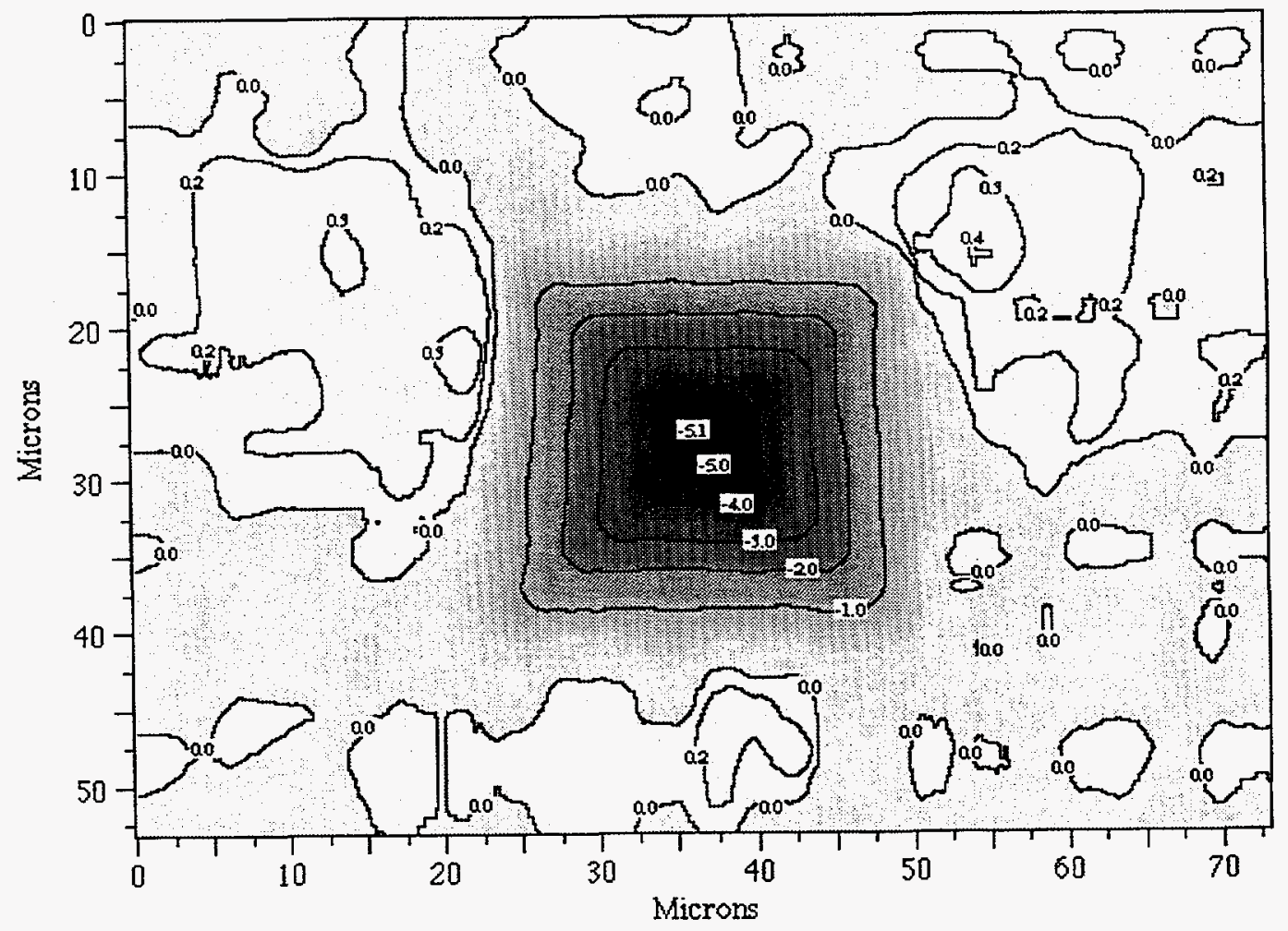


Contour Plot: Ann SS 200g -- Indent 10

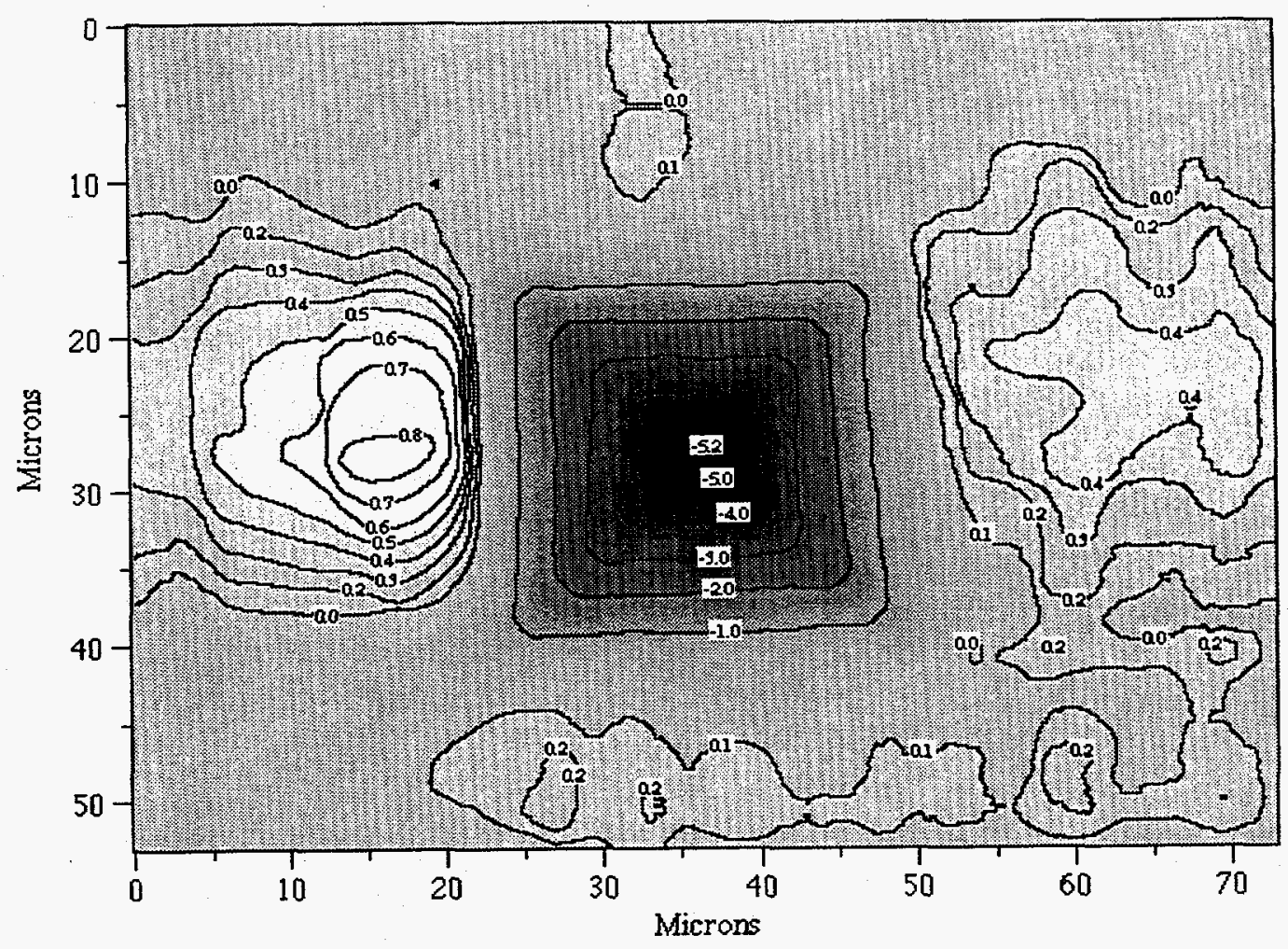


HT-9 Indent 1

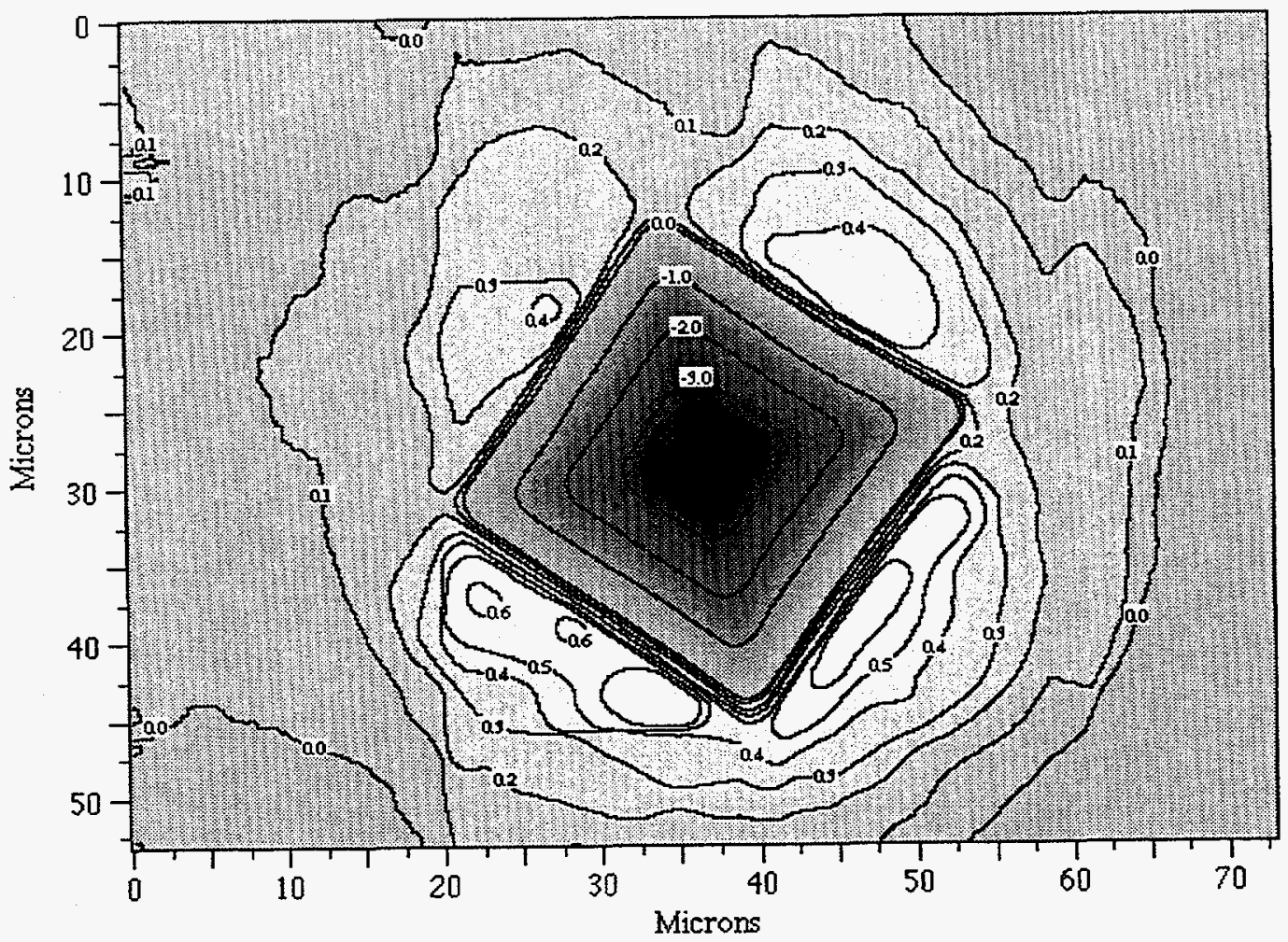


Contour Plot: HT9 $200 \mathrm{~g}$ load -- Indent 2

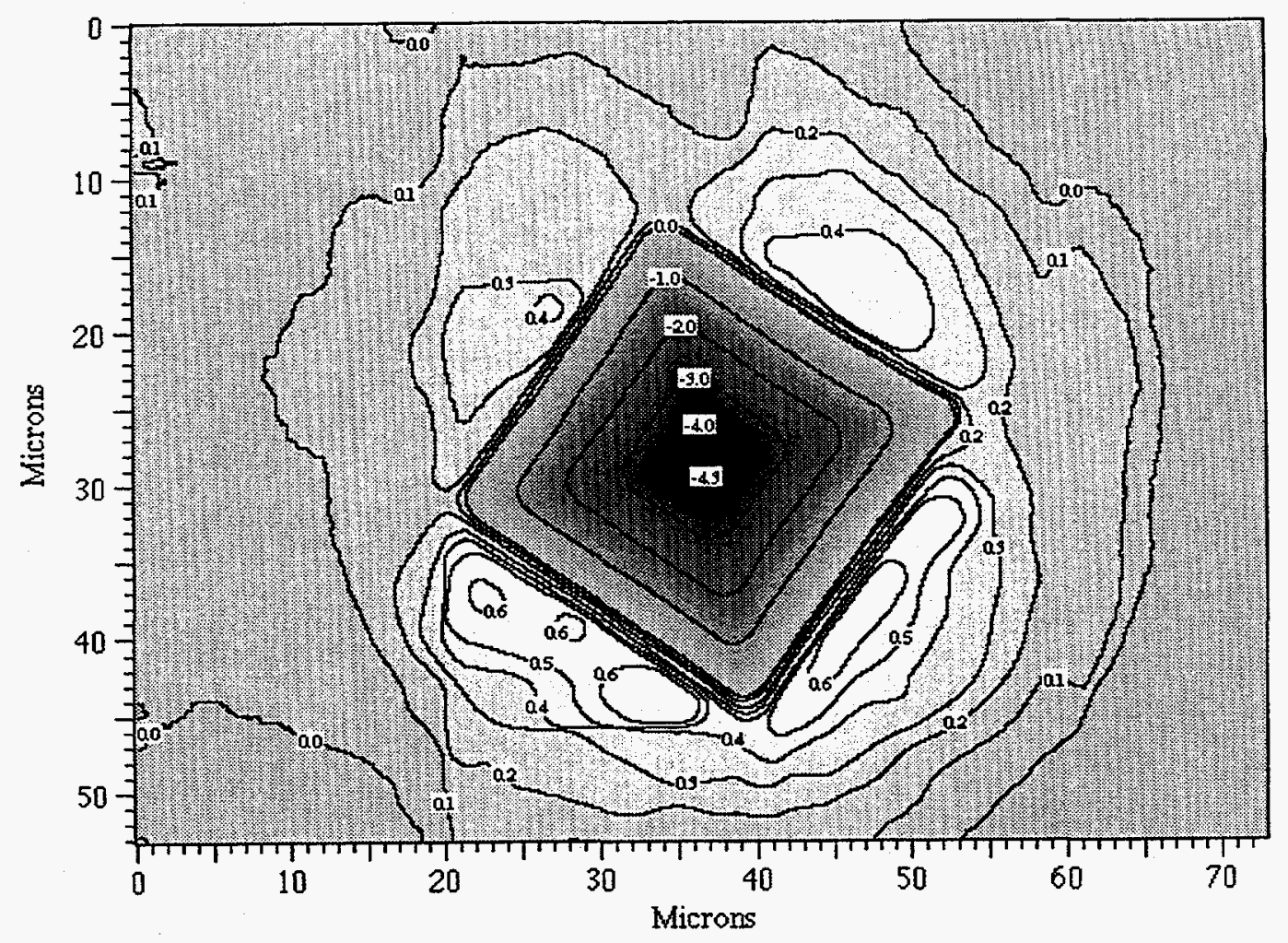


Contour Plot: HT9 $200 \mathrm{~g}$ load -- Indent 3

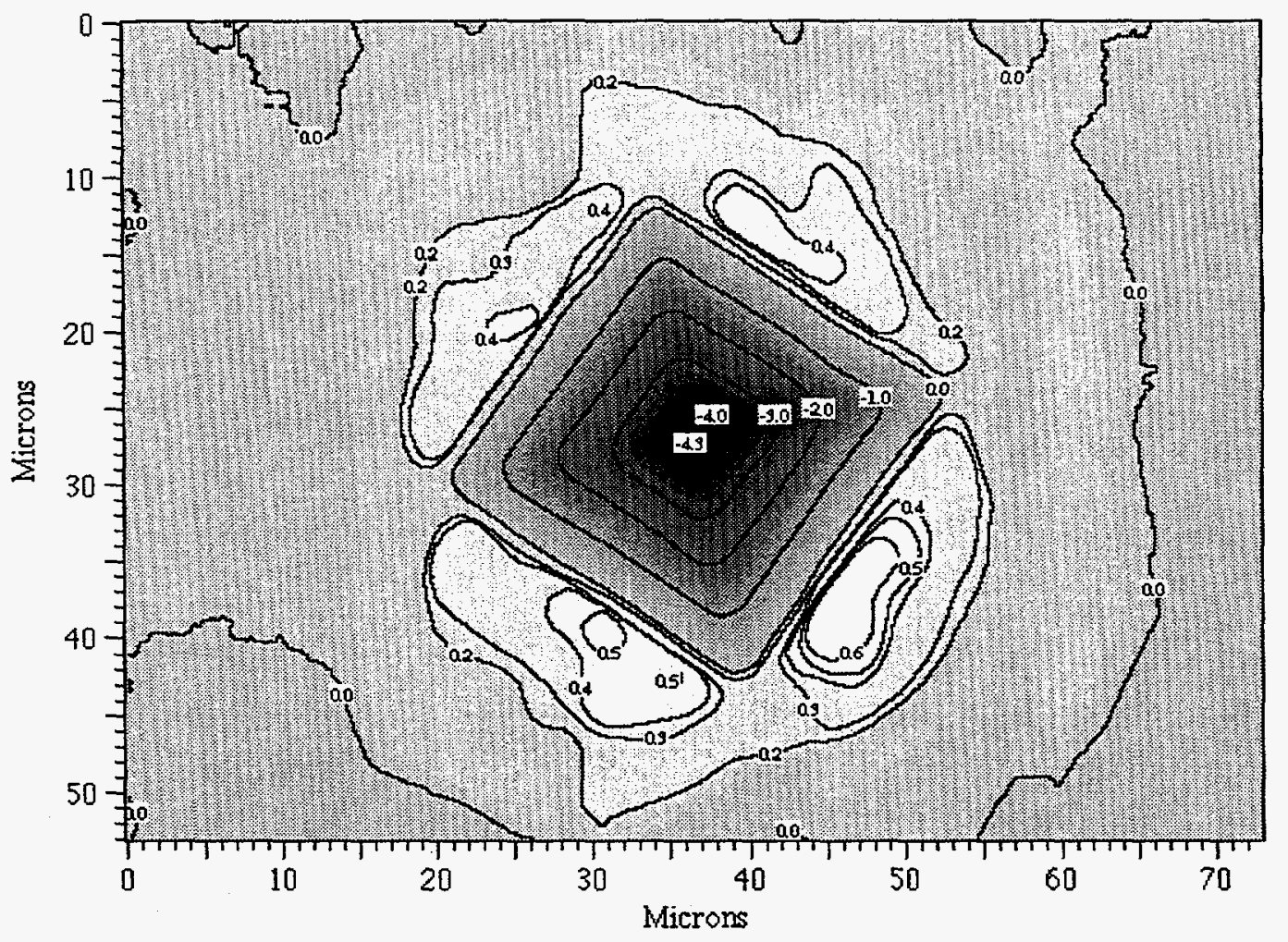




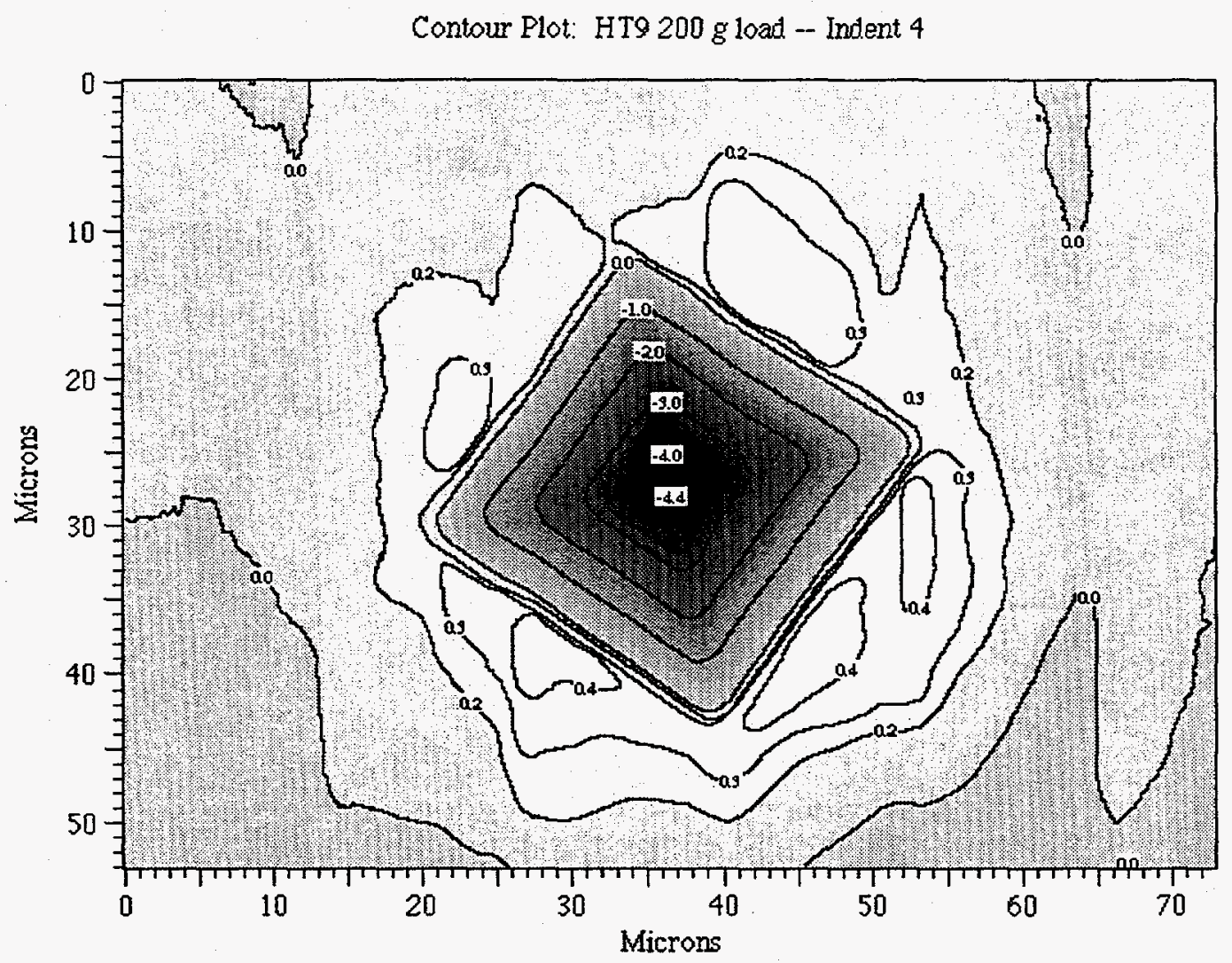


Contour Plot: HT9 200 g load -- Indent 5

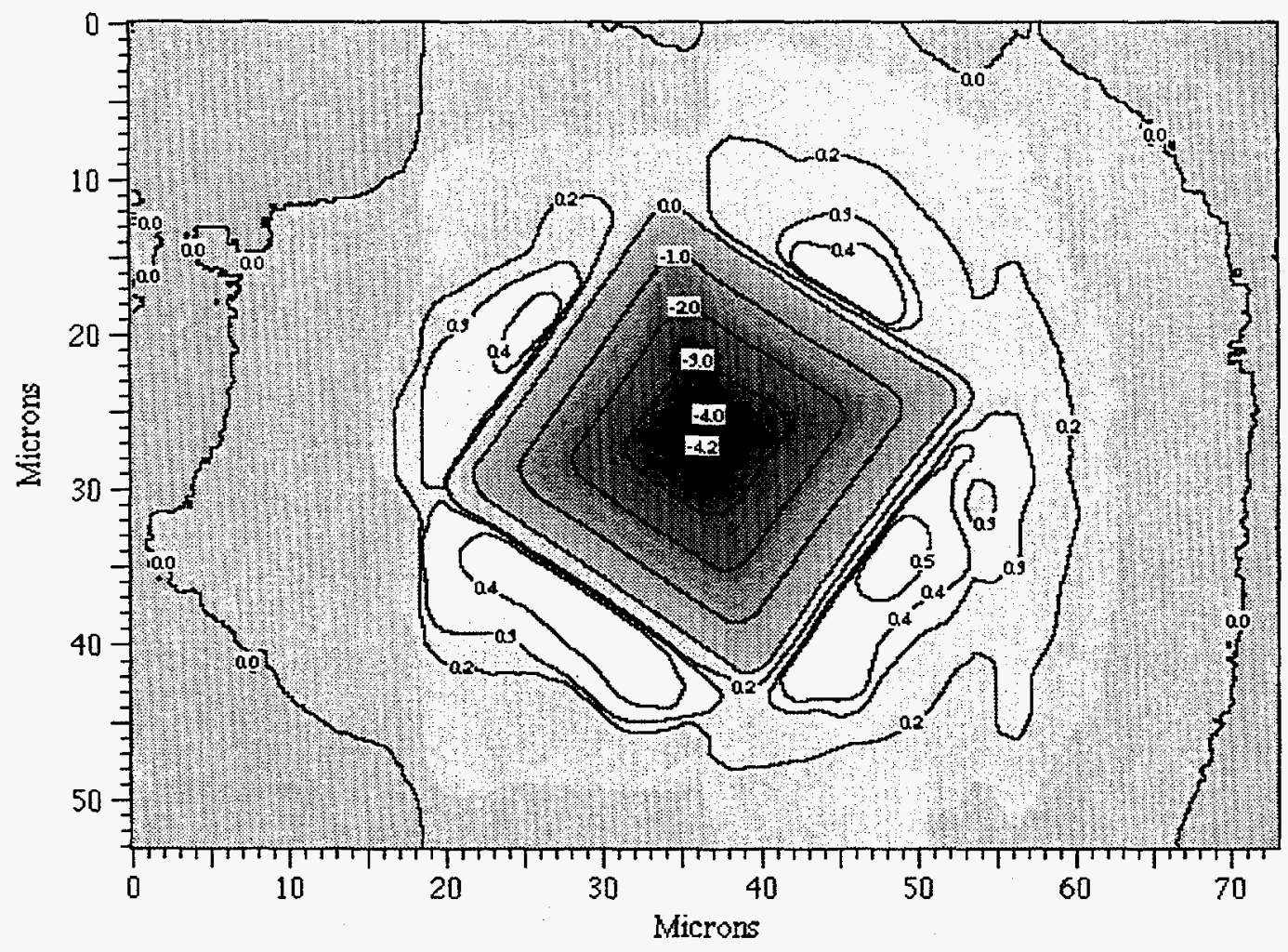


Contour Plot: A533B Model Control Indent 1

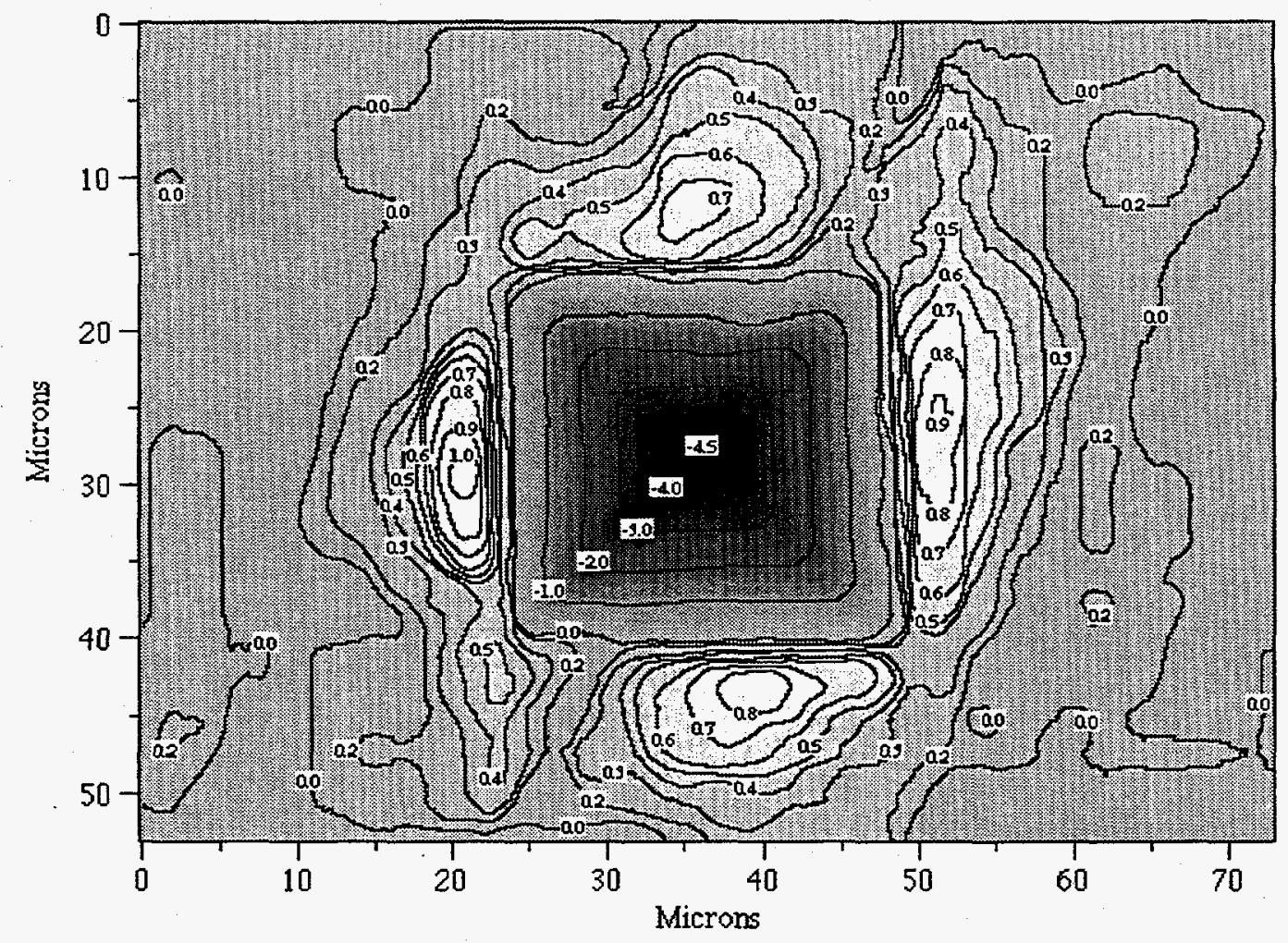


Contour Plot: A533B Model Control Indent 2




Contour Plot: A533B Model Control Indent 3

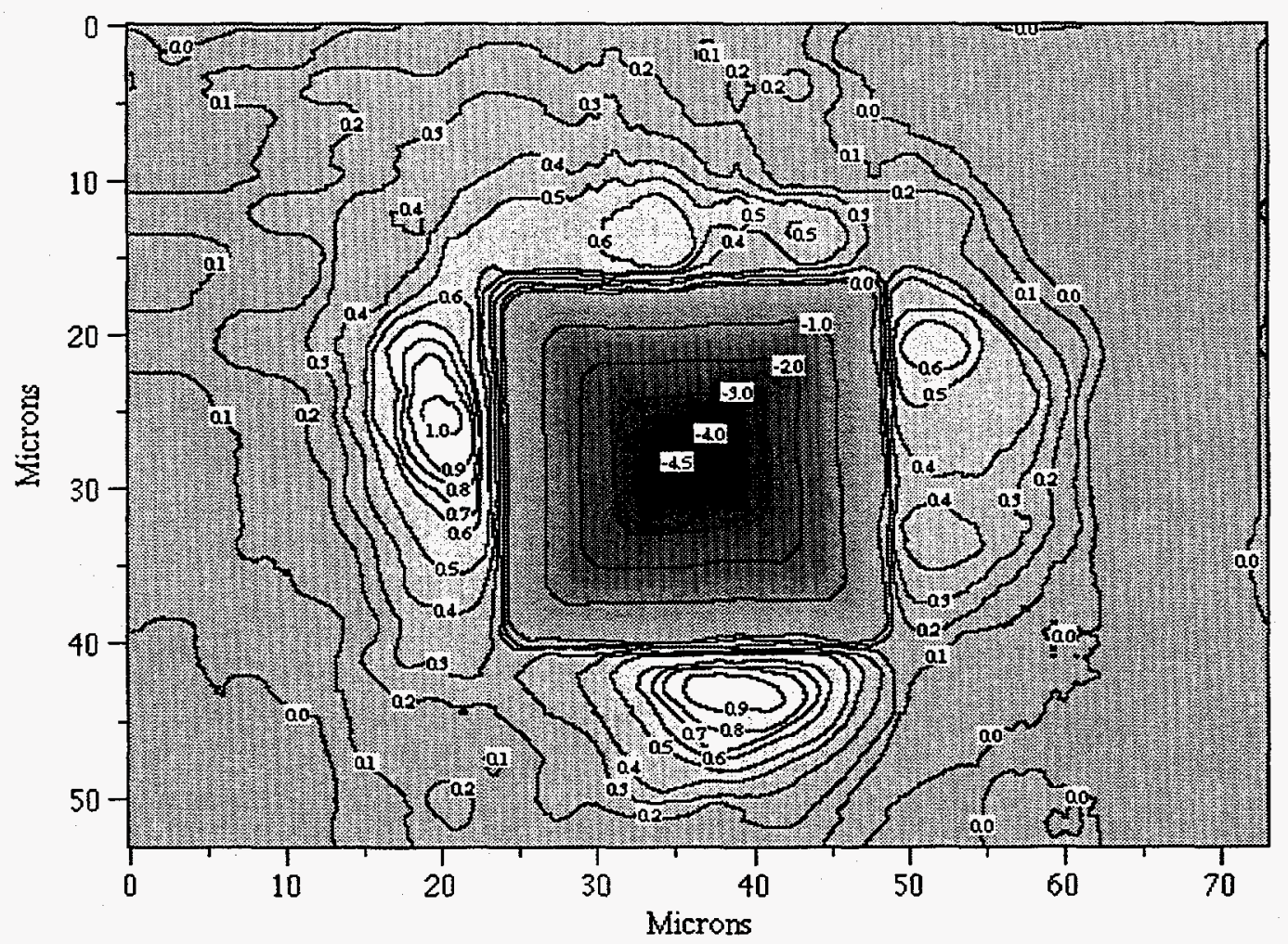


Contour Plot: A533B Model Control Indent 4

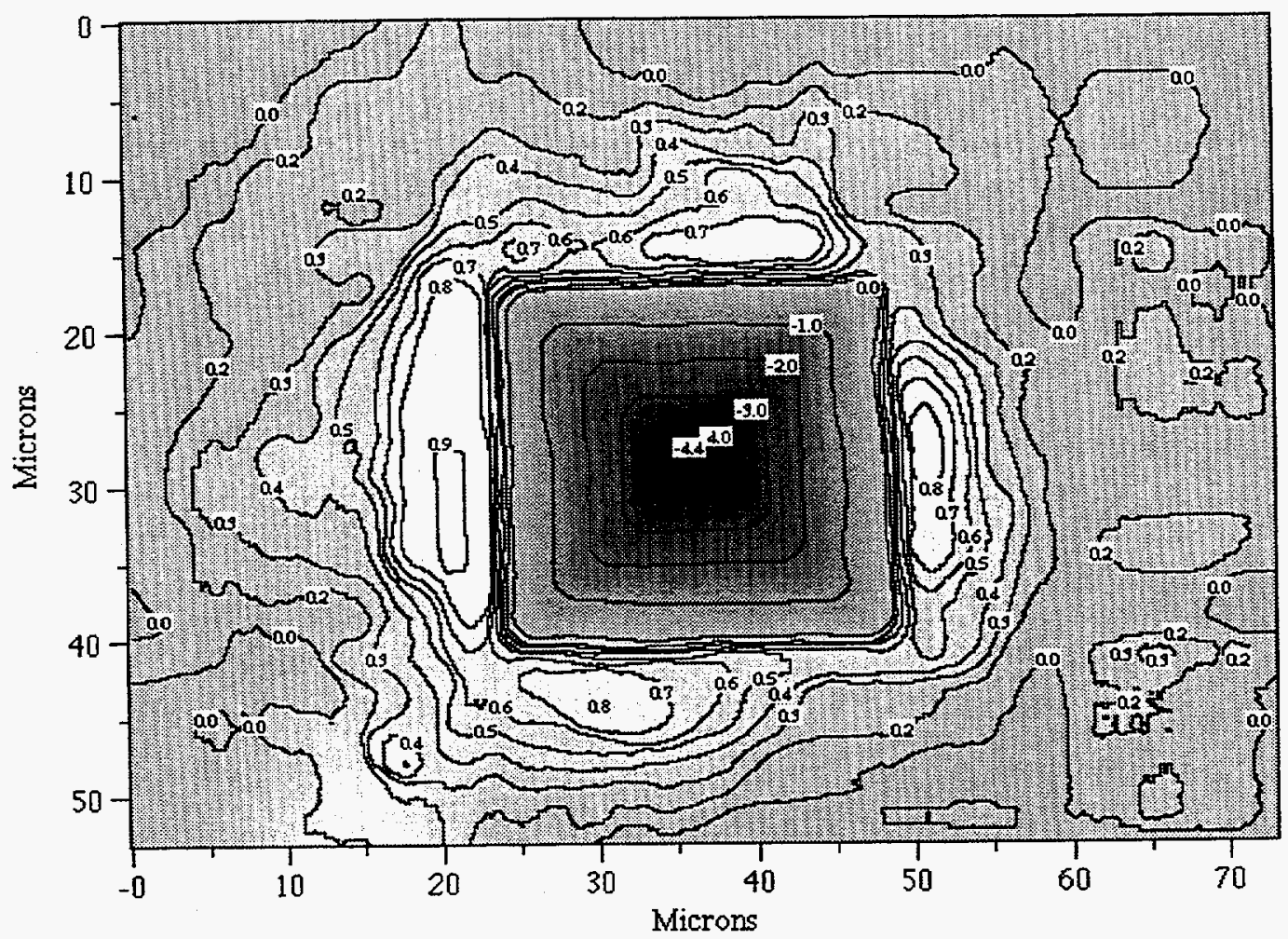


Contour Plot: A533B Model Control Indent 5

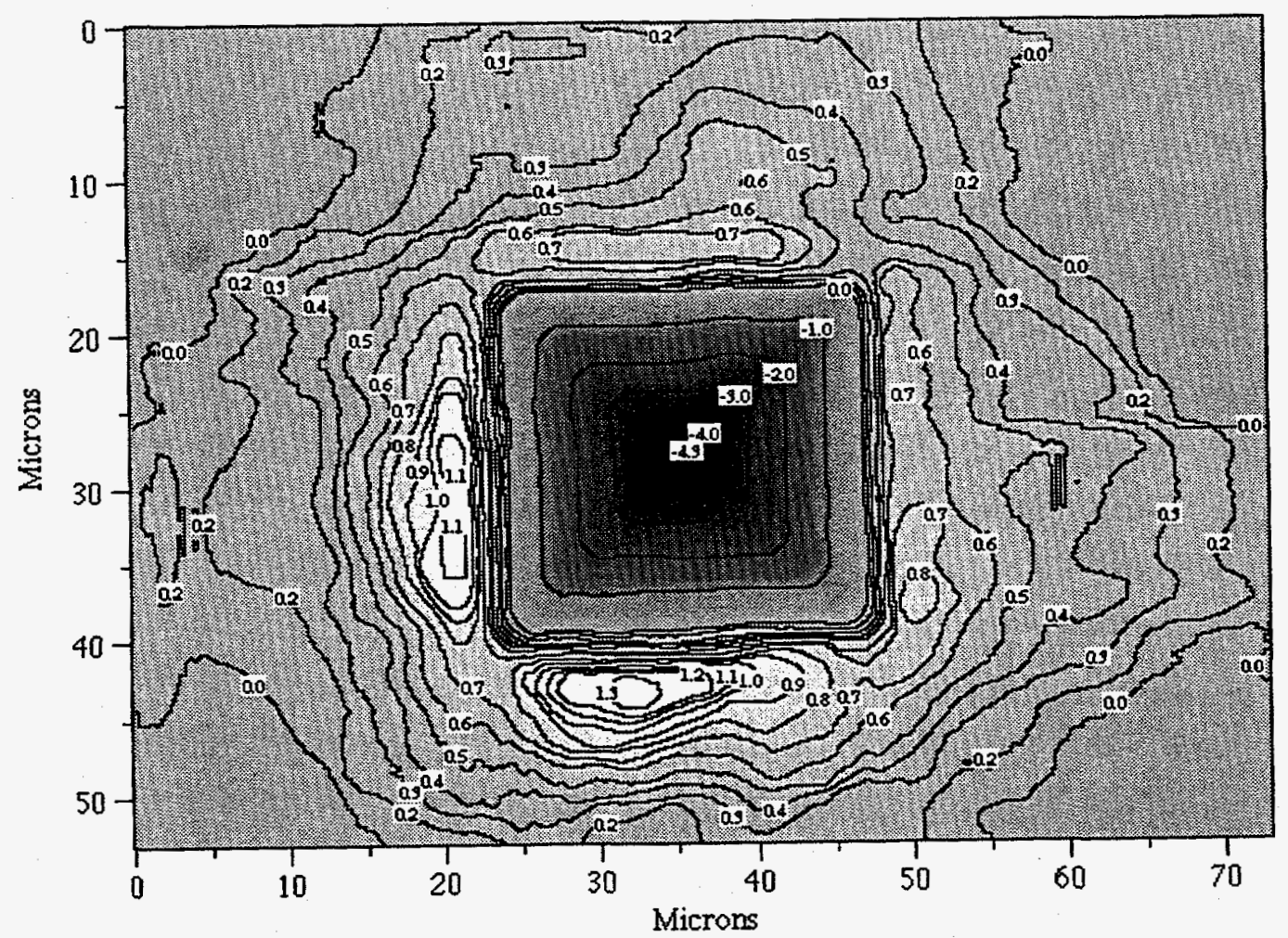


Contour Plot: A533B Model Control Indent 6

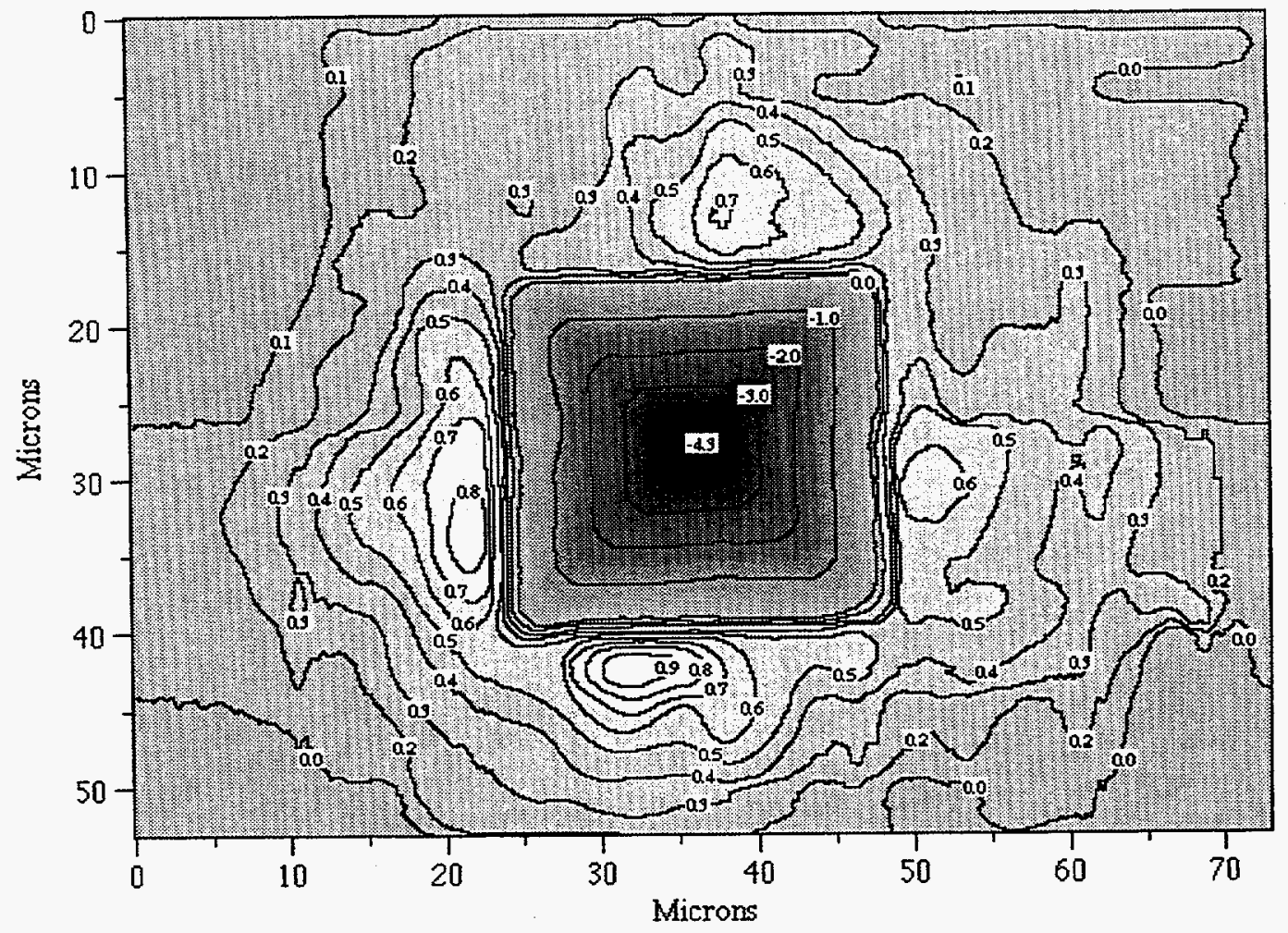


Contour Plot: A533B Model Control Indent 7

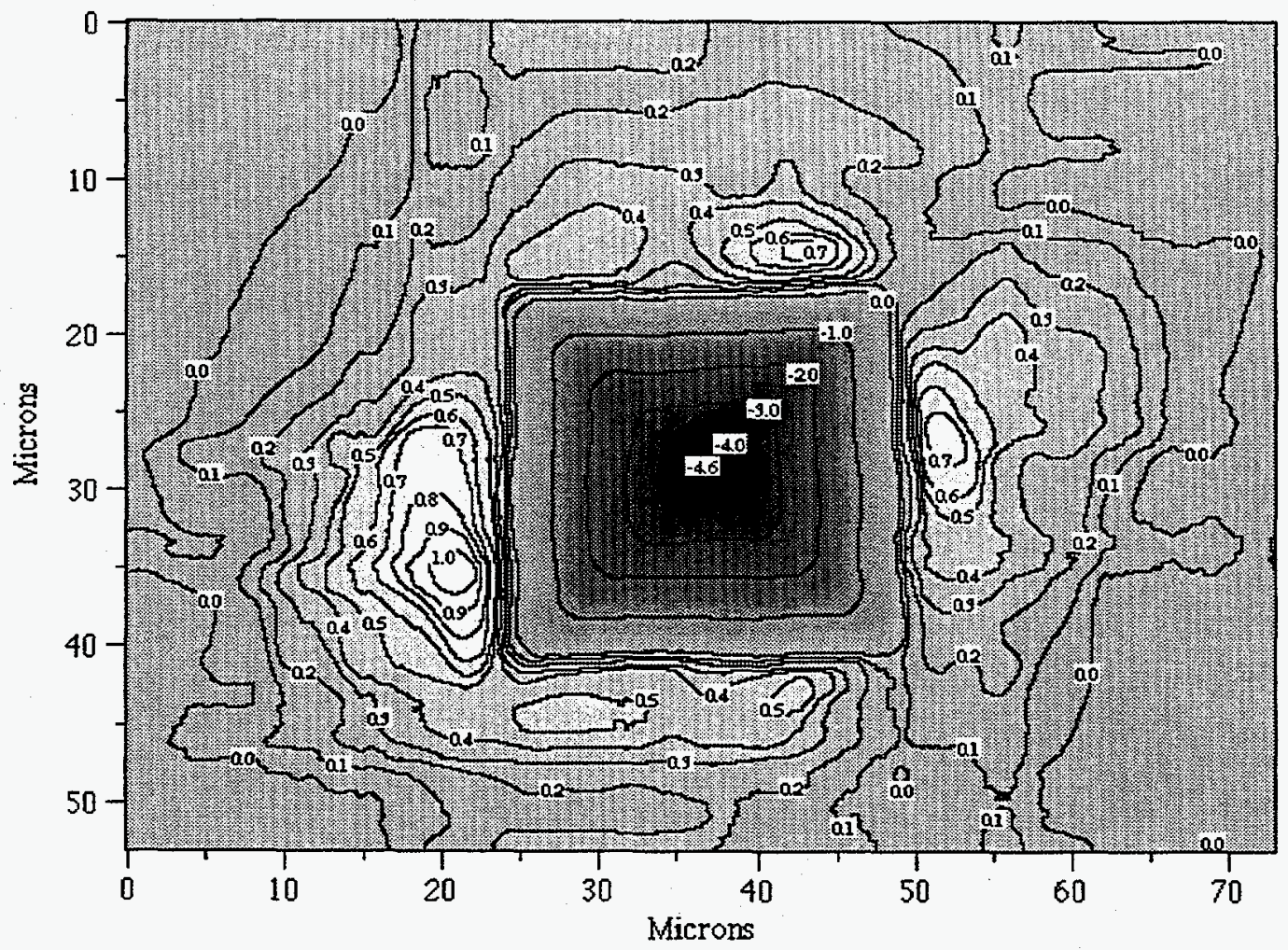


Contour Plot: A533B Model Control Indent 8

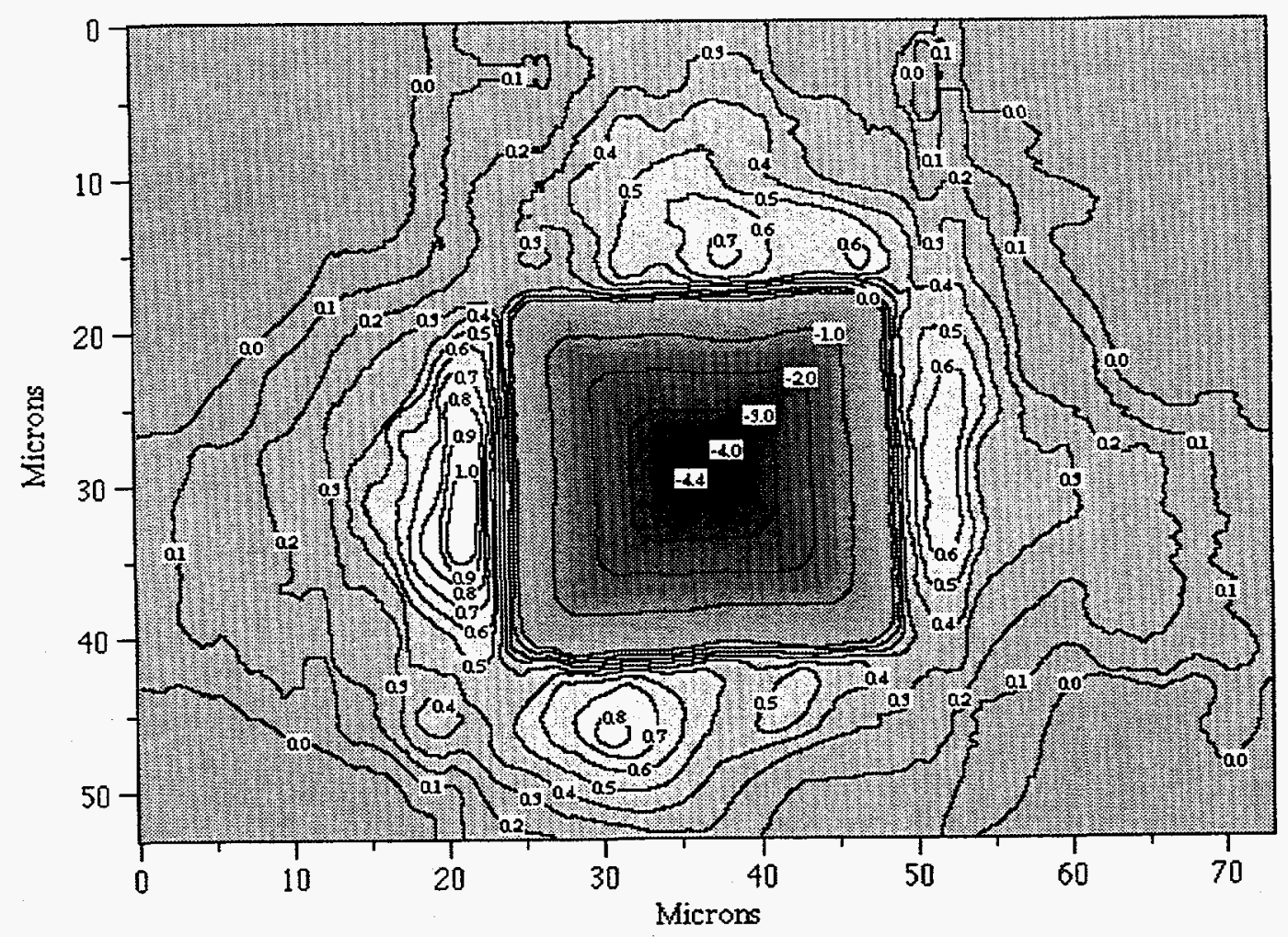


Contour Plot: A533B Model Control Indent 9

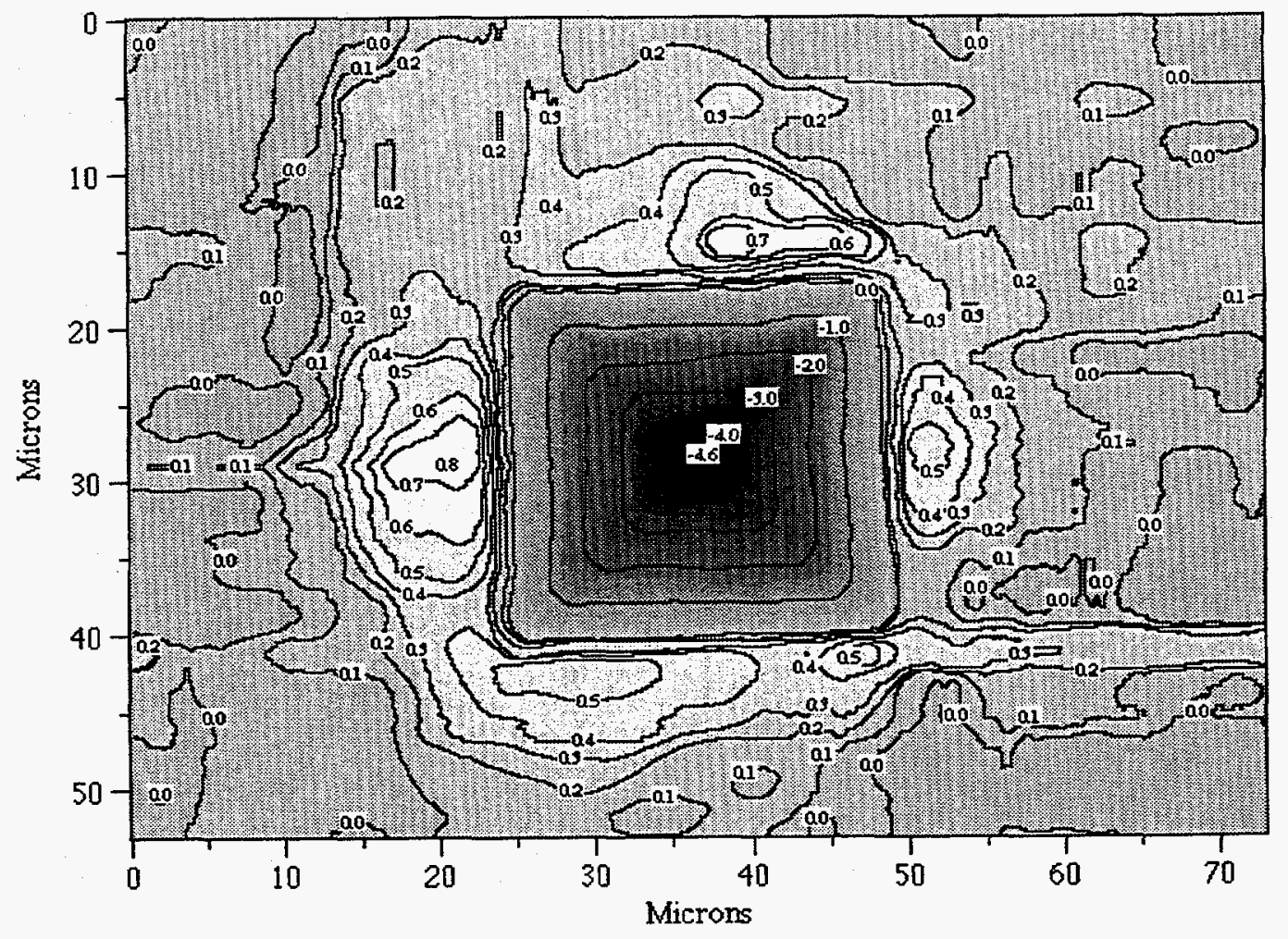


Contour Plot: A533B Model Control Indent 10

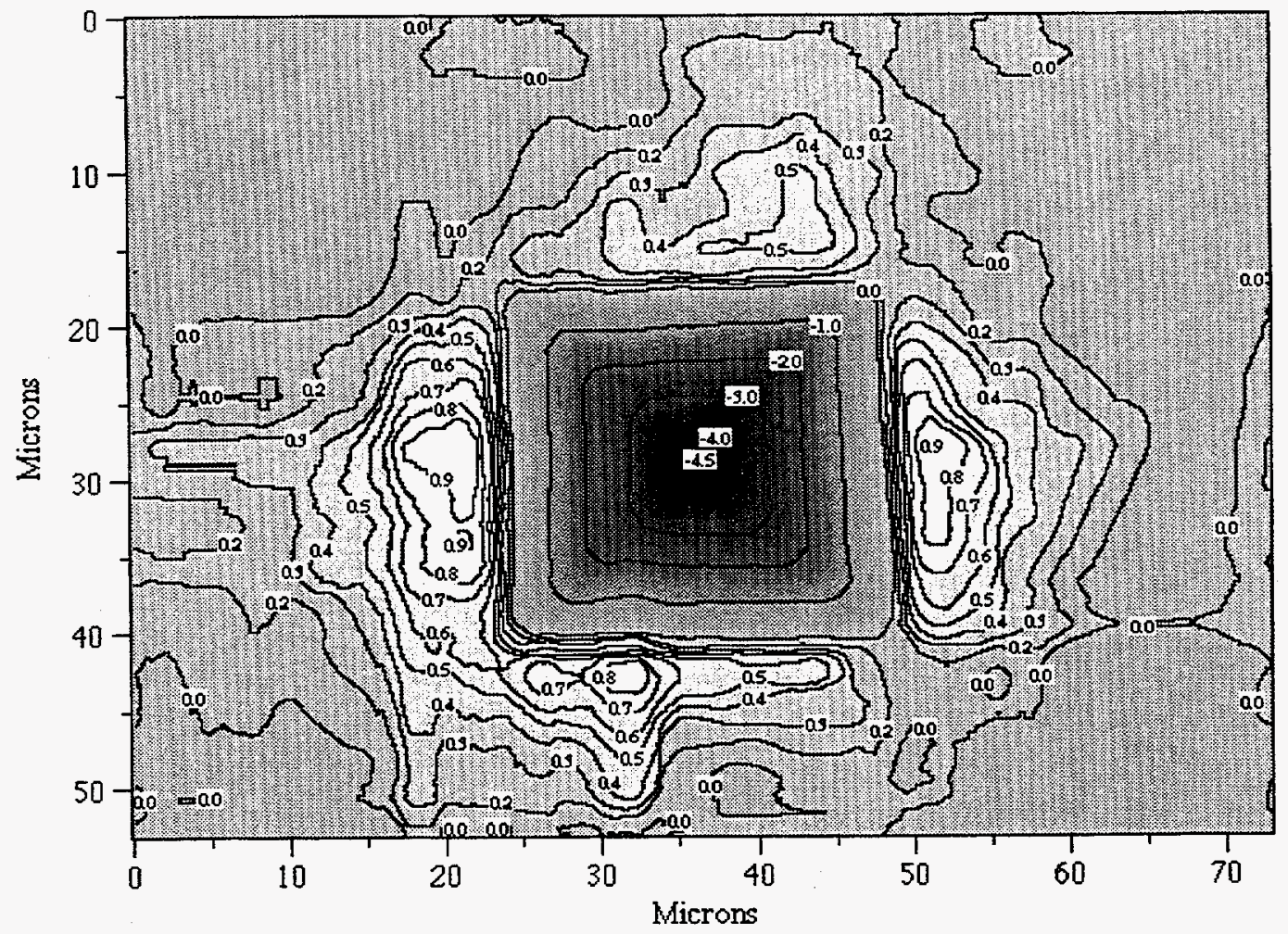


Contour Plot: A533B Model ITI Indent 1

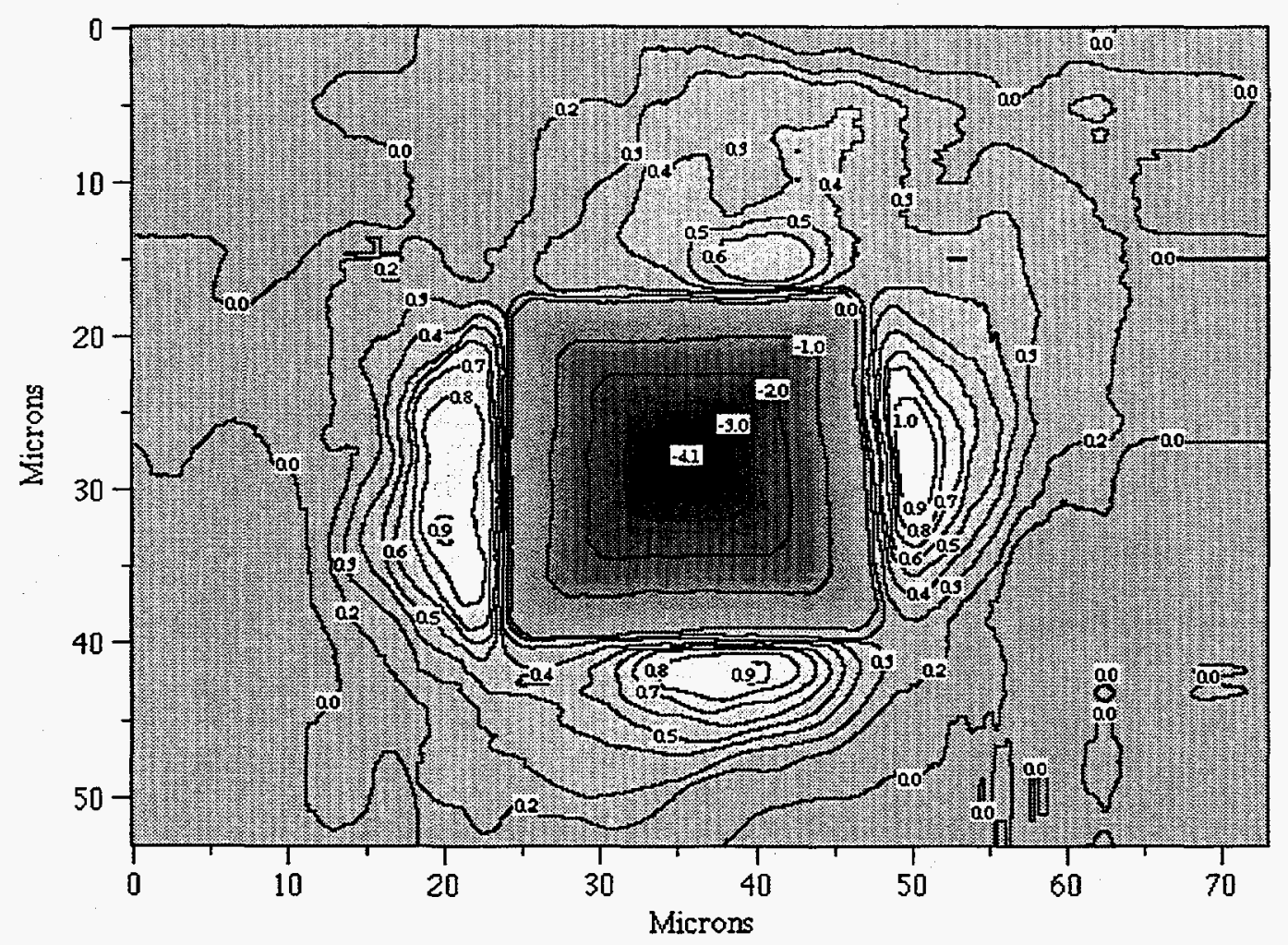


Contour Plot: A533B Model ITI Indent 3

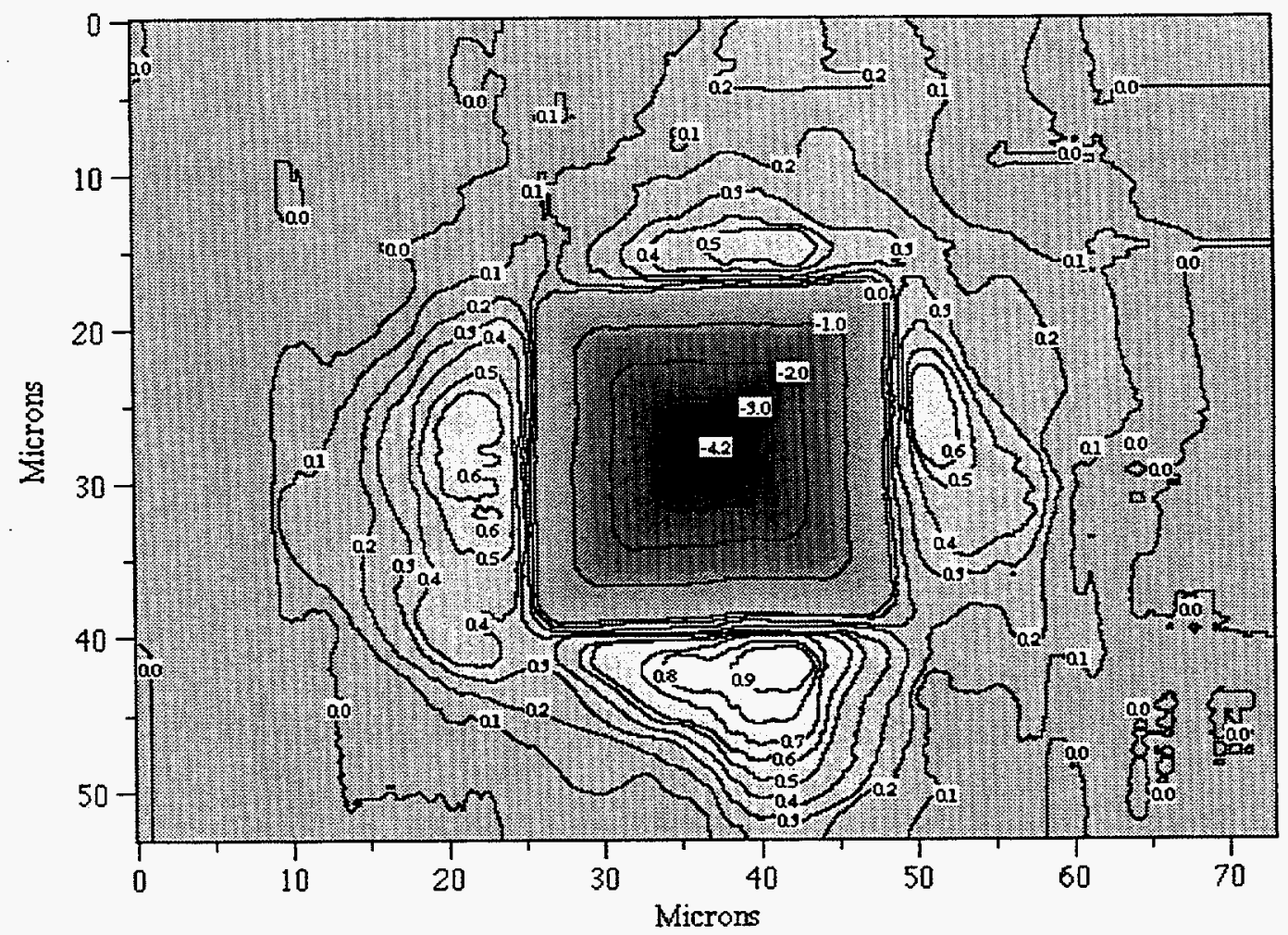


Contour Plot: A533B Model ITI Indent 4

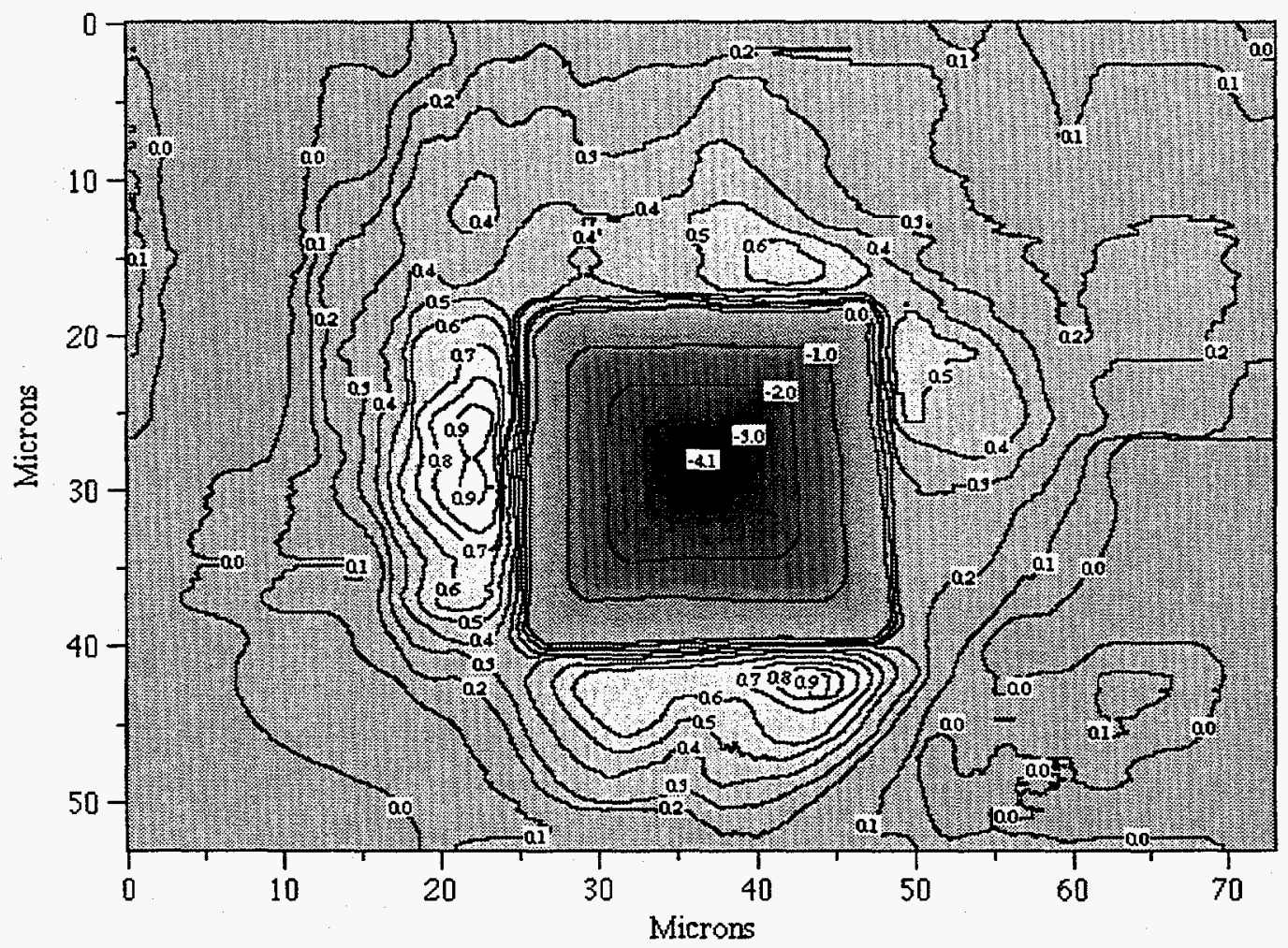


Contour Plot: A533B Model ITI Indent 6

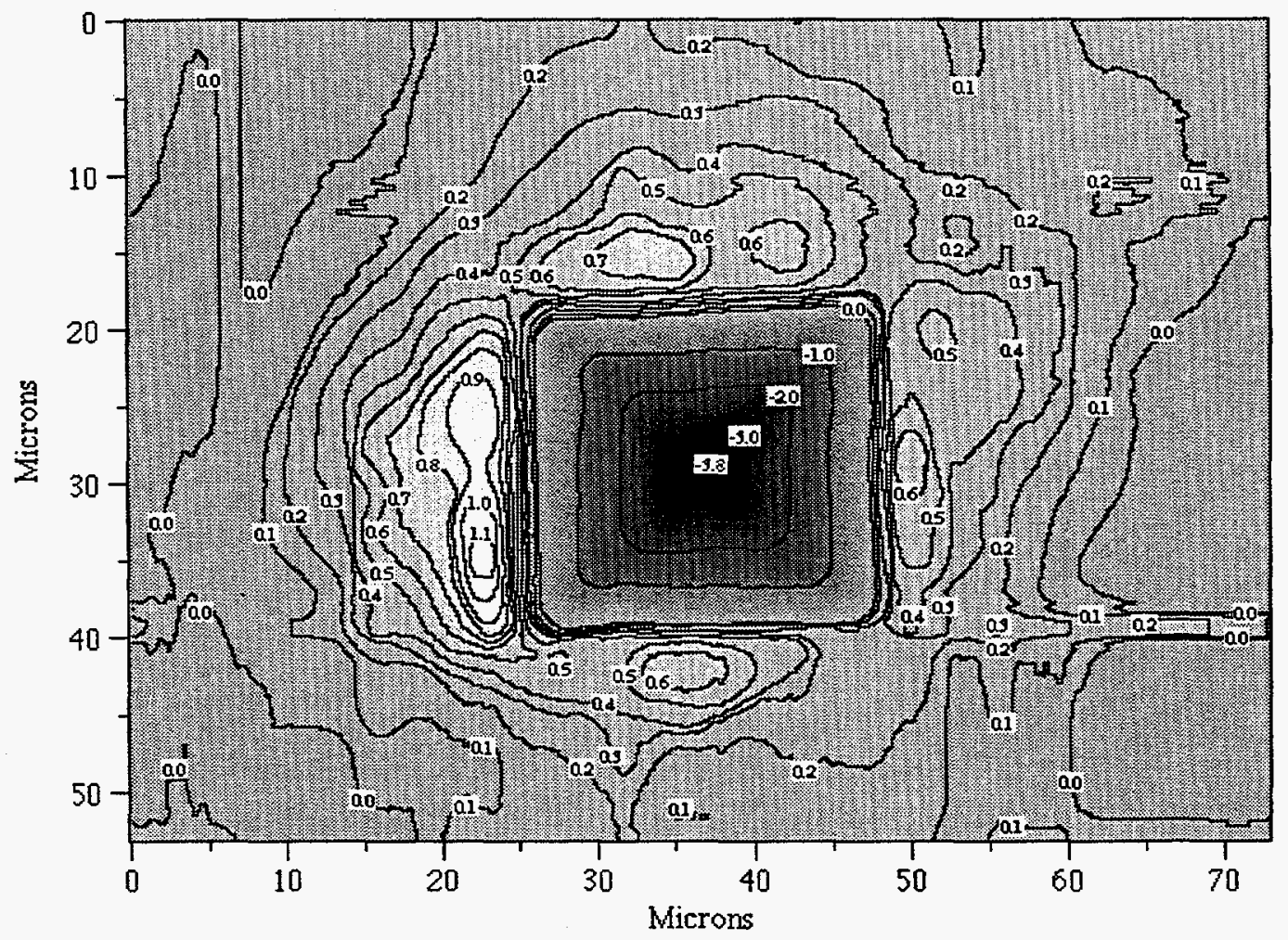


Contour Plot: A533B Model ITI Indent 7

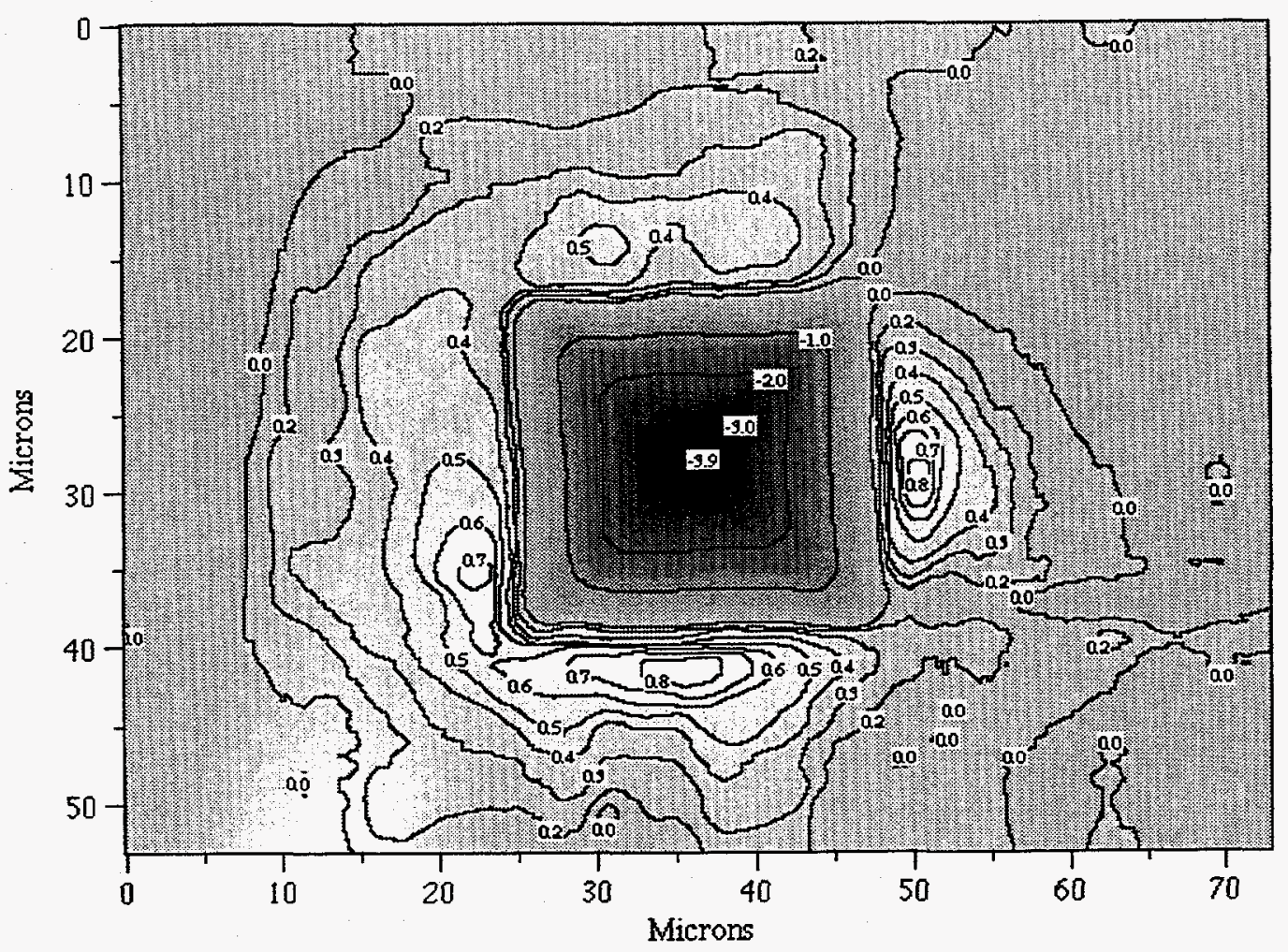


Contour Plot: A533B Model LTI Indent 1

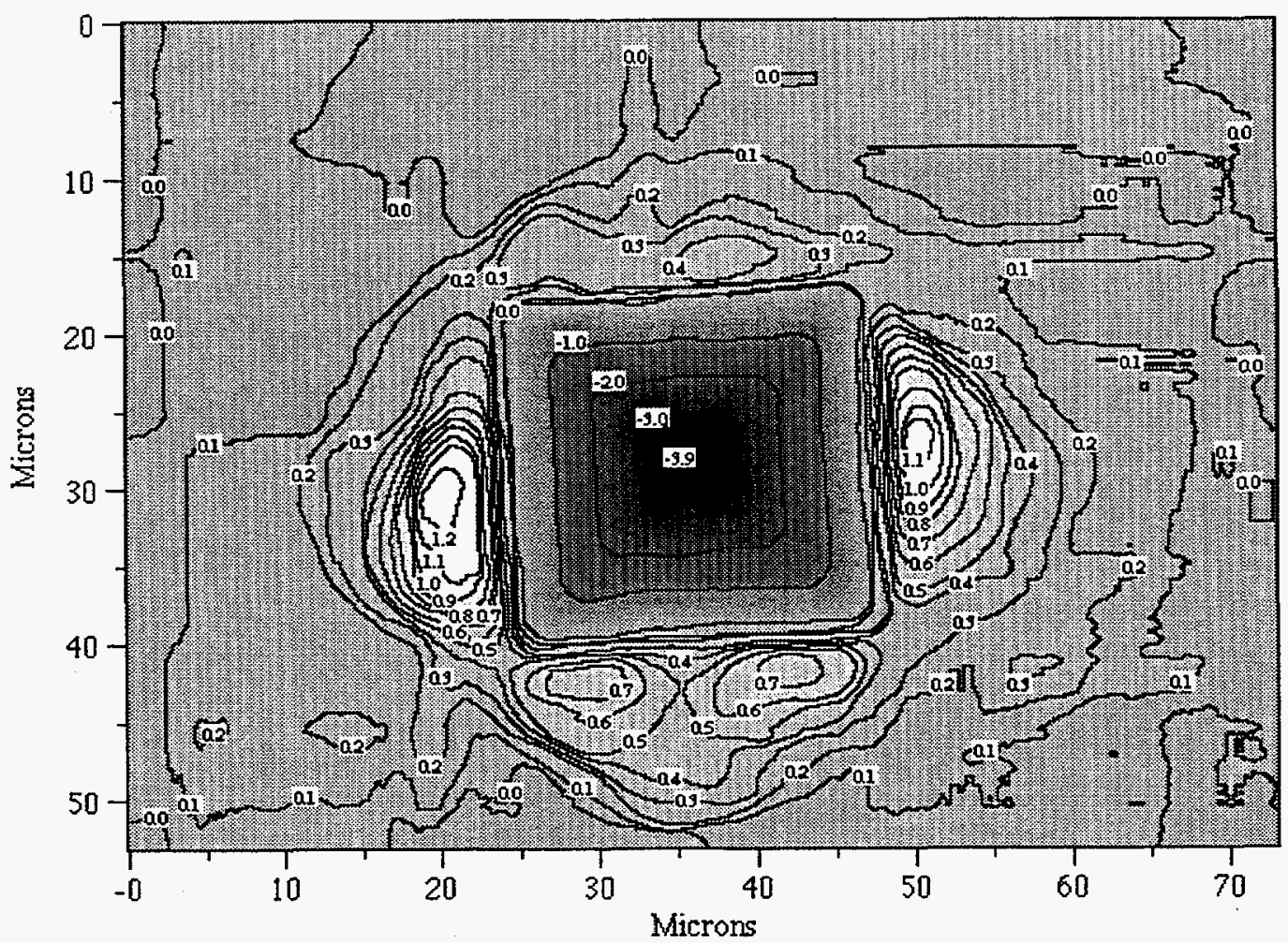


Contour Plot: A533B Model LTI Indent 3

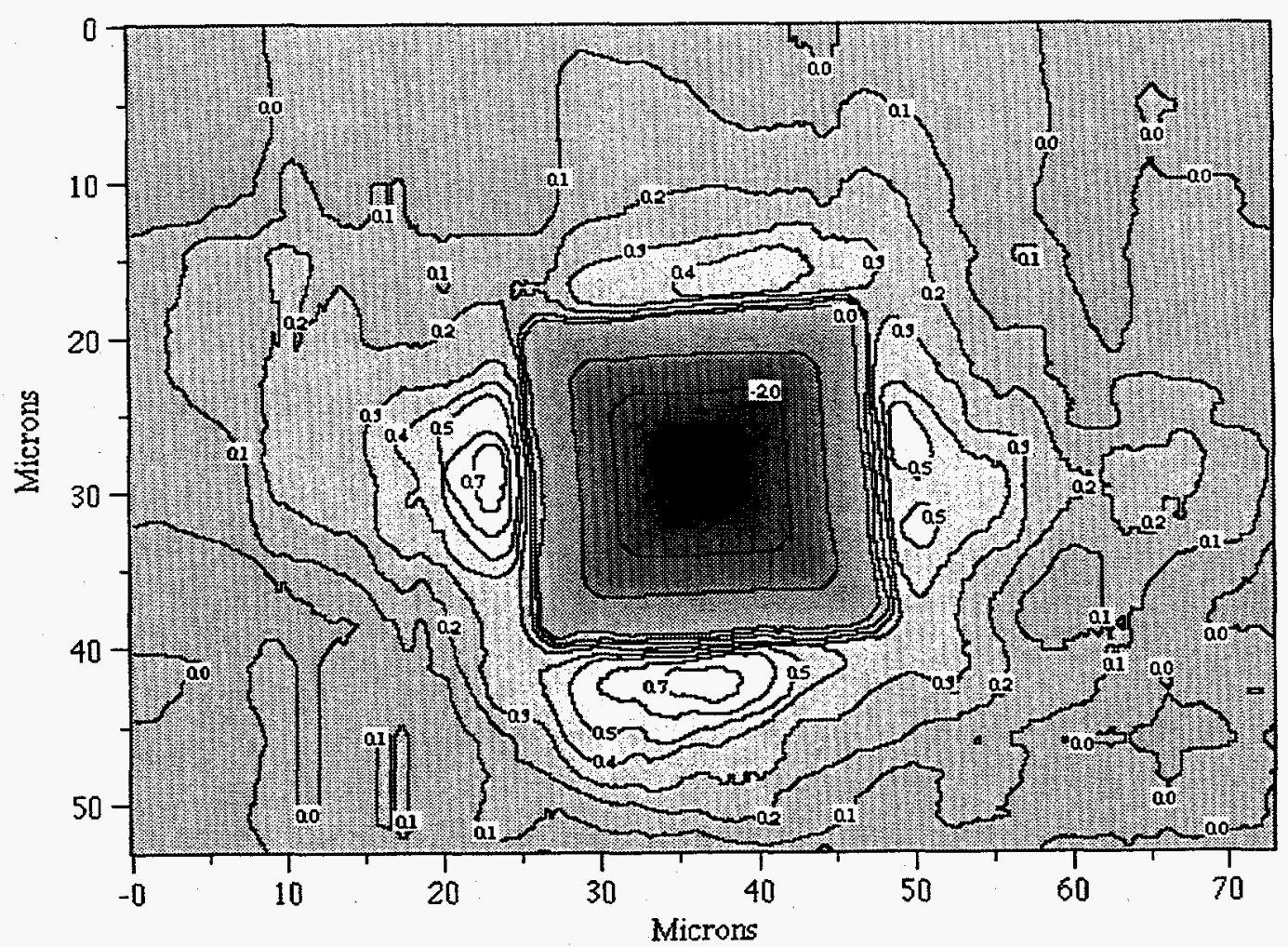


Contour Plot: A533B Model LTI Indent 4

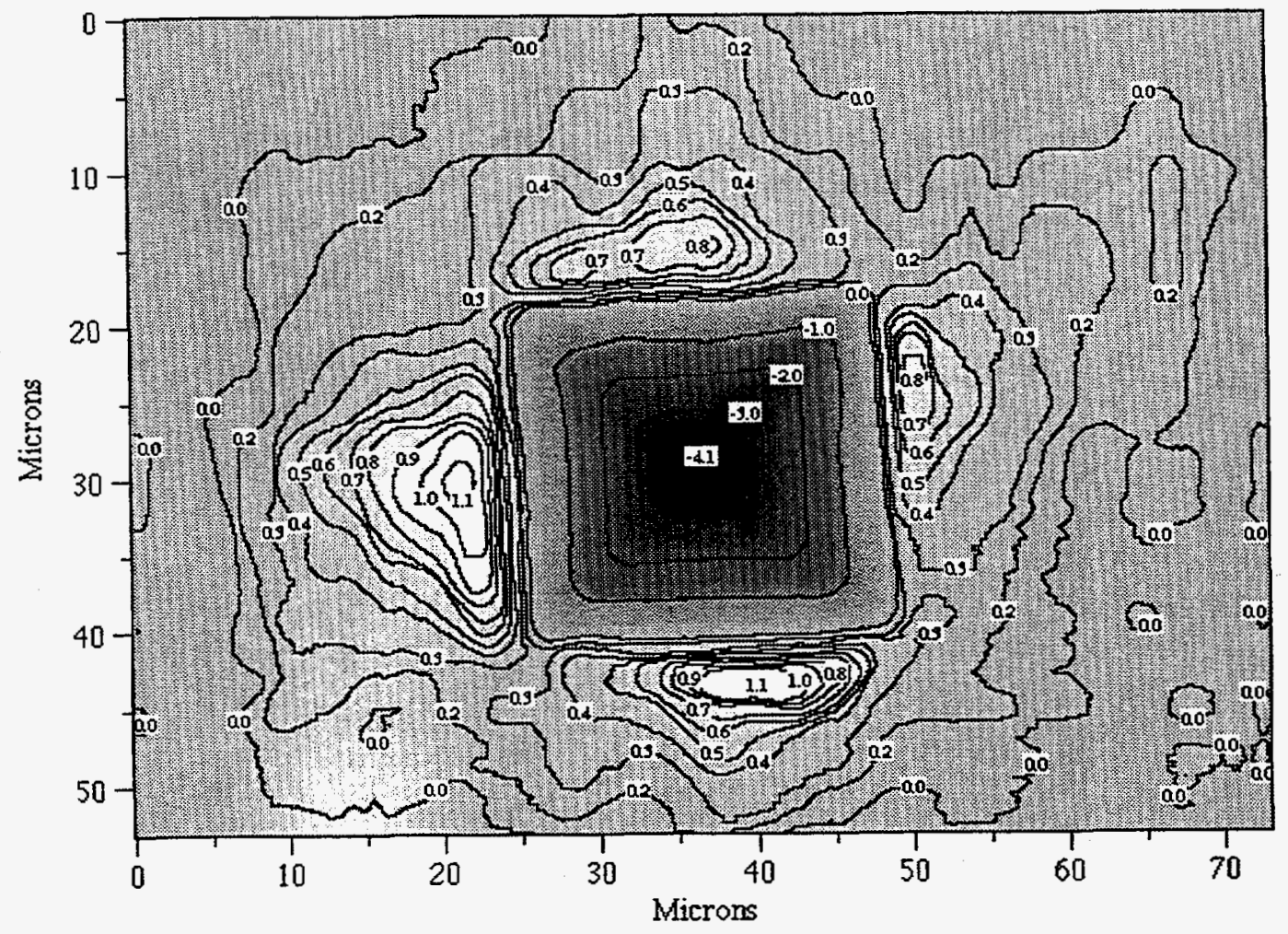


Contour Plot: A533B Model LTI Indent 5

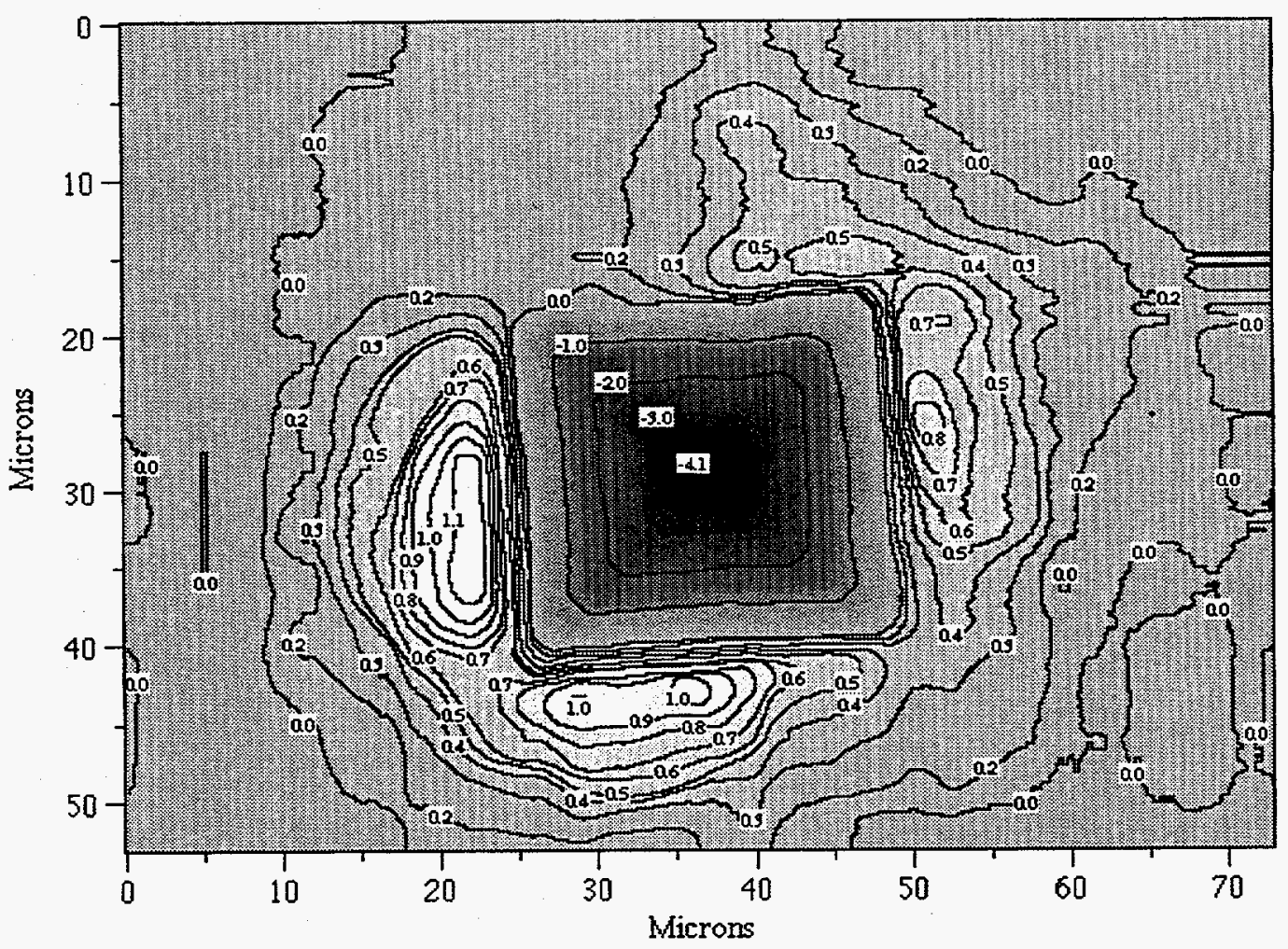


Contour Plot: A533B Model LTI Indent 6

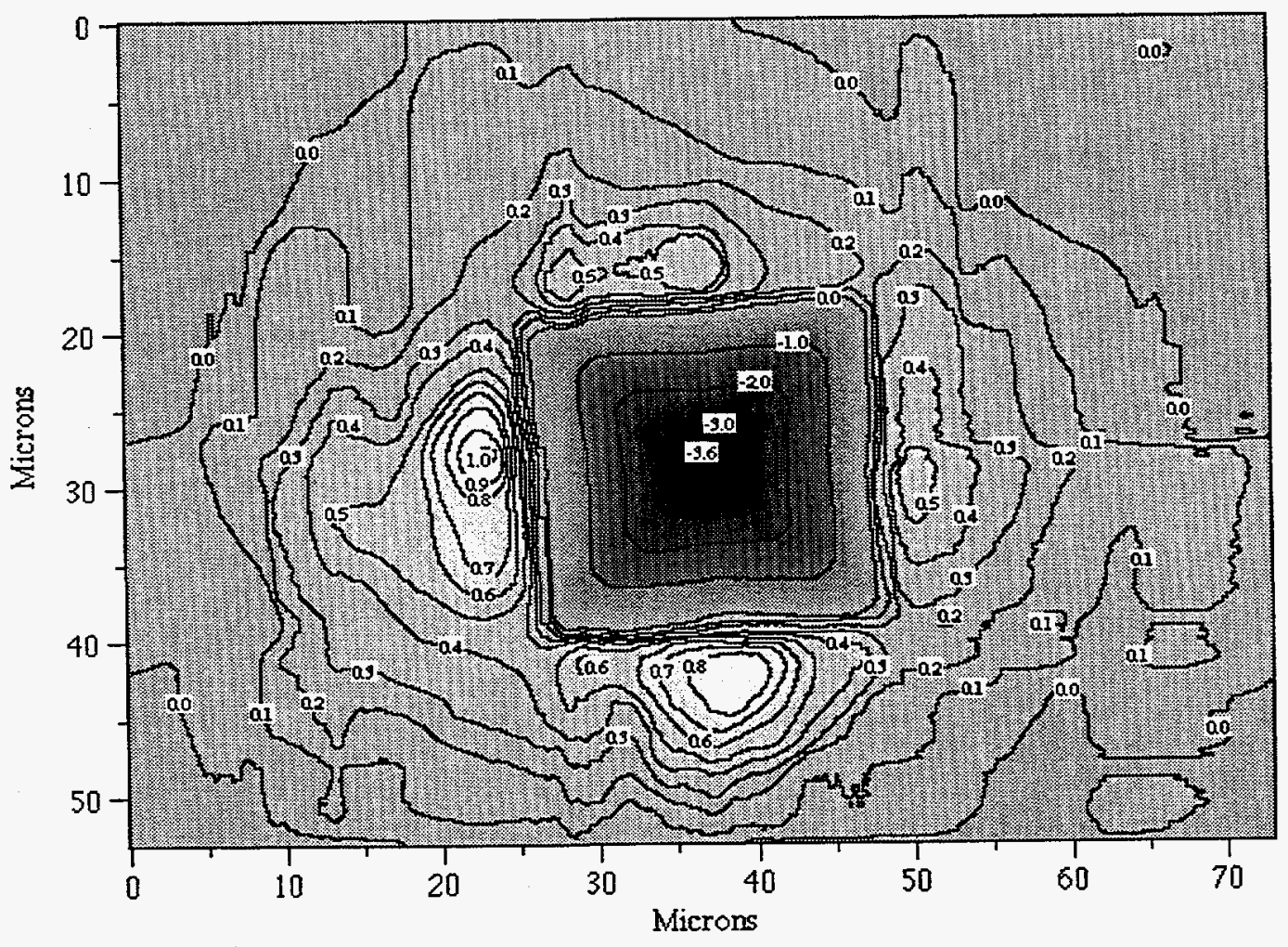


Contour Plot: A533B Model LTI Indent 7

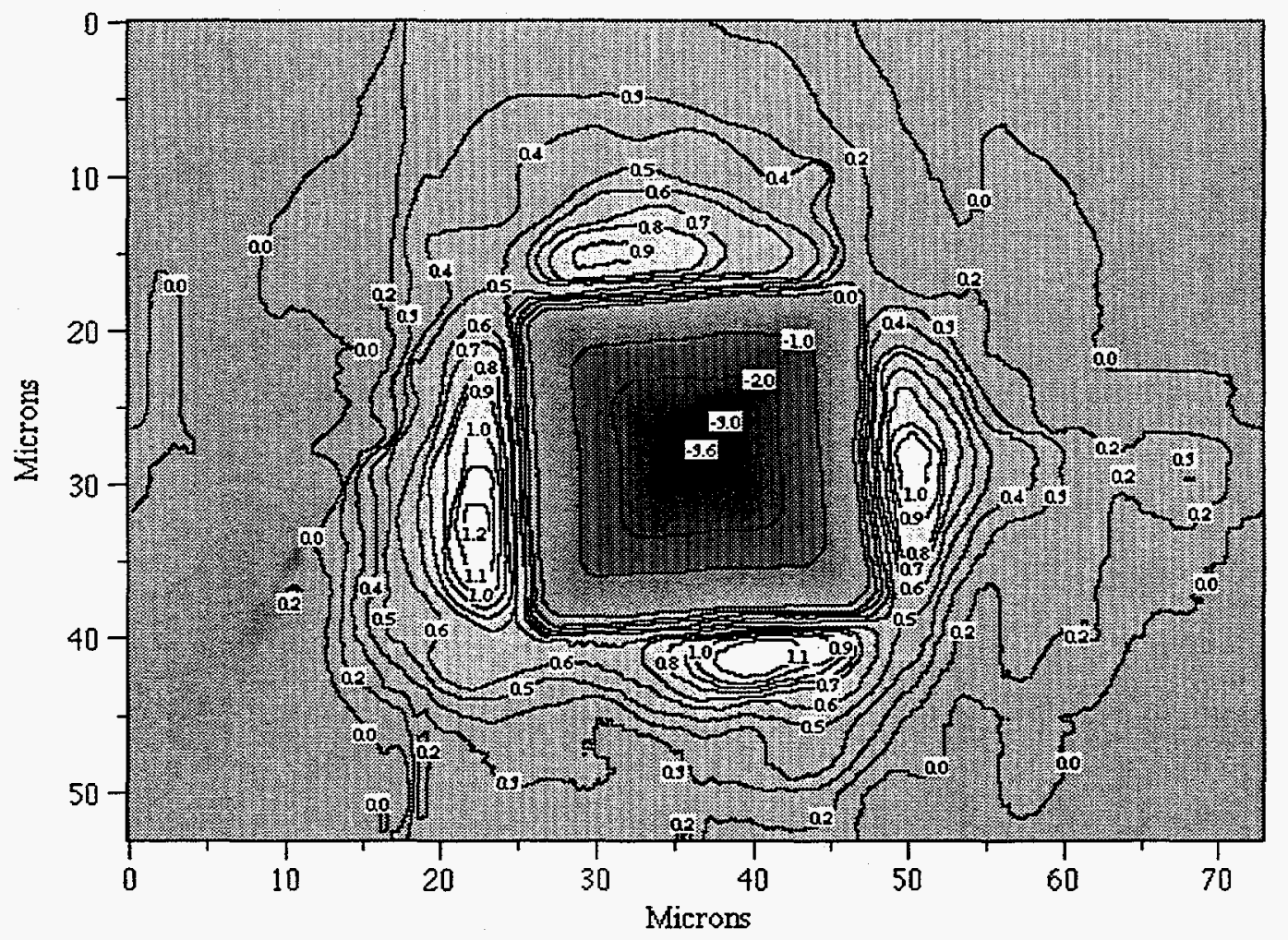


Contour Plot: A533B Model LTI Indent 10

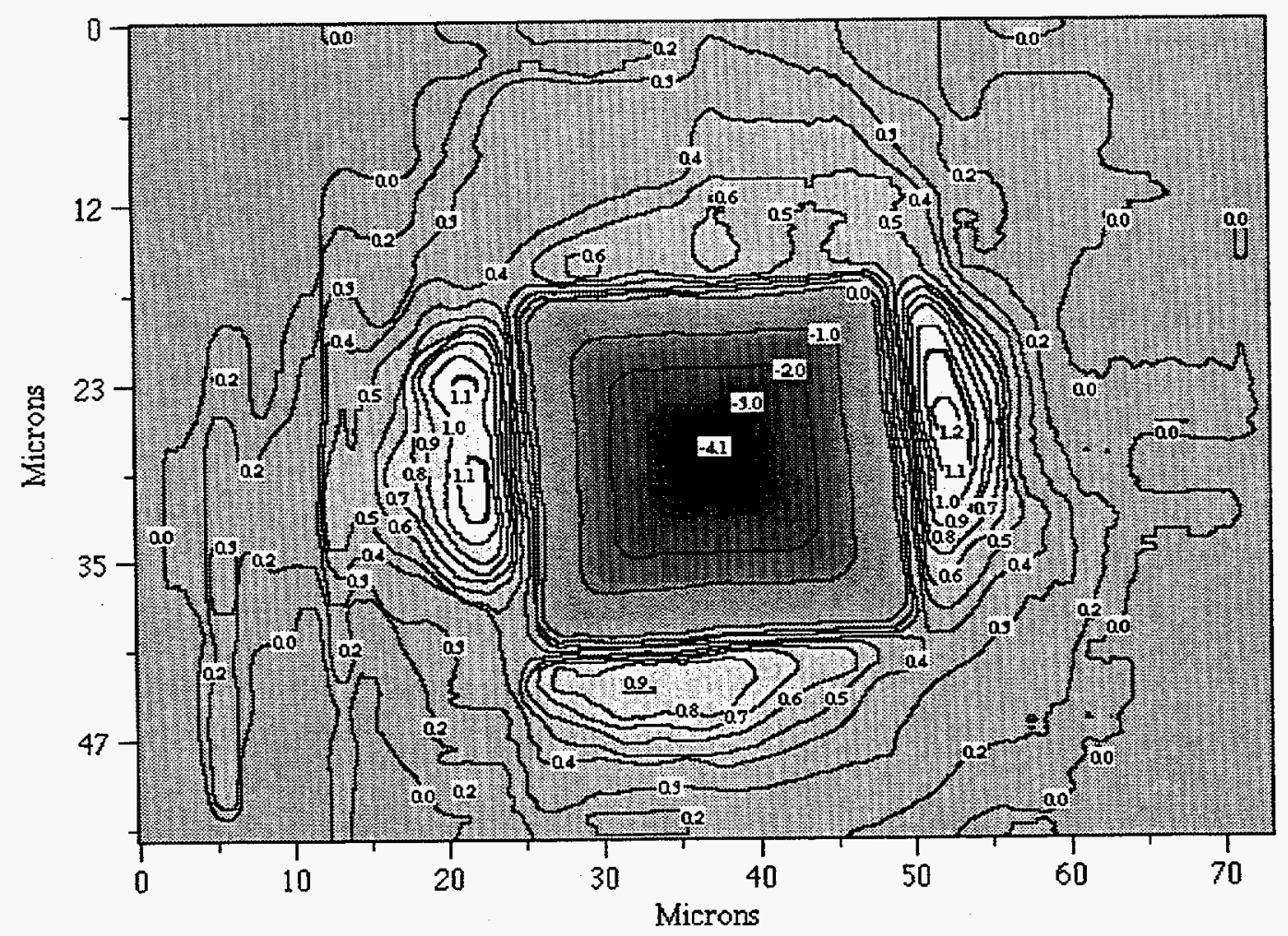


NbTi Indent 1

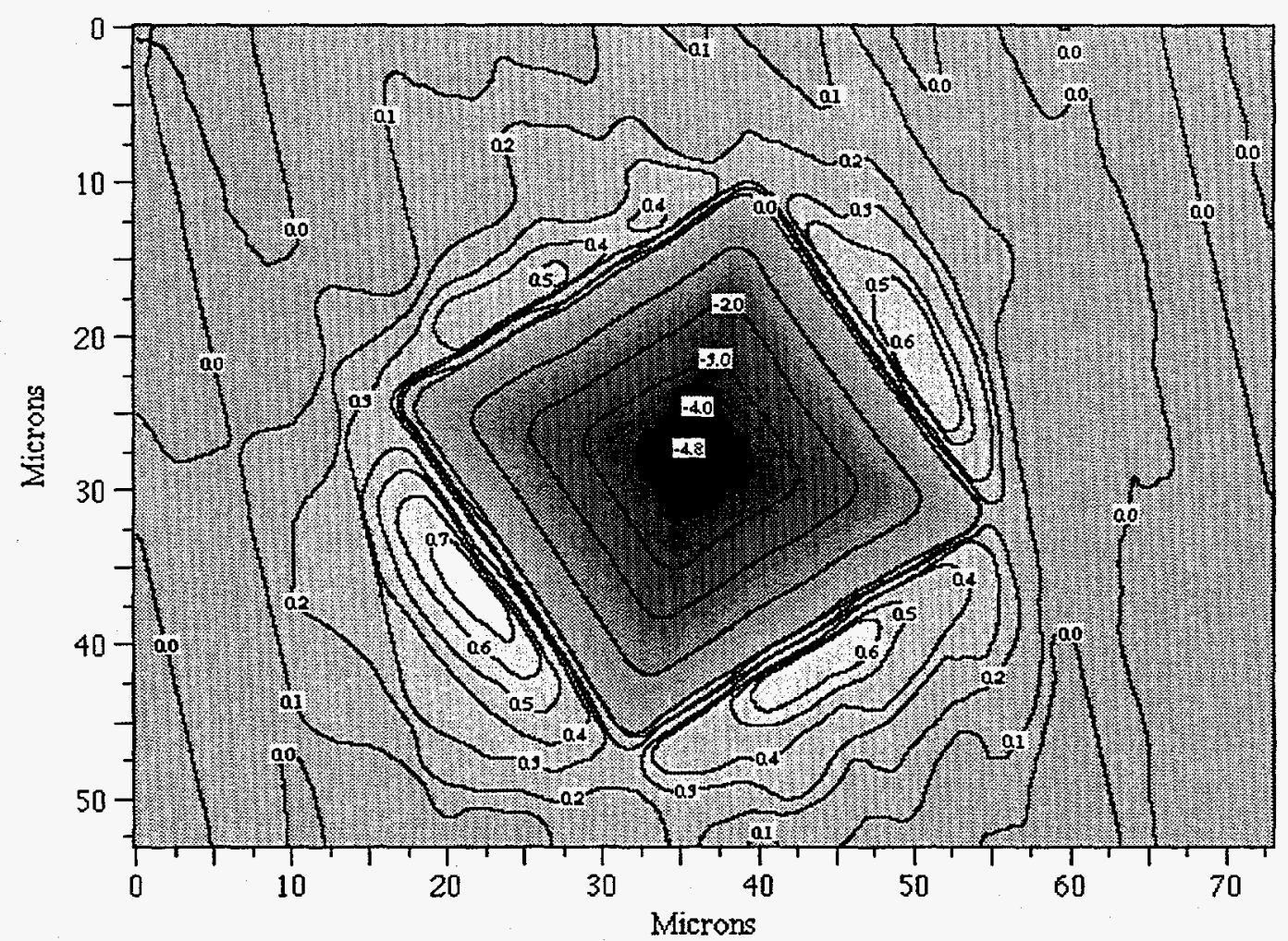


Contour Plot: Nb-Ti $200 \mathrm{~g}$ load -- Indent 2

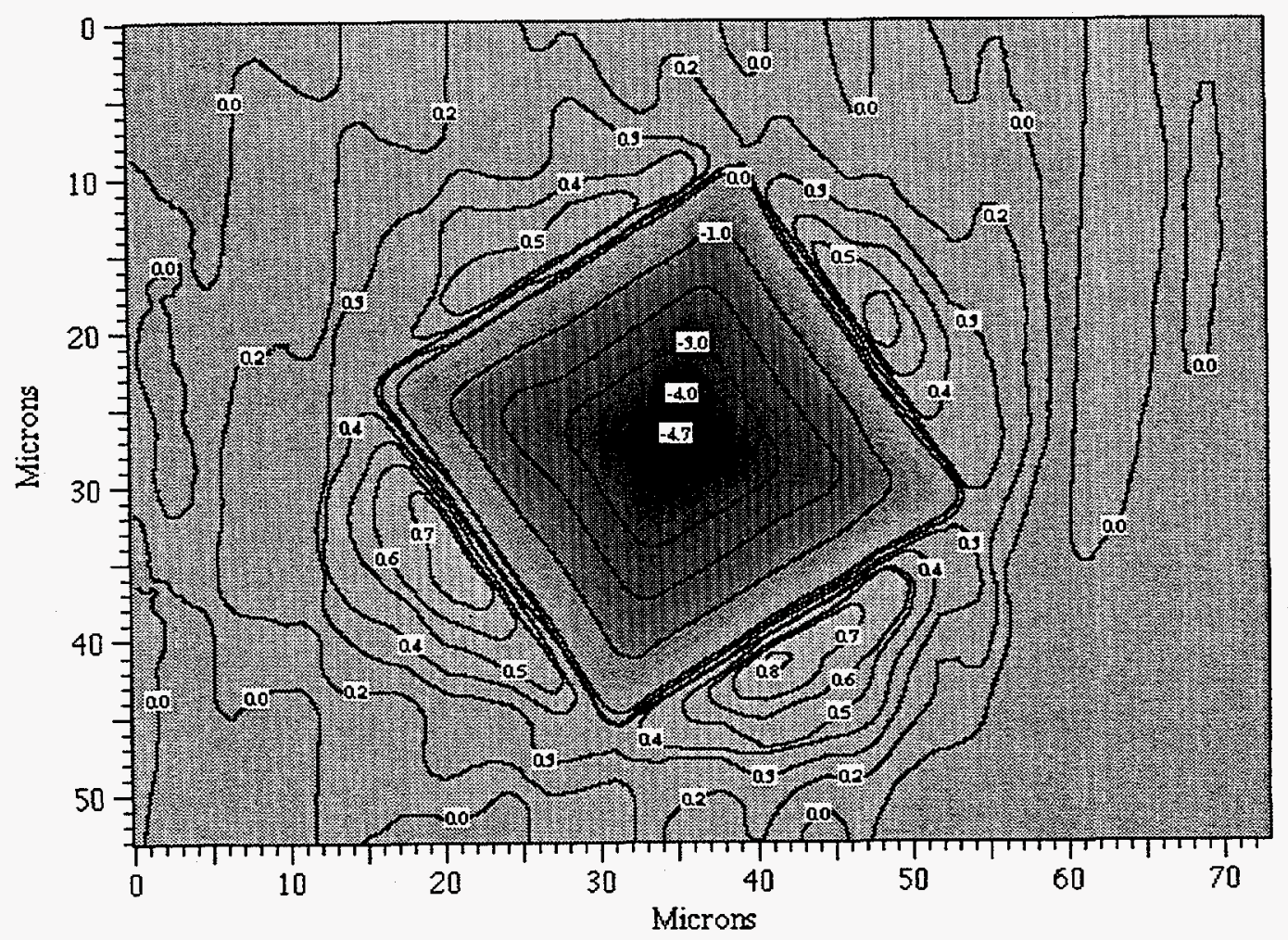


NbTi Indent 3

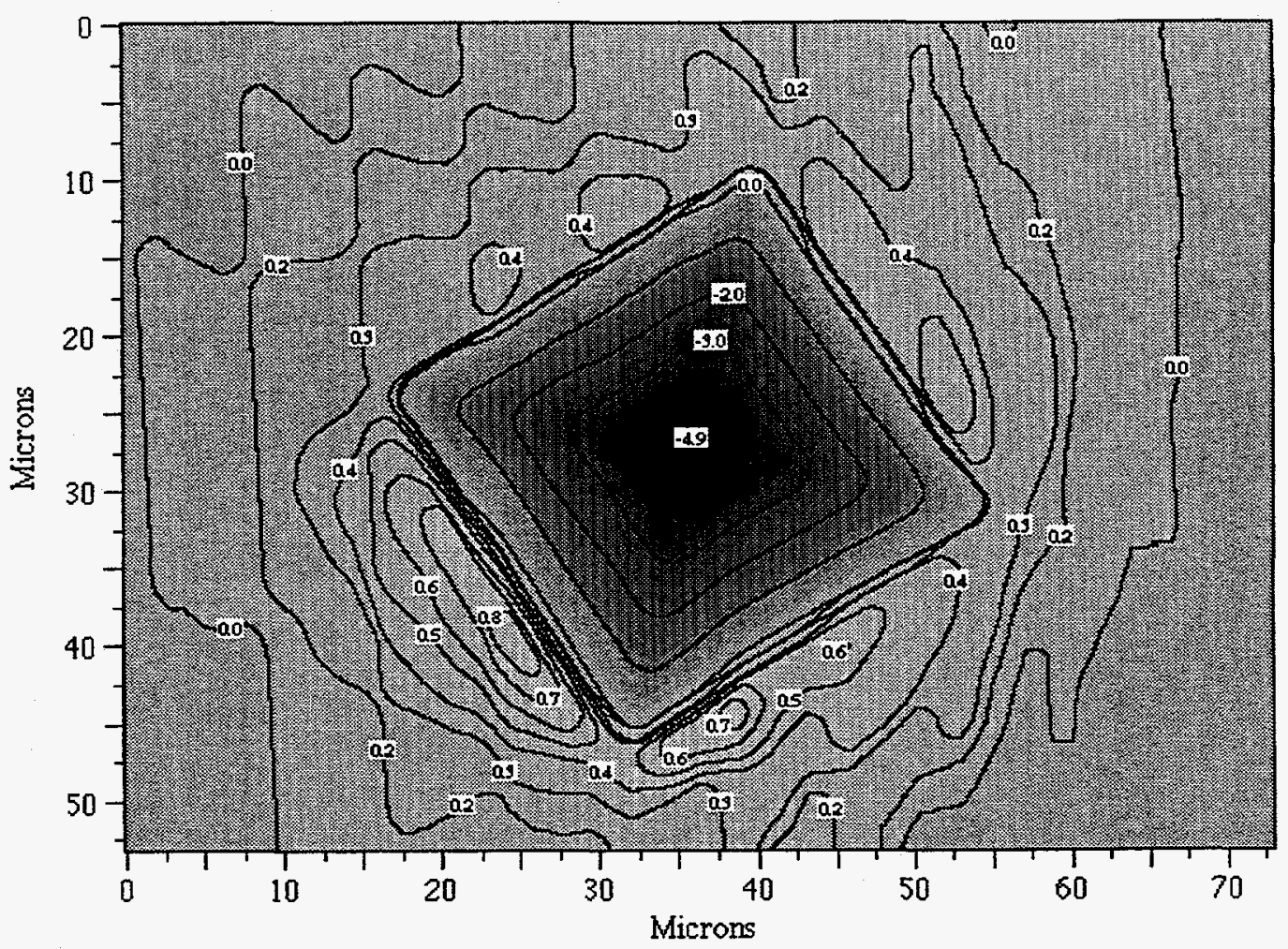


Contour Plot: Nb-Ti $200 \mathrm{~g}$ load -- Indent 4

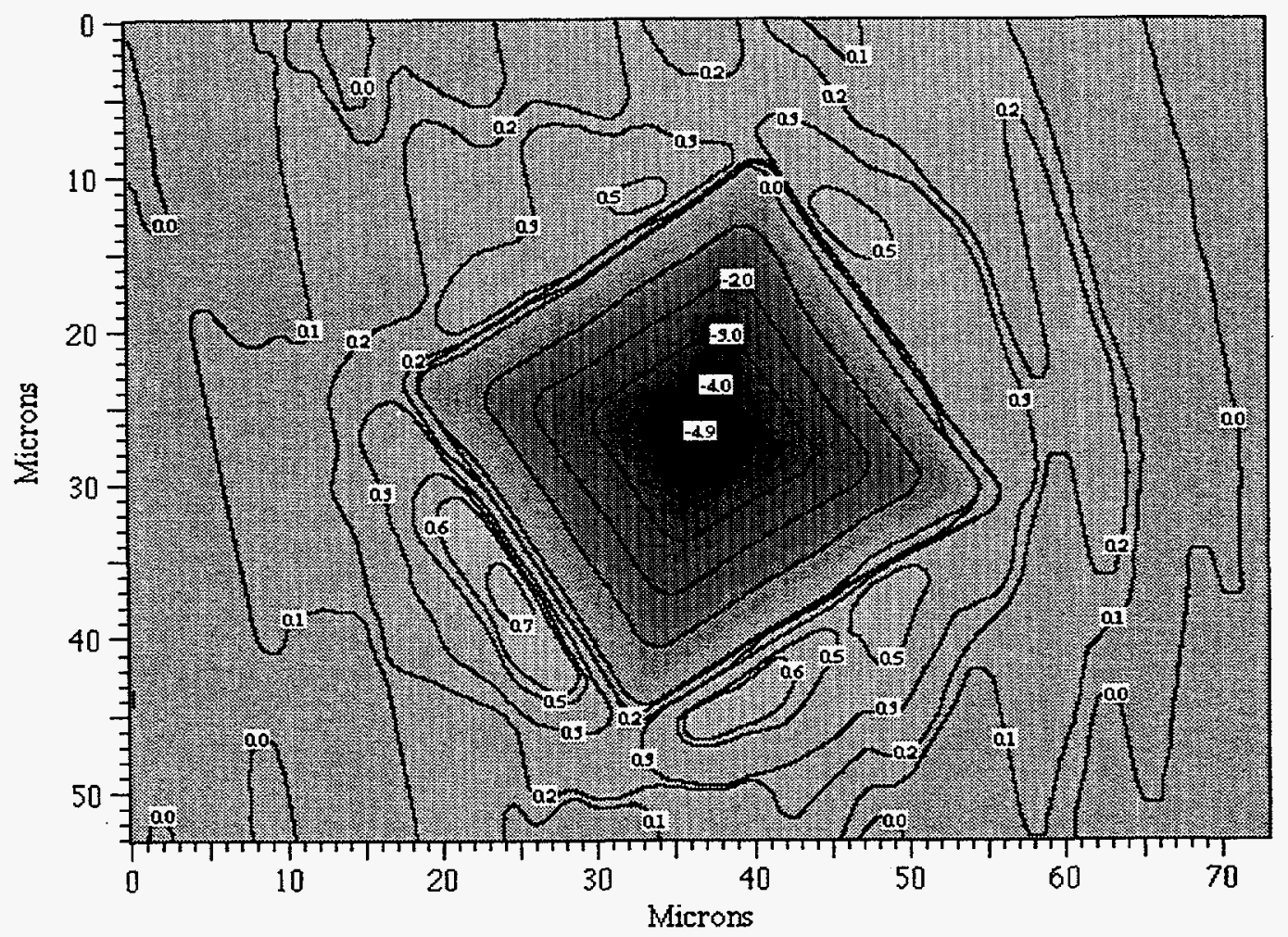


Contour Plot: Nb-Ti $200 \mathrm{~g}$ load -- Indent 5

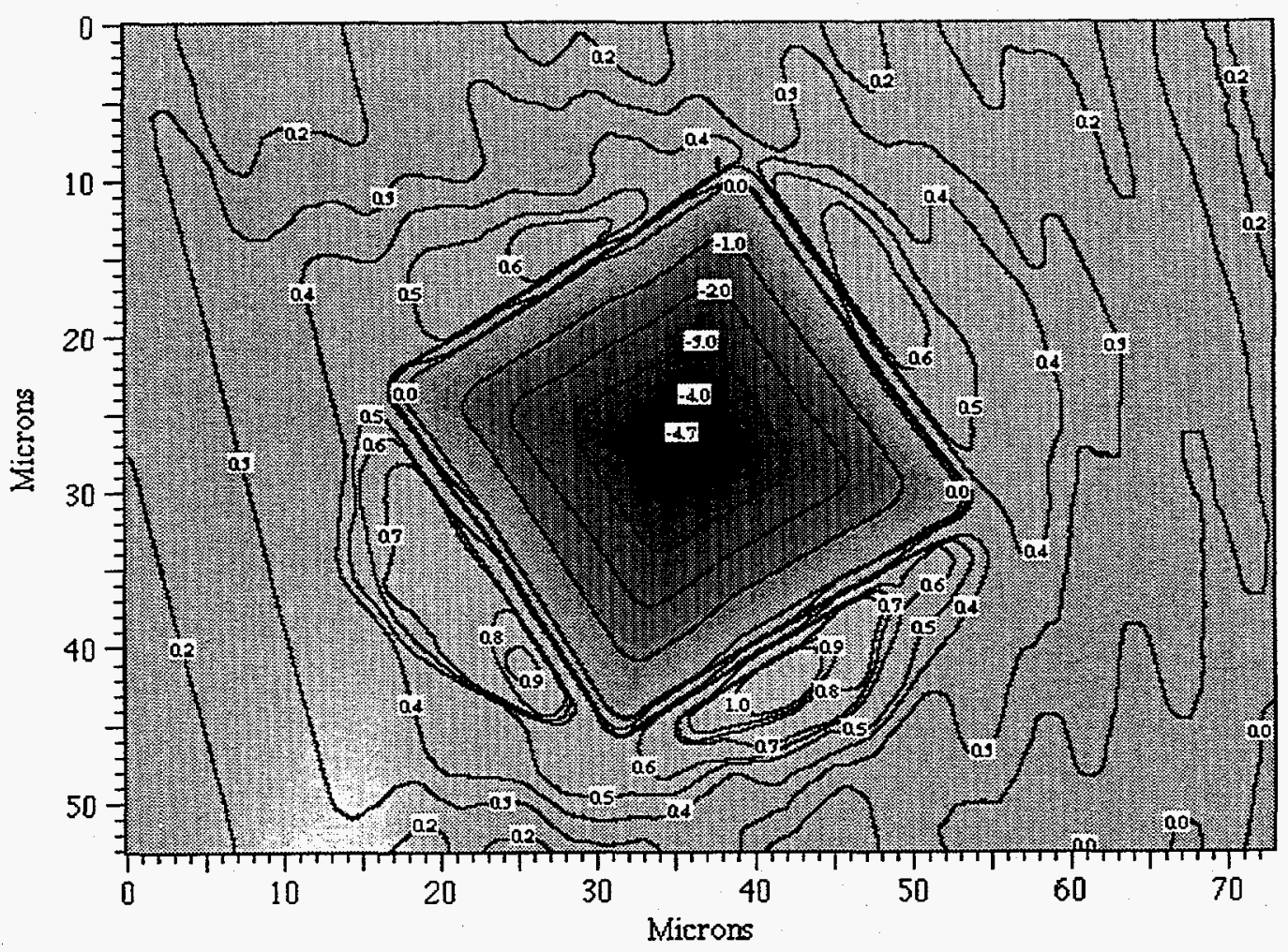


The Characterization of Vicker's Microhardness Indentations and Pile-up Profiles as a StrainHardening Microprobe

(Assigned by NRC, Add Vol., Supp., Rev.,
(A S and Addendum Numbers, if any.)

\begin{tabular}{l} 
\\
\hline 5. AUTHOR(S)
\end{tabular}

5. AUTHOR(S)

C. Santos Jr. / NRC

G.R. Odette, G.E. Lucas, B. Schroeter, D. Klinginsmith / UC

T. Yamamoto/ TU

\section{3}

\begin{tabular}{l|c|}
\hline 3. & DATE REPORT PUBLISHED \\
\hline MONTH & YEAR \\
APr $i$ I & 1998 \\
\hline $\begin{array}{c}\text { 4. FIN OR GRANT NUMBER } \\
\text { W6212 }\end{array}$ \\
\hline
\end{tabular}

6. TYPE OF REPORT

Technical

7. PERIOD COVERED (Inelusive Dates)

October 1995-October 1997

8. PERFORMING ORGANIZATION - NAME AND ADDRESS (If NRC, provide Division, Office or Region, U.S. Nuclear Regulatory Commission, and mailing address; if contractor, provide name and mailing address.)

Department of Mechanical Engineering

University of California at Santa Barbara

Santa Barbara, CA 93106

Institute for Materials Research

Tohoku University

211 Katahira, Aoba-ku

Sendai Japan $980-77$

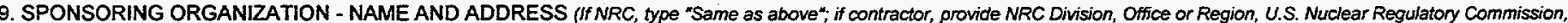
and mailing address.)

Division of Engineering Technology

Office of Nuclear Regulatory Research

U.S. Nuclear Regulatory Commission

Washington DC 20555

10. SUPPLEMENTARY NOTES

Thesis written in partial fulfillment of the requirements for a Master's of Science Degree in Materials at the Univeristy of California

11. ABSTRACT (200 words or less)

Microhardness measurements have long been used to examine strength properties and changes in strength properties in metals, for example, as induced by irradiation. Microhardness affords a relatively simple test that can be applied to very small volumes of material. Microhardness is nominally related to the flow stress of the material at a fixed level of plastic strain. Further, the geometry of the pile-up of material around the indentation is related to the strain-hardening behavior of the material; steeper pile-ups correspond to smaller strain hardening rates. In this study the relationship between pile-up profiles and strain hardening is examined using both experimental and analytical methods. Vicker's microhardness tests have been performed on a variety of metal alloys including low alloy, high $\mathrm{Cr}$ and austenitic stainless steels. The pile-up topology around the indentations has been quantified using confocal microscopy techniques. In addition, the indentation and pile-up geometry has been simulated using finite element method techniques. These results have been used to develop improved quantification of the relationship between pile-up geometry and the strain hardening constitutive behavior of the test material.

Vickers, microhardness, strain-hardening, steels, confocal microscopy, pile-up, finite element modeling

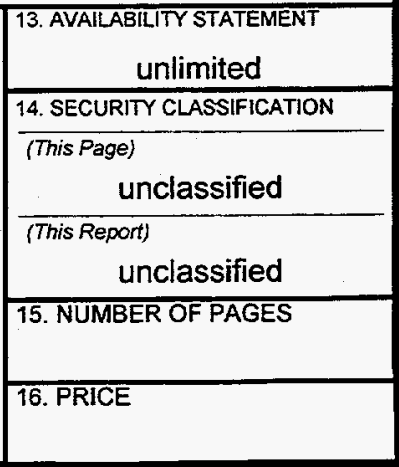

